\title{
Discrete Element Analysis of Granular Materials
}

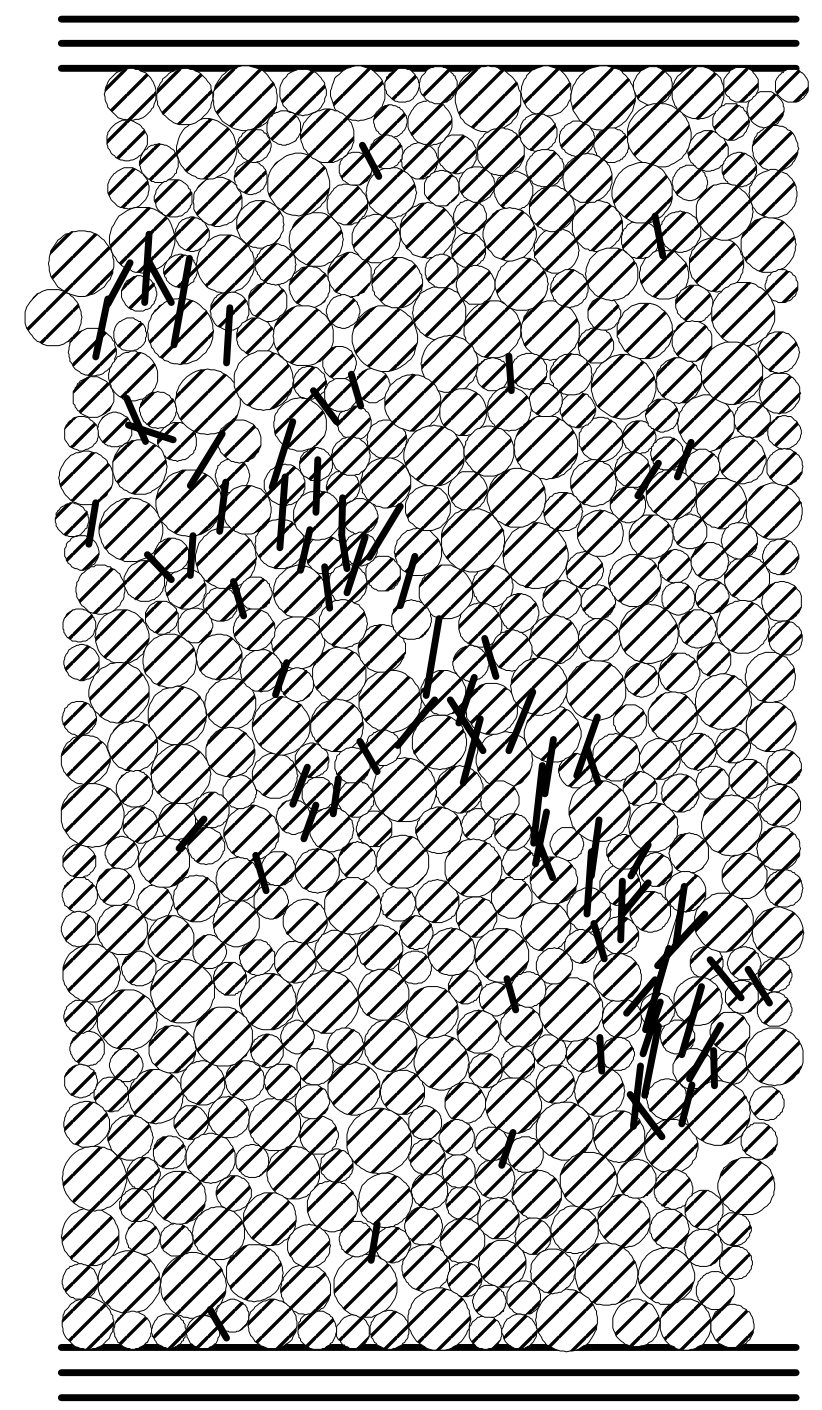

Stefan van Baars 
TU Delft

Delft University of Technology
Faculty of Civil Engineering 


\section{Discrete Element Analysis of \\ Granular Materials}

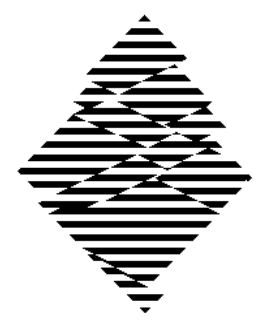




\section{Discrete Element Analysis of \\ Granular Materials}

\section{Proefschrift}

ter verkrijging van de graad van doctor aan de Technische Universiteit Delft,

op gezag van de Rector Magnificus Prof. ir. K. F. Wakker, in het openbaar te verdedigen ten overstaan van een commissie, door het College van Dekanen aangewezen, op donderdag 19 september 1996 te 13.30 uur,

door

Stefan van Baars

civiel ingenieur

geboren te Zevenaar. 
Dit proefschrift is goedgekeurd door de promotor:

Prof. dr. ir. A. Verruijt

Samenstelling promotiecommissie:

Rector Magnificus,

Prof. dr. ir. Verruijt,

Prof. dr. ir. F.B.J. Barends,

Prof. dr. ir. E. van der Giessen,

Prof. dr. ir. P.A. Vermeer,

Prof. drs. ir. J.K. Vrijling,

Dr. ir. H.G.B. Allersma,

Ir. C.J. Kenter,

Prof. ir. A.F. van Tol,
T. U. Delft,

T. U. Delft,

T. U. Delft,

T. U. Delft,

Universität Stuttgart,

T. U. Delft,

T. U. Delft,

Shell International,

T. U. Delft.

\section{CIP-GEGEVENS KONINKLIJKE BIBLIOTHEEK, DEN HAAG}

Discrete element analysis of granular materials

Stefan van Baars

Proefschrift Technische Universiteit Delft

met samenvatting in het Nederlands

ISBN 90-9009494-6

NUGI 816

Trefwoorden: geotechnics, discrete elements, shear band, crack growth

Omslag:

Figuur 39. Microscheuren in een cohesief granulair materiaal 


\section{Psalm 2}

Why do the heathen rage, and the people imagine a vain thing?

The kings of the earth set themselves, and the rulers take counsel together, against the Lord, and against his anointed, saying, Let us break their bands asunder, and cast away their cords from us.

He that sitteth in the heavens shall laugh: the Lord shall have them in derision.

Then shall He speak unto them in his wrath, and vex them in his sore displeasure.

Yet have I set my king upon my holy hill of Zion.

I will declare the decree:

the Lord hath said unto me,

Thou art my Son; this day have I begotten thee.

Ask of Me, and I shall give thee the heathen for thine inheritance, and the uttermost parts of the earth for thy possession.

Thou shalt break them with a rod of iron;

Thou shalt dash them in pieces

like a potter's vessel.

Be wise now therefore, $O$ ye kings:

Be instructed, ye judges of the earth.

Serve the Lord with fear, and rejoice with trembling.

Arm yourself with righteousness, lest He be angry,

and ye perish from the way,

when his wrath is kindled but a little.

Blessed are all they that put their trust in Him. 


\section{ACKNOWLEDGEMENTS}

The research reported in this communication has been carried out at the Department of Geotechnics. I would like to express my gratitude to all my colleagues for their support. I also want to thank Shell Research B.V., Royal Shell Exploration and Production Laboratory, for their financial support. 


\section{CONTENTS}

ACKNOWLEDGEMENTS

CONTENTS 9

SUMMARY 11

1. INTRODUCTION 13

2. DISCRETE ELEMENT MODELLING 15

2.1. Micro modelling $\quad 15$

2.2. Motion modelling 19

2.3. Equilibrium modelling 21

2.4. Elasto-plastic modelling 23

2.5. Characteristic tests 24

2.6. Motion versus equilibrium 26

3. NON-COHESIVE GRANULAR MATERIALS 29

3.1. Default parameters 29

3.2. Micro behaviour versus macro behaviour $\quad 32$

3.3. Continuum modelling 46

4. COHESIVE GRANULAR MATERIALS 61

4.1. Default parameters $\quad 61$

4.2. Micro behaviour versus macro behaviour 62

4.3. Continuum modelling $\quad 72$

4.4. Cylinder test $\quad 75$

4.5. Three point bend test $\quad 82$

5. CRYSTAL STRUCTURES

6. CONCLUSIONS AND RECOMMENDATIONS 89

6.1. Conclusions $\quad 89$

6.2. Recommendations 90

REFERENCES 91

APPENDIX $\quad 93$

CURRICULUM VITAE 131

SAMENVATTING 133 


\section{SUMMARY}

\section{Discrete Element Analysis of Granular Materials}

During oil and gas production, several years after drilling a borehole, sand particles and small sandstone particles start to break away from the borehole surface. These particles can damage the transport pipes and other equipment in a short period of time. By simulating this borehole behaviour with the thick-walled cylinder test, four phenomena were found which cannot be explained by conventional continuum mechanics:

1. Despite the compressive stress, failure occurs on the micro level due to tension cracks.

2. These cracks are not diagonal to, but parallel to, the borehole surface.

3. These cracks cause two diametrically opposite breakouts.

4. The functional failure of the borehole starts at a higher radial pressure than predicted.

In 1979, Cundall developed a computer model, based on the basic elements of granular materials, i.e. the grains themselves and their interactions, to describe the behaviour of these materials. Lindhout tried, in 1992, to use this model to describe the cylinder test. Due to compaction problems, stability problems and the large computational time, this could not be achieved. Therefore a new model was developed by the author, which does not use the equations of motion, but the equations of equilibrium, to calculate the new grain positions. This model can be used both for non-cohesive grains (sand) and for cohesive grains (sandstone). The results can generally be described by an advanced Mohr-Coulomb model. However, there are a few exceptions.

Firstly, during loading of a granular structure, many contacts between the grains will collapse, not due to shear deformation as Coulomb suggests, but due to tension failure. Secondly, these micro cracks always occur in the direction of the major principal stress, which might be another direction than the observed failure surface. In this way, the axial micro cracks form a diagonal failure surface during a biaxial test, but the axial micro cracks in a cylinder test may form a failure surface parallel to the borehole surface.

During the formation of natural sandstone, the difference between the horizontal and vertical stress causes anisotropy in the strength behaviour of this material. This or other anisotropies may explain the diametrically opposite breakouts.

The conclusion that a borehole fails at a higher radial pressure than predicted, originates from the definition difference between local failure and functional failure and the large rest capacity of a thick-walled cylinder. 


\section{INTRODUCTION}

This study on the behaviour of granular materials originates from offshore engineering. During oil and gas exploitation, several years after the drilling of a borehole, sand particles and small sandstone particles start to break away from the borehole surface. The number of particles which is transported by the oil or gas, can reach such an amount that the transport pipes and other equipment will be damaged, in a short period of time, by the scouring of these particles. The only solution up till now is to make a new borehole, which is, especially off shore, a huge financial loss.

Therefore laboratory research has been started to get insight into this problem. One of the main characteristic tests to simulate the failure of a borehole is the thick-walled cylinder test, which consists of a sandstone cylinder of several centimetres with an axial borehole in the middle. By radial compression of this cylinder four phenomena were found which cannot be explained by conventional continuum mechanics. These are:

1. Despite the compressive stress, failure occurs on micro level due to tension cracks.

2. These cracks are not diagonal to, but parallel to, the borehole surface.

3. These cracks cause two diametrically opposite breakouts.

4. The failure of the borehole starts at a higher radial confining pressure than predicted. According to many researchers, like Ewy and Cook (1990 I), the measured strength of the borehole surface is even two to four times as high as calculated.

The idea existed that this could be explained by the specific behaviour of granular materials, which is lost in continuum mechanics. Therefore the models which describe the materials by their basic elements became more popular.

De Josselin de Jong and Verruijt (1969) have applied an optical method to determine the magnitude and the direction of the contact forces between grains, by measuring the rotation of polarised light through these grains made of photoelastic materials. In this way the local displacements and forces could be studied.

About ten years later, Cundall developed a computer model, named Ball, to describe the behaviour of granular materials. This model is based on the basic elements of these materials, i.e. the grains themselves and their interactions. It can handle both non-cohesive grains and cohesive grains. The method was validated by Cundall and Strack (1979) by comparing force vector plots obtained from the computer program Ball, with the corresponding plots obtained from the photoelastic analysis, which was done by De Josselin de Jong and Verruijt. The correspondence between the plots was sufficiently good to conclude that the distinct element method is a valid tool for fundamental research. 
There are two major advantages of computer models in comparison to prototype tests. Firstly, all grain displacements, contact forces and micro cracks are known. Secondly, one specific sample can be tested many times. One of the major problems with Cundall's model was the computational time. According to Ting (1989), it is not feasible to simulate more than a few tens of thousands of grains, even with the fastest super computers currently available.

Lindhout (1992) tried to model the cylinder test with Trubal, which is the next version of Ball. Due to compaction problems, stability problems and the large computation time this could not be done. Therefore this new research project has been set up to solve these problems. The idea was that if the quasi-dynamical analysis of Cundall, which uses artificial damping, can be replaced by a technique which uses the so called finite element method, the model will become more useful.

This model can be used to understand better local stresses and displacements, because this micro mechanical analysis can investigate the behaviour of sand and sandstone on a very detailed scale. By simulating the actual grain structure, the analysis can perhaps bridge the gap between experimental observations and theoretical modelling. For Shell, this is of a special importance due to their oil and gas production boreholes. If the method is successful there will also be interest from other areas, like the mechanics of soft soils, powder technology or concrete technology.

The objective of the present study was to simulate and investigate granular mechanical behaviour on a micro scale (elements representing grains) and to translate this behaviour into a continuum approach or to determine the limitations of such an approach. 


\section{DISCRETE ELEMENT MODELLING}

Discrete element modelling, which is also called distinct element modelling, is in fact a type of finite element modelling. Every element represents one grain. The main difference from the normal finite element modelling is that due to deformation some contacts between the grains can be lost and new contacts can be made. This causes softening and hardening respectively of the structure. Because of this, the global stiffness matrix of the complete structure has to be rebuilt constantly.

For non-cohesive materials there is also a second reason why this matrix has to be updated; the behaviour of the contacts, both in the normal and the shear direction, is not linear, which means that the stiffnesses, $k_{n}$ and $k_{s}$, of these contacts, have to be recalculated continuously.

If the boundary conditions of the structure (forces or displacements) are changed, then this will effect every grain. All grains will be displaced then in such a way that a new force equilibrium is created (quasi-static approach) or a new time step is reached (dynamic approach).

Until recently only the dynamic approach has been worked out, mainly by Cundall. His model is based on the equations of motion. In this thesis, mainly the quasi-static approach is used, which is based on the equations of equilibrium. This approach is completely new. Both models will be worked out for a twodimensional rectangular Cartesian (OXY)- field.

\subsection{Micro modelling}

The behaviour of granular structures depends on the individual grains and their interaction. In order to be able to model this on a microscopic level, three simplifications are made (figure 1).

The first simplification is made by reducing the number of dimensions. Threedimensional computer modelling consumes a lot of time and memory. Besides, two-dimensional modelling gains more insight in the results obtained, because of its simplicity.

The second simplification is made to the grain shape. The most common one, a circle, reduces the calculation substantially. However, elliptical grains show failure at a larger stress ratio than circular grains during a loading test, according to Rothenburg and Bathurst (1992). Thus, circular grains will roll easier than grains of a more complex shape. 


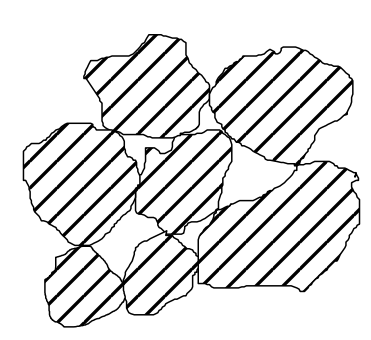

Two-dimensional

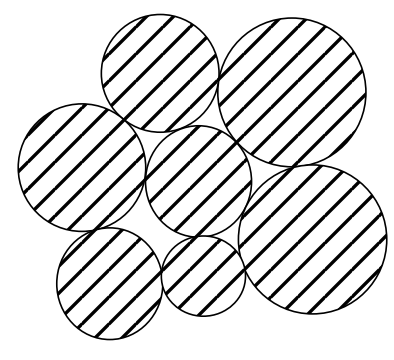

Circle shaped

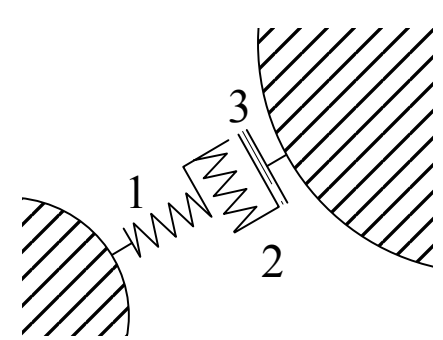

Contact behaviour

Figure 1. Simplifications

Cross sections of several types sandstone, like Fontainebleau Sandstone (David and Darot, 1993), make clear that the grains in these sandstones can be well described by polygons (figure 2 ).

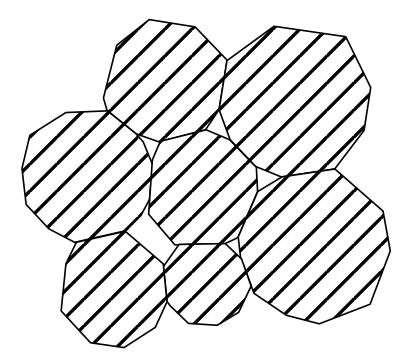

Figure 2. Fontainebleau Sandstone

During the formation of sandstone, the stress in the contacts is so high that the quartz material in the contact between the grain particles becomes a little bit viscous. Thus, the shear forces slowly fade away in time. Because of this creeping behaviour, the lateral stress of a one-dimensional compression test on sand increases with time under any stress conditions, according to Yamamuro (1996). The contact surfaces become flat in time and will fit more and more. The modelling of these sandstones with circular grains, will probably not cause too large errors as long as the contact behaviour, i.e. the strength and stiffness properties, is well modelled. This is because of the fact that the cemented grains in the sandstone will hardly roll.

The description of the contact behaviour between two grains contains the last simplification. This behaviour is divided in three parts:

1. Normal deformation.

2. Shear deformation.

3. Slip or crack.

All differences between real measurements and model results have to be explained by these three simplifications. Non-cohesive granular materials, such as sand or powders, and cohesive granular materials, such as sandstone or mortar, 
will be treated separately, because their contact behaviours are different from each other.

\subsubsection{Contact behaviour of non-cohesive granular materials}

The force-displacement relation in normal direction of two non-crushing balls was solved by Hertz (1881). The definitions of the used micro parameters are presented in figure 3. These parameters are also mentioned in appendix 1, Symbol list.
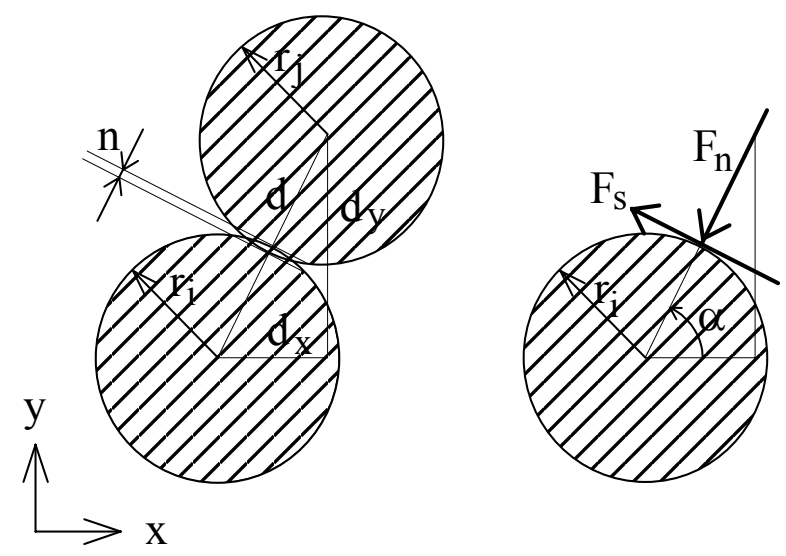

Figure 3. Definition of micro parameters

The relation between the normal force $F_{n}$ and the normal displacement $n$ is given by:

$$
F_{n}=M(n)^{\frac{3}{2}}
$$

in which:

$$
\begin{aligned}
M & =\frac{2 \sqrt{2 \bar{r}} G_{\mu}}{3\left(1-v_{\mu}\right)} \\
n & =r_{i}+r_{j}-d \\
\bar{r} & =\frac{2 r_{i} r_{j}}{r_{i}+r_{j}}
\end{aligned}
$$

The grain stiffness $M$ depends on the shear modulus $G_{\mu}$ and the Poisson's ratio $v_{\mu}$ of the grain material and also on the average size $\bar{r}$ of both grains. The reason why this relation is not linear is that the contact surface between the grains depends on the deformation, so during loading the geometry is not constant. This causes in its way the non-linear stress-strain behaviour of non- 
cohesive granular materials. A verification test of this relation is presented in appendix 2, Hertzian contact.

The force-displacement relation in shear direction between two balls was solved by Mindlin and Deresiewicz (1953) and verified by Deresiewicz (1958). The shear force $F_{s}$ is proportional to the shear displacement $s_{h}$ for the elastic area.

$$
F_{s}=k_{s} s_{h}
$$

The stiffness in shear direction $k_{s}$ depends on the normal force:

$$
k_{s}=\frac{2 G_{\mu}^{\frac{2}{3}}\left[3\left(1-v_{\eta}\right) \bar{r} F_{n}\right]^{\frac{1}{3}}}{2-v_{\mu}}
$$

But for solving a system of equations, linear relations are necessary, such as:

$$
F_{n}=k_{n} n
$$

So, the stiffness in normal direction $k_{n}$ is not constant because it depends on the normal displacement:

$$
k_{n}=M \sqrt{n}
$$

Because of this linearisation, the stiffness in shear direction can be related to the stiffness in normal direction:

$$
k_{s}=\kappa_{v} k_{n}
$$

in which:

$$
\kappa_{v}=3 \frac{1-v_{\mu}}{2-v_{\mu}}
$$

This means that the relation between the stiffnesses of the normal and shear direction depends only on the Poisson's ratio $v_{\mu}$ of the grain material.

Slip or plastic deformation occurs when the shear force exceeds, in comparison to the normal force, a certain level which depends on the friction $f_{g g}$ between two grains:

$$
\text { if }\left|F_{s}\right|>f_{g g} F_{n} \text { then }\left|F_{s}\right|=f_{g g} F_{n}
$$

in which:

$$
f_{g g}=\tan \phi_{\mu}
$$




\subsubsection{Contact behaviour of cohesive granular materials}

Since the contact surface between two cemented grains remains more or less constant, the force-displacement relation in the normal direction between two grains is assumed to be linear:

$$
F_{n}=k_{n} n
$$

The shear force is proportional to shear displacement for the elastic area:

$$
F_{s}=k_{s} s_{h}
$$

The shear stiffness is related to the normal stiffness:

$$
k_{s}=\kappa_{v} k_{n}
$$

Crack or plastic deformation occurs when the shear force exceeds a certain level:

$$
\text { if }\left|F_{s}\right|>f_{g g} F_{n}+F_{t} \text { then } F_{t}=0 \quad \text { so }\left|F_{s}\right|=f_{g g} F_{n}
$$

And if a tension force cut-off $F_{t}$ is used, also:

$$
\text { if } F_{n}<-F_{t} \quad \text { then break contact so } F_{n}=0
$$

in which:

$$
\begin{aligned}
& f_{g g}=\tan \phi_{\mu} \\
& F_{t}=c_{\mu} \bar{r}^{2} \text { or }=c_{\mu} r_{i} r_{j}
\end{aligned}
$$

\subsection{Motion modelling}

The modelling of granular structures can be divided in four phases (see figure 4):

1. Creation of the particles.

2. Calculation of the boundary conditions such as wall displacements.

3. Calculation of the grain displacements and the contact forces.

4. Saving of wall forces, displacements or other necessary information.

In phase 1. all grains are randomly placed between the walls with a grain size of one percent of its final size. During the next iterations the grains are blown up to fill the volume between the walls.

In phase 2. the displacements of the stress controlled walls and the new stresses of the displacement controlled walls will be calculated.

In phase 3. all grains will be one by one checked and recalculated. In Cundall's model, which is based on the equations of motion, this is done every time step. This grain calculation in a motion model consists of three parts:

A. With the two force-displacement relations,

$$
\begin{aligned}
& F_{n}=k_{n} n \\
& F_{s}=k_{s} s_{h}
\end{aligned}
$$

all forces on one particular grain are calculated. 
B. With these forces and the equations of motion (second law of Newton), the acceleration of the grain is determined:

$$
\begin{aligned}
& \sum F_{x}=m \ddot{x} \\
& \sum F_{y}=m \ddot{y} \\
& \sum M=I \ddot{\phi}
\end{aligned}
$$

in which:

$$
\begin{aligned}
M & =\text { moment on a grain } \\
m & =\text { mass of a grain }
\end{aligned}
$$

For the next time step, the new position of the grain is found with two integration steps:

$$
\begin{aligned}
& \ddot{x}=\frac{1}{m} \sum F \\
& \dot{x}=\int \ddot{x} d t \\
& x=\int \dot{x} d t
\end{aligned}
$$

This integration is not very stable and therefore small time steps and damping are necessary. Extra calculation time and less accuracy are the result of this.

C. All contacts of the grain are checked for:

I. Plastic deformation (slip or crack).

$$
\text { if }\left|F_{s}\right|>f_{g g} F_{n}+F_{t} \text { then }\left|F_{s}\right|=f_{g g} F_{n}
$$

where for sand and after cracking:

$$
F_{t}=0
$$

II. Contact breaking.

$$
\text { if }-F_{n}>F_{t} \text { then break contact }
$$

III. Contact making.

$$
\text { if } n>0 \text { then make contact }
$$

With the new positions, the new forces for part A. can be calculated. In this way, for every time step, all contact forces and grain positions are determined. The computer models, Ball, Trubal and PFC (particle flow code) from Itasca in Minneapolis USA are all based on this method. 


\subsection{Equilibrium modelling}

The new model is based on the equations of equilibrium. Only part B in which the displacements of the grains are calculated is different from the motion modelling:

A. The first part is the same as the motion model.

B. In the new approach, equilibrium equations are used instead of equations of motion:

$$
\begin{aligned}
& \sum F_{x}=0 \\
& \sum F_{y}=0 \\
& \sum M=0
\end{aligned}
$$

By disregarding time, dynamic problems like explosions, vibrations and quakes can not be modelled. The three equations form a $3 \times 3$ matrix:

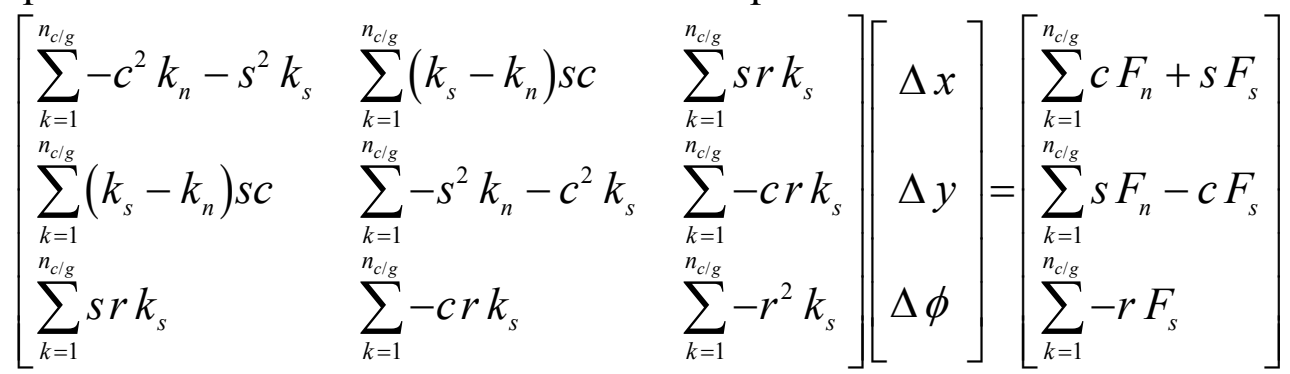

in which:

$$
\begin{aligned}
n_{c / g} & =\text { number of contacts per grain } \\
s & =\sin (\alpha) \\
c & =\cos (\alpha) \\
r & =\text { radius of the grain }
\end{aligned}
$$

and:

$$
\begin{aligned}
& \Delta x=x_{\text {new }}-x_{\text {old }} \\
& \Delta y=y_{\text {new }}-y_{\text {old }} \\
& \Delta \phi=\phi_{\text {new }}-\phi_{\text {old }}
\end{aligned}
$$

All the forces and stiffnesses on one particular grain are placed in this matrix. The displacements, and thus also, the new equilibrium positions of the grains, can directly be calculated by Gauss elimination.

C. The third part is the same as the motion model. 
Although the equilibrium position is directly calculated, the displacement of a grain will effect its neighbouring grains. Therefore several iterations through the whole structure are necessary to find the total equilibrium state of the grain structure. The computer model Grain, written by the author, is based on this method. A structure diagram of this model is given in figure 4.

\section{Grain}

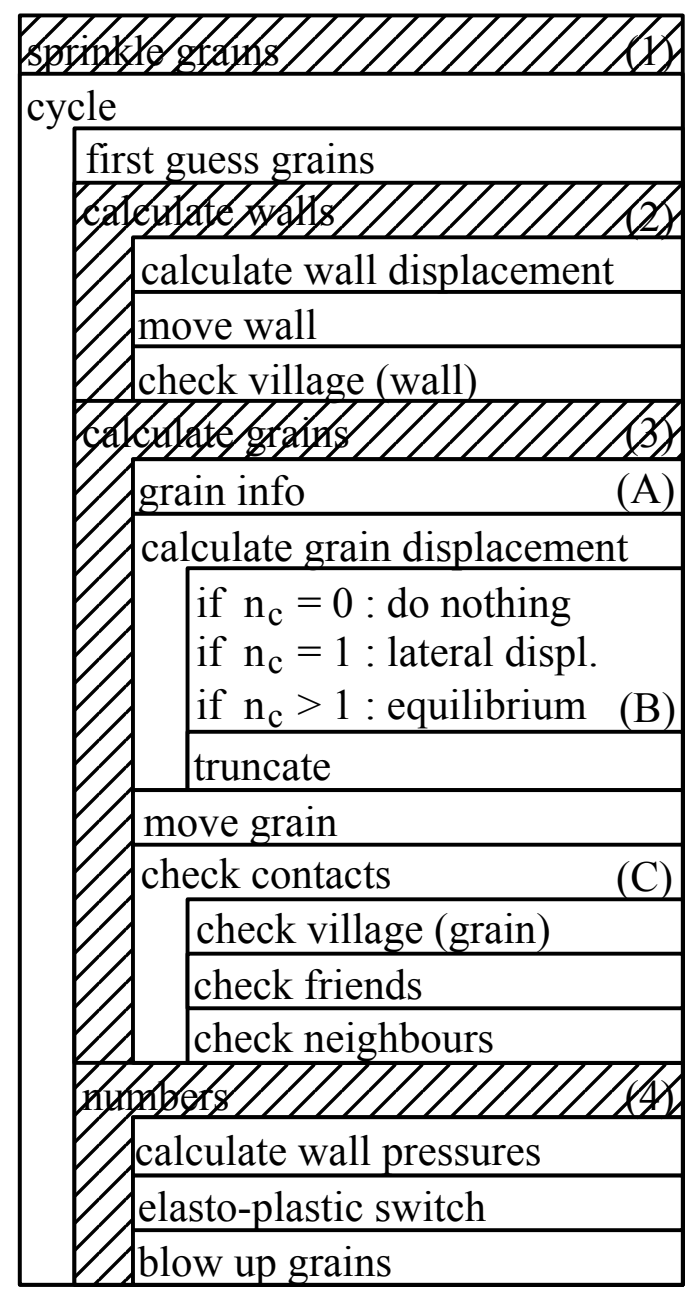

make new grains if necessary repeat until end of simulation each $n_{i}$ times displace all grains do for all walls each $\mathrm{n}_{\mathrm{i}}$ times displace walls

collect $\mathrm{n}_{\mathrm{c}}$ and $\mathrm{F}_{\mathrm{n}}, \mathrm{F}_{\mathrm{s}}, \mathrm{k}_{\mathrm{n}}, \mathrm{k}_{\mathrm{s}}, \mathrm{sh}_{\mathrm{h}}, \mathrm{s}, \mathrm{c}$ for all contacts

$$
\mathrm{k}_{\mathrm{s}}=0 \text { for plastic calculations }
$$

$3 \times 3$ matrix

for elasto-plastic modelling

if $-\mathrm{n}<\mathrm{r} \quad$ : make friends

if $\mathrm{n}>0 \quad$ : make contact

if $-\mathrm{F}_{\mathrm{n}}>\mathrm{c}_{\mu} \cdot \mathrm{r}^{2}$ : break contact

if $\left(2 . \mathrm{i}<\mathrm{n}_{\mathrm{i}}\right)$ elastic otherwise plastic enlarge new grains if necessary

Figure 4. Schematic overview of the computer program Grain 
Because the grains can gain and loose contacts during the simulation, not only the calculation of the grains but also keeping track of the grain data and contact data is important. It is time consuming to check, each time, all possible grain contacts. To avoid this, each grain has a list of the contacts between its neighbours and also a list of the grains which are nearby but not connected. These are called friends. After the grains are sprinkled between several walls (Phase 1), the entire group of grains is considered as a village surrounded by city walls. Every grain has to check the complete village in order to make its personal list of close friends. This has to be done only once after the creation of the grains and every time a grain has been displaced outside his defined friend-area. This happens only occasionally. In this way only the friends have to be checked for contact-making and the neighbours for contact-breaking. This "book-keeping" is explained in appendix 3, Discrete element book-keeping.

\subsection{Elasto-plastic modelling}

In fact, both models calculate the shear deformation $s_{h}$ completely elastically and they both cut off the shear forces at shear, as shown in figure 5 .

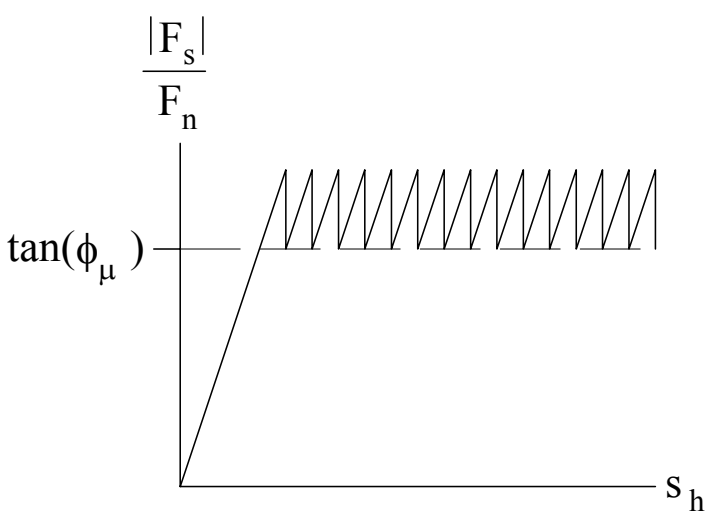

Figure 5. Elastic modelling

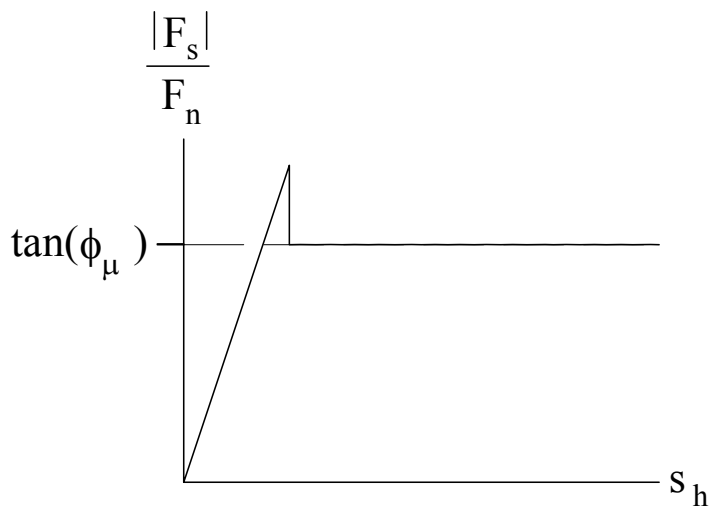

Figure 6. Elasto-plastic modelling

Especially for a low friction $\phi_{\mu}$ and a high shear stiffness $k_{s}$, a large amount of iterations are necessary to model the plastic deformations properly. An effective solution is to make the shear stiffness $k_{s}$ zero after shear is detected, so that the shear force will not increase any more. If the shear force decreases or the normal force increases the stiffness has to return to its former value. This elasto-plastic modelling, shown in figure 6 , iterates much faster.

Because the shear deformations are unlimited in the plastic state, the elastoplastic modelling causes one particular problem. In the same way as a round object, for instance a pen, can also be launched by squeezing it between two 
finger tips, a grain can be launched, when the plastic state is reached, as shown in figure 7.

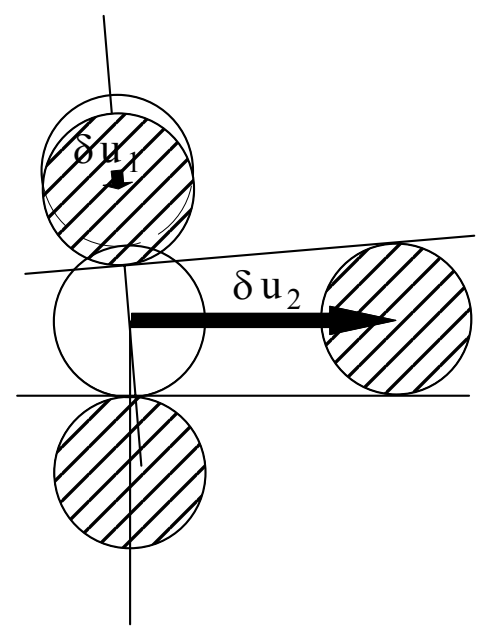

Figure 7. Squeezing of a grain

The small displacement $\delta u_{1}$ causes a larger displacement $\delta u_{2}$. Such a large displacement will be divided, just as any large displacement, into several smaller steps by the procedure "truncate", to prevent the grain from jumping to an empty place without noticing potential geometrical limitations.

Elasto-plastic modelling has been installed in Grain. With this computer model all numerical calculations in the following chapters have been done.

\subsection{Characteristic tests}

Five characteristic tests are standardised in Grain to study the micro-mechanical behaviour of cohesive and non-cohesive granular materials. The first three are sketched in figure 8 , the last two in figure 9.

The most common test, to measure the Young's modulus $E$ in the elastic phase is the one-dimensional compression test. This compression test can also give the Poisson's ratio $v$, if the horizontal stresses are known.

With the confined biaxial test, the strains are prescribed, so volumic deformations are easily measured. If shear bands occur then the stresses can become not homogeneous, especially for cohesive materials. Therefore this test will only be used for non-cohesive materials.

The unconfined biaxial test is suitable to determine both the Young's modulus $E$ and the strength parameters $c^{\prime}$ and $\phi^{\prime}$. The lateral pressure remains constant during loading. Because of the rubber membranes (wall number 2 and 4), shear bands can occur. 


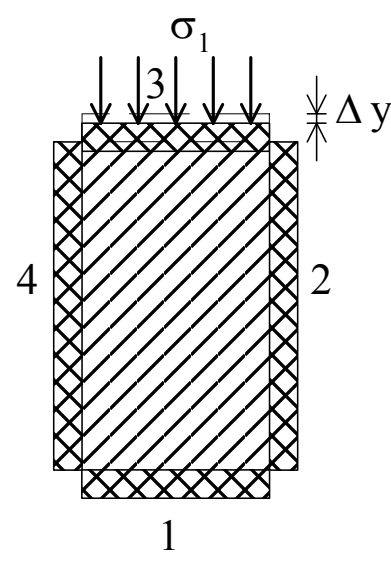

Compression test

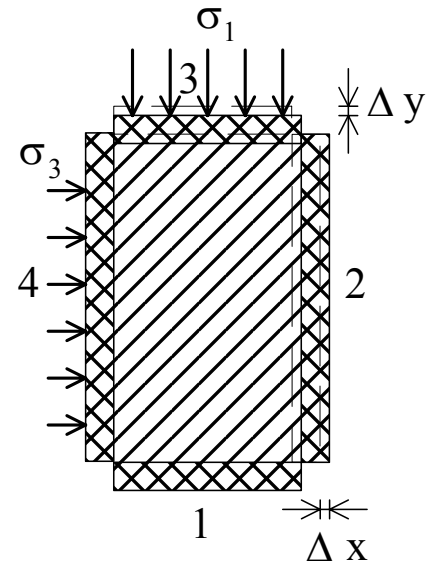

Confined biaxial test

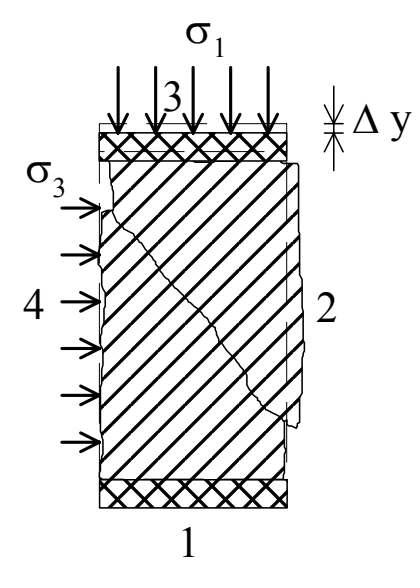

Unconfined biaxial test

Figure 8.

The simple shear test seems to be, in theory, a simple test for measuring the shear modulus and the angle of internal friction in a direct way. In practice the results are not always found to be consistent and therefore this test is not so often used any more. Characteristic of this test is the rotation of the principal directions during shearing.

In the oil and gas industry, the failure of boreholes is important. The cylinder test models this phenomenon. A thick-walled sandstone cylinder with a borehole in the middle will be radially compressed until it fails.

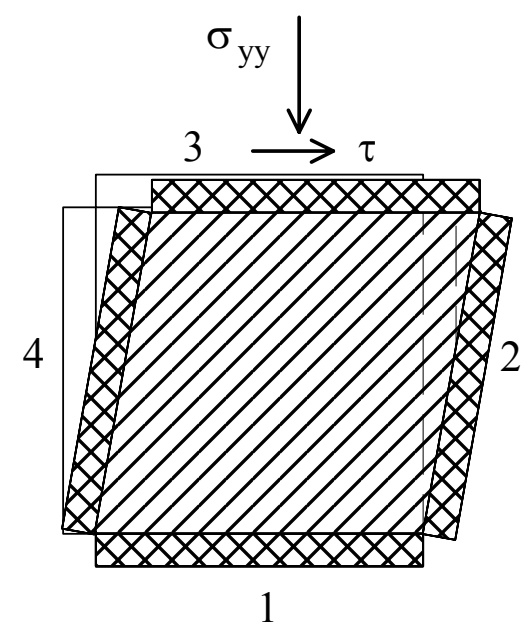

Simple shear test

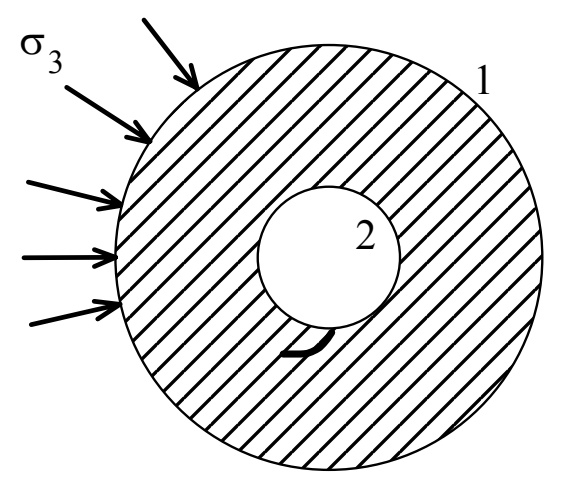

Cylinder test

Figure 9. 


\subsection{Motion versus equilibrium}

The main advantage of the motion model is that it can handle dynamic problems, although this is not necessary for this particular research. The main advantage of the equilibrium model is calculation speed.

When this research was started in 1993, one of the most used motion models was New Trubal (NTB) from Itasca, developed by Cundall. This model had no stress controlled walls or membranes and also no circular walls, so the only characteristic test which could be used to compare Grain and NTB was the compression test. The final results of both models were found to be equal, although Grain was much faster. For each iteration step of Grain, 4000 iteration steps were necessary with NTB. Because NTB was not able to handle certain characteristic tests and needed too much calculation time, only Grain is used to do the rest of the numerical simulations in this report.

Two years later (February 1995) a new version called Particle Flow Code (PFC) was released by Itasca. It had two major improvements:

1. PFC could use stress controlled walls, although in a complicated way.

2. The calculation speed was much improved.

In figure 10 we see an identical unconfined biaxial test on 250 cohesive grains done by PFC (motion model) and Grain (equilibrium model).

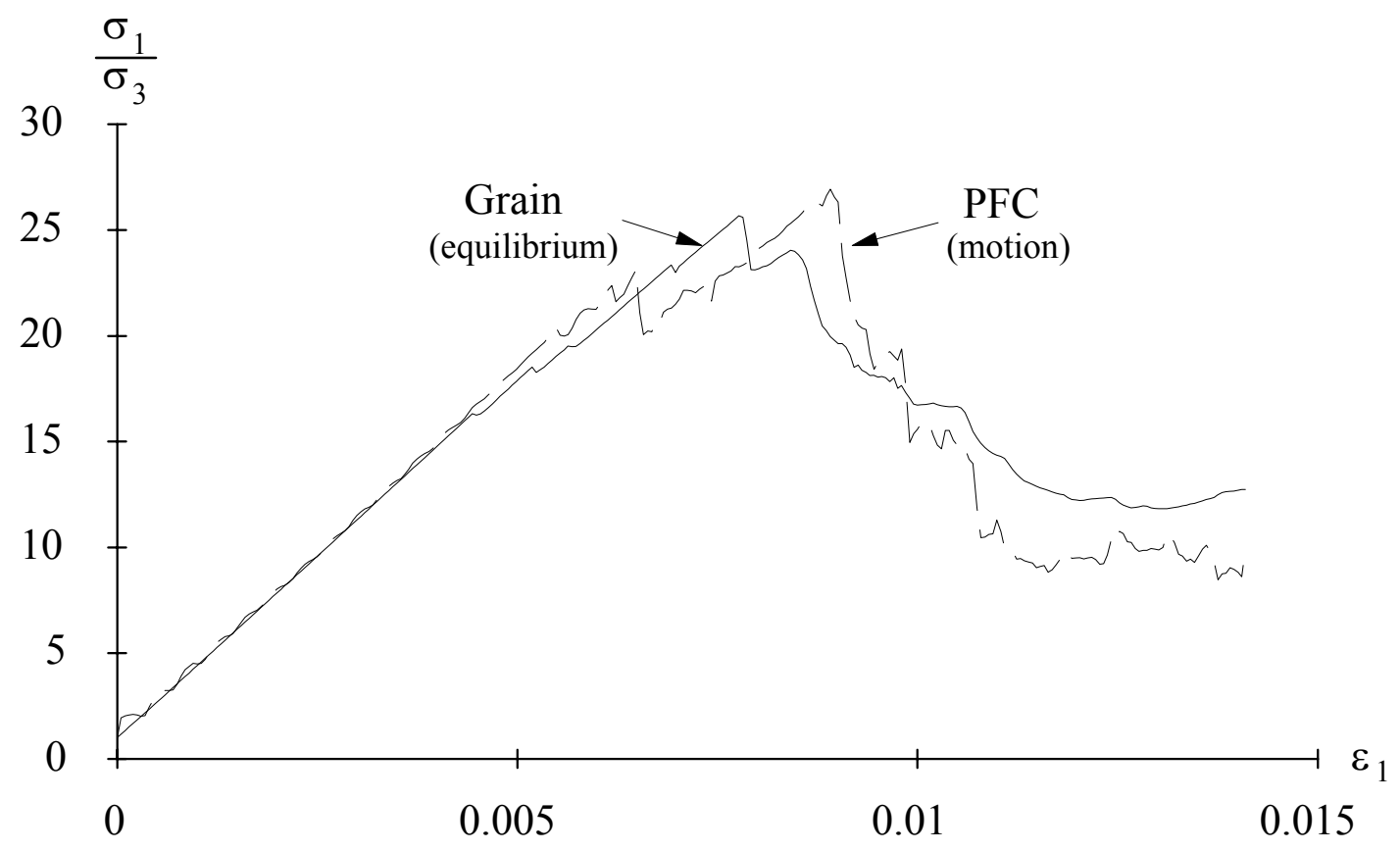

Figure 10. Identical biaxial test on 250 cohesive grains by PFC and Grain 
Because PFC is a motion model, the sample is oscillating between the two horizontal walls. This effect will be less marked during the elastic phase if more iterations are used. Although the models are based on different basic principles, the final results are quite similar. The only difference now is that PFC uses about fifty times more iteration steps than Grain.

Sometimes the results of Grain and PFC are less identical and if a smaller time step is chosen (i.e. more iteration steps), the stress-strain behaviour during failure can become very unstable for the motion model as demonstrated in figure 11 . These are not the only problems of this motion model. Waves propagate too slowly: Thus, the dynamic elasticity of an assembly of grains is about 50 percent lower than the static elasticity.

Because of these problems, PFC is not used for doing verification.

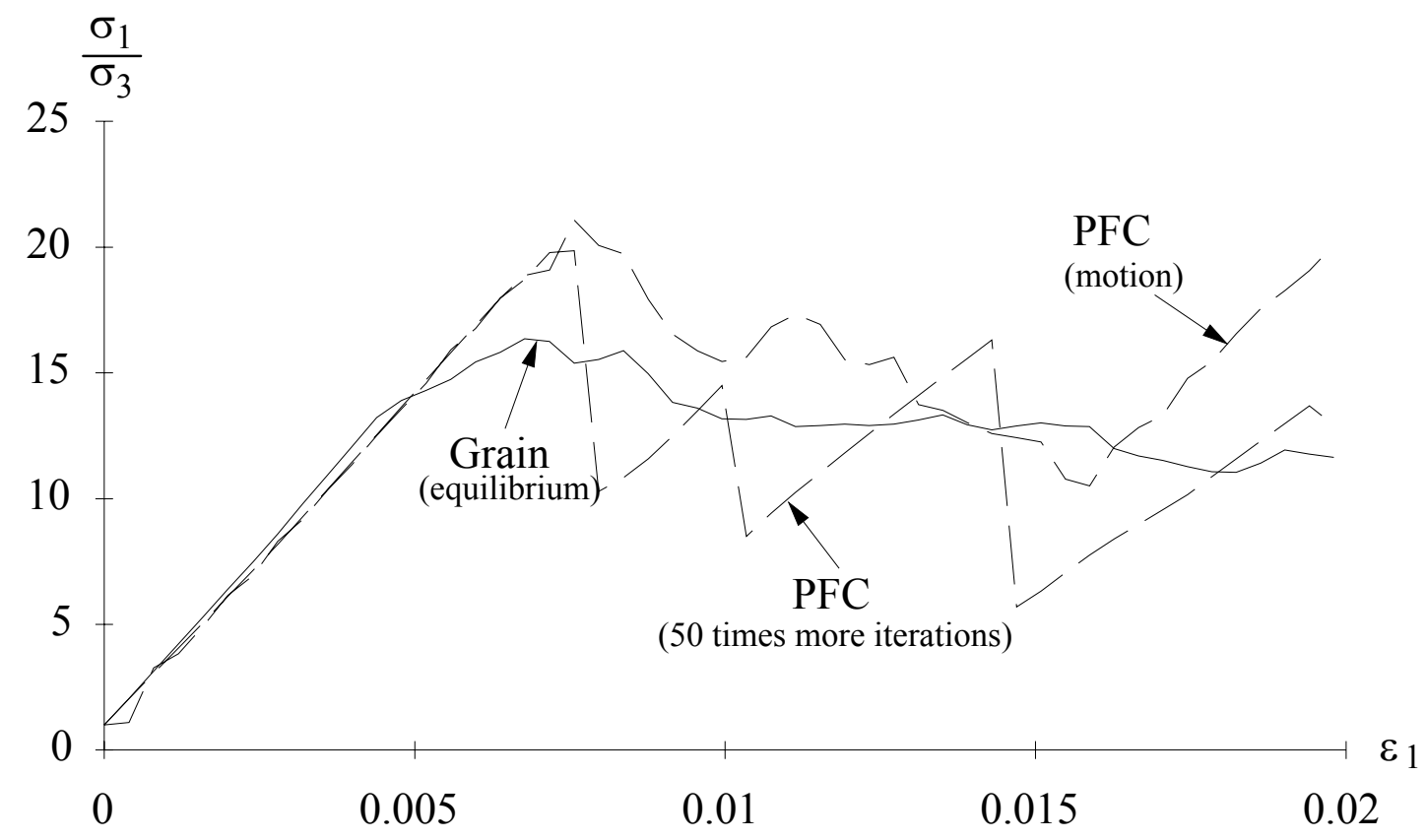

Figure 11. Instability of PFC model 


\section{NON-COHESIVE GRANULAR MATERIALS}

\subsection{Default parameters}

Several characteristic tests have been done to measure the influence of a number of specific micro parameters, such as relative density, lateral pressure or internal friction, on the macro behaviour of non-cohesive granular materials. Most of the tests are carried out on a structure of a thousand grains. The default micro parameters are chosen to be representative for sand of dense compaction, as presented in table 1 . If confusion between micro and macro parameters can occur, then the micro parameters are marked with a " $\mu$ ".

\begin{tabular}{||c|c||c|c||c|c||}
\hline \multicolumn{2}{|c||}{ soil data } & \multicolumn{2}{c||}{ grain size } & \multicolumn{2}{c||}{ test parameters } \\
\hline$k_{n}$ & - & $\bar{r}$ & $0.1 \mathrm{~mm}$ & $\sigma_{3}$ & $1 \mathrm{bar}$ \\
\hline$G_{\mu}$ & $1000 \mathrm{MPa}$ & type & $\mathrm{A}(\mathrm{B})$ & $\frac{\Delta H}{H}$ & $4.0 \times 10^{-5}$ \\
\hline$v_{\mu}$ & 0.16 & $\frac{r_{\max }}{r_{\min }}$ & 4.00 & $n_{i}$ & 20 \\
\hline$f_{g g}$ & 0.60 & $\frac{H}{W}$ & $\begin{array}{c}2.50 \\
(1.00)\end{array}$ & $\sigma_{1, \max }$ & $\left(6 \times \sigma_{3}\right)$ \\
\hline$f_{g w}$ & $0.00(\infty)$ & & & $\sigma_{1, \min }$ & $\left(3 \times \sigma_{3}\right)$ \\
\hline$c^{\prime}{ }_{\mu}$ & $0 \mathrm{kN} / \mathrm{m}$ & $n_{g}$ & $\begin{array}{c}1000 \\
(4000)\end{array}$ & & \\
\hline \hline
\end{tabular}

Table 1. Default micro parameters for sand

The making of a compact sample from a large amount of free grains with low grain friction can cost more than a day's calculation time because the continuous making and breaking of the contacts, i.e. the updating of the matrix, leads continuously to new solutions. Once a sample is created, many tests can be done with this sample. These tests seldom take more than one hour. 


\subsubsection{Soil data}

The tests on sand are based on the non-linear Hertzian contacts and therefore the shear modulus $G_{\mu}$ is used, instead of the linear spring constant $k_{n}$. The value of this shear modulus is not free of controversy. According to the Handbook of Chemistry and Physics, it should be about $G_{\mu} \approx 34 \times 10^{9} \mathrm{~Pa}$ for quartz. If this is filled out in Hertz's contact relation, the stiffness of the total grain structure is found to be too high. Because of this a lower value of $G_{\mu} \approx 1 \times 10^{9} \mathrm{~Pa}$ had to be chosen, in order to give a more realistic stiffness behaviour. Three analytical explanations for this problem do not seem to agree with reality:

1. The shear modulus of the grain material cannot be about 30 times smaller, because real compression tests on sand grains and on glass pearls (also: $G_{\mu} \approx 34 \times 10^{9} \mathrm{~Pa}$ ) show identical macro stiffness behaviour.

2. Small ridges on the grain surface with a radius of $r_{\text {ridge }}=\frac{1}{2000} r_{\text {grain }}$ will solve the problem analytically (equation 1.), but then the deformation $n$ of the ridge on the grain becomes even larger than the ridge size $r_{\text {ridge }}$ itself.

3. More complex spheres, for example ellipses, will give a higher strength but not a lower stiffness according to Rothenburg and Bathurst (1992).

This means that the contact behaviour between two grains needs more attention. The Poisson's ratio of quartz is about $v_{\mu} \approx 0.16$. The friction angle is mostly between $\phi_{\mu} \approx 20^{\circ}$ and $\phi_{\mu} \approx 30^{\circ}$. The latter gives a friction between two grains of about $f_{g g}^{I I}=\tan \left(\phi_{\mu}\right) \approx 0.60$. Before a test, the grain friction will be temporarily decreased to $f_{g g}^{I}=0.0$ to obtain a high density. The friction between grain and wall, for all tests, is zero $f_{g w}=0$, except for the simple shear test, where no shearing is allowed, so $f_{g w}=\infty$. 


\subsubsection{Grain size}

The average grain size is chosen to be $r=0.1 \mathrm{~mm}$. In theory an infinite number of grain size distributions can be made, however for most sands the sieve curves show a straight line in a logarithmic graph. Those distributions are defined by the average grain size $\bar{r}$ and the grain size ratio $\frac{r_{\max }}{r_{\min }}$ as can be seen in appendix 4, Grain size distribution. The probability function of this "Type A" distribution is illustrated in figure 12. Also a second distribution "Type B" is used, which can be described by a linear function. The shape of the sample (i.e. the whole grain structure), for all tests, is rectangular $\frac{H}{W}=2.50$ except for the simple shear test in which the sample is square: $\frac{H}{W}=1.00$. All tests are carried out on a sample of a thousand grains, because this amount was more than sufficient to get identical test results for different samples created with identical micro parameters. Only for the simple shear test, 4000 grains were used, because during this test also the stresses in the centre of the sample are measured over about a thousand grains.

\section{Type A}

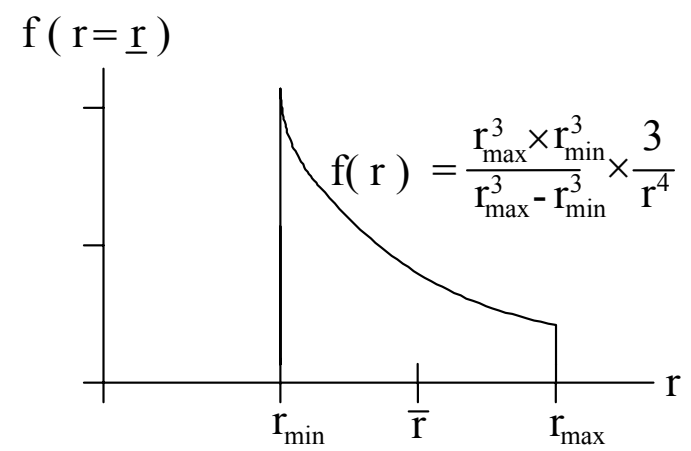

$\mathrm{P}(\mathrm{r} \leqq \underline{\mathrm{r}})$

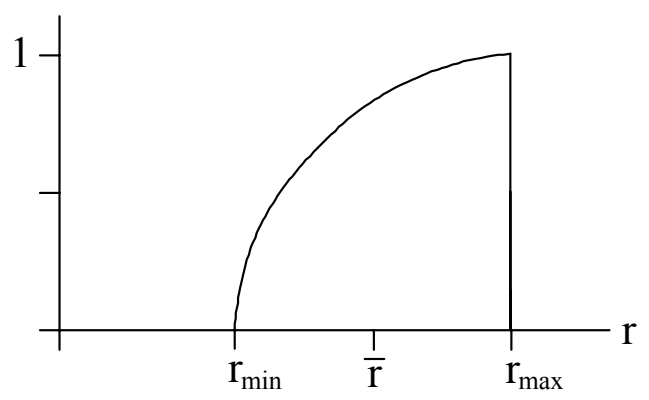

Type B
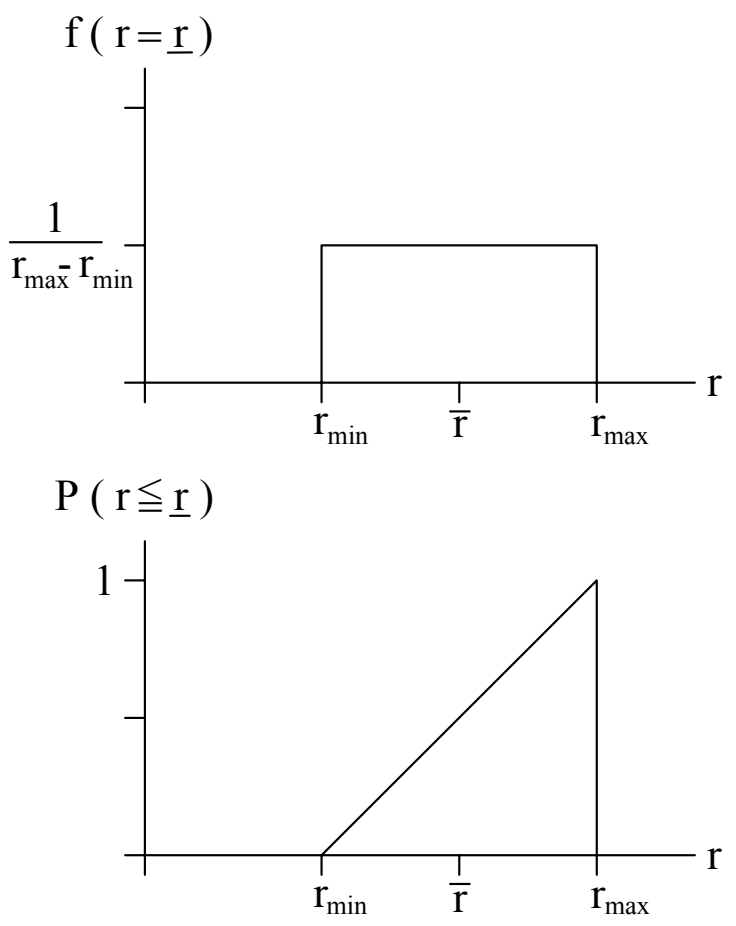

Figure 12. Probability function: grain size distribution type $A$ and $B$ 


\subsubsection{Test parameters}

The default lateral pressure was set at $\sigma_{3}=0.1 \mathrm{MPa}=1 \mathrm{bar}$. The total sample deformation of $4 \%$ is reached in a thousand load steps: $\frac{\Delta H}{H}=4.0 \times 10^{-5}$. Twenty iterations per loading step were sufficient to iterate accurately enough to the equilibrium state. The cyclic loading of the compression test is between the 3 and 6 bar. In all cases the depth of a sample is chosen to be equal to the average diameter of the grain $(D=\bar{d}=2 \bar{r}$ ) in order to be able to calculate the stresses.

\subsection{Micro behaviour versus macro behaviour}

\subsubsection{Relative Density}

When free grains are carefully compressed then a loose structure will be created with a maximum volume of pores and a minimum of contacts per grains. In this case, the relative density will be zero $(R \cdot D \cdot=0)$. For two dimensions the minimum number of contacts needed for creating a stable structure is on average three per grain (for three dimensions this will be four).

By temporarily decreasing of the friction $f_{g g}{ }^{I}$ between the grains, the sample will shear to a denser structure. After compaction the friction will be increased to a friction level $f_{g g}{ }^{I I}$ which is necessary for the real test. In this way the relative density can be controlled. For a temporary friction of $f_{g g}{ }^{I}=0$ the highest density will be found ( R.D.=1). A maximum density can also be reached by sprinkling the grains one by one. A new grain will always create two new contacts for itself and one for both neighbours, so the maximum number of contacts per grain will be four (for three dimensions, this will be six).

\begin{tabular}{||c|c|c||}
\hline density: & low & high \\
\hline sample I & 3.1 & 4.1 \\
\hline sample II & 3.0 & 3.9 \\
\hline sample III & 3.0 & 3.9 \\
\hline sample IV & 3.1 & 4.0 \\
\hline
\end{tabular}

Table 2. Number of contacts per grain

Table 2 shows the influence of the density on the average number of contacts per grain for eight different samples, made by Grain. The results are as expected. For 
a low density the number of contacts is: $n_{c / g} \approx 3.0$ and for a high density $n_{c / g} \approx 4.0$.

Figure 13 illustrates that the number of contacts per grain is not constant during a confined biaxial test. At failure this number becomes more or less constant $\left(n_{c / g} \approx 3.3\right)$ for all samples.

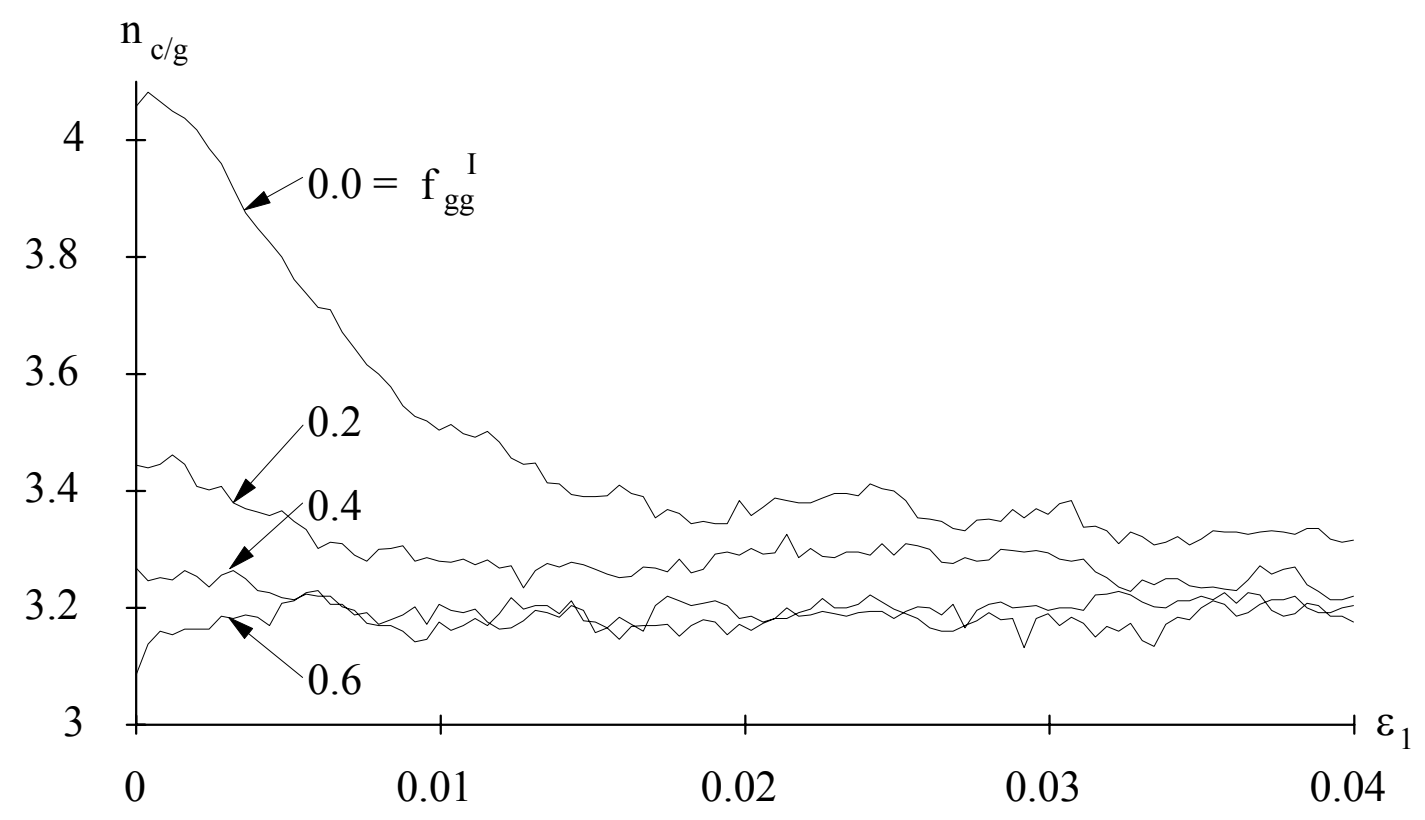

Figure 13. Biaxial test: influence of the density on the number of contacts per grain

During loading the number of axial (vertical) contacts increase somewhat, but the number of lateral (horizontal) contacts decreases greatly. This can be seen in the radar plot in figure 14. The grain-wall contacts are neglected in this plot. Since the grain structure used, contains only 4000 grains, there would otherwise be too many contacts for which the contact angle is exactly $0,90,180$ or 270 degrees.

The decrease in lateral contacts is a sign of failure for granular materials. It suggests a failure of the structure by loosening and eventually loss of lateral contacts. It seems that granular materials fail because of tension failure. The loss of horizontal contacts starts to become clearer when:

$$
\frac{\sigma_{1}}{\sigma_{3}} \approx 2
$$

just as predicted in appendix 7, Biaxial test: analytical. This will not be the maximum strength, because the grains still have to roll over each other for a complete failure, which requires a higher loading stress. 


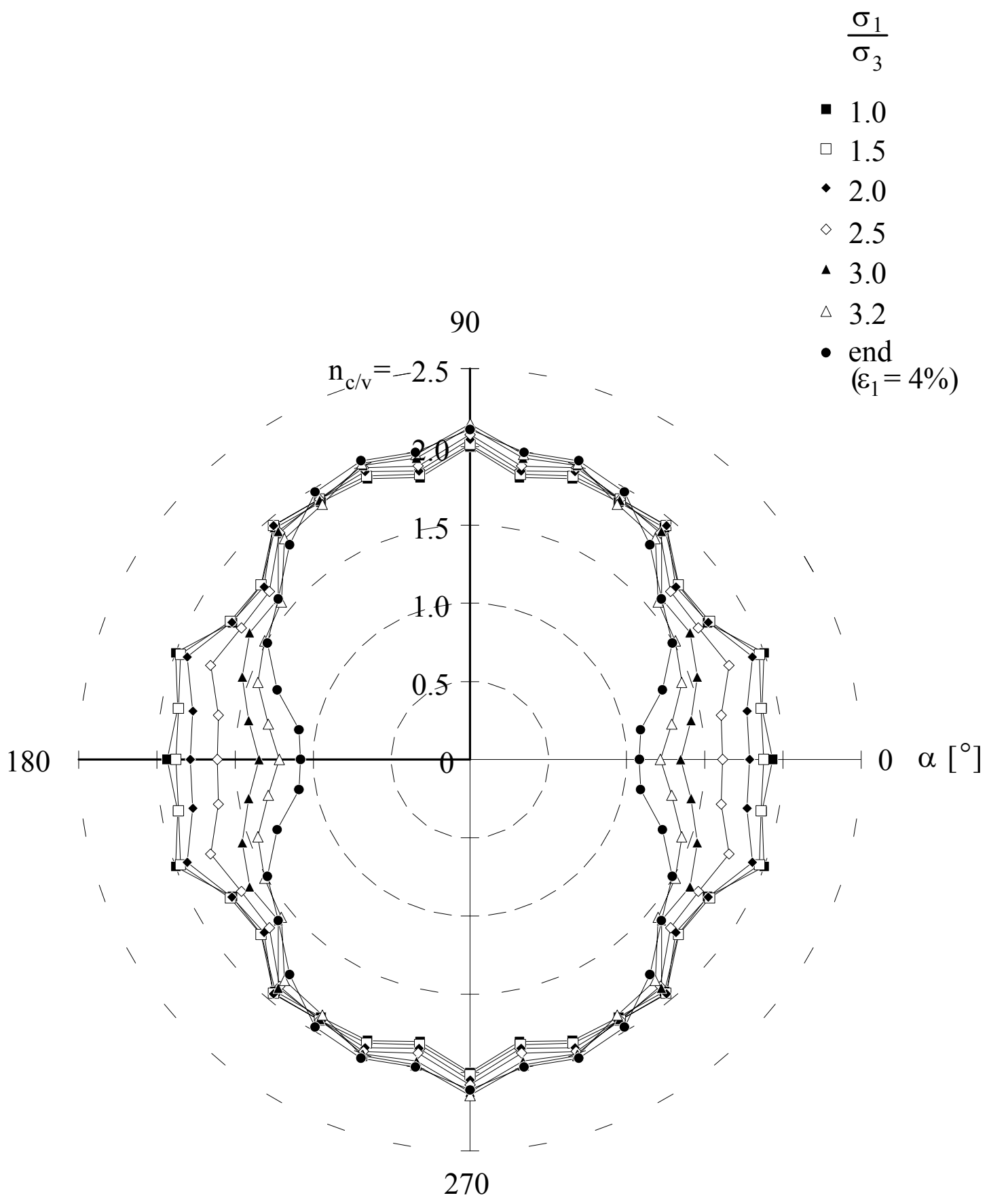

Figure 14. Number of contacts per volume versus the contact angle during a biaxial test 
The Mohr-Coulomb model gives a relation between the angle of internal friction and the strength of a non-cohesive materials:

$$
\frac{\sigma_{1}}{\sigma_{3}}=\frac{1+\sin \left(\varphi^{\prime}\right)}{1-\sin \left(\varphi^{\prime}\right)}
$$

in which:

$$
\begin{aligned}
& \sigma_{1}=\text { major principal stress } \\
& \sigma_{3}=\text { minor principal stress }
\end{aligned}
$$

The density, which is controlled by the friction during compaction $f_{g g}^{I}$, has a major influence on the strength of these samples as can be seen in figure 15 . Several conclusions can be drawn from these curves:

1. Relative density is an important parameter for strength and elasticity.

2. A higher density causes a higher angle of dilatancy.

3. During failure the samples with low density will hardly consolidate to higher compaction.

Especially for high density samples the angle of dilatancy is quite large. Perhaps this is because in a two-dimensional model grains at failure have to roll completely over another grain while in the three-dimensional reality grains can pass partially sideways.

Bishop (1954) suggests that the analytical solutions of the angle of internal friction by Caquot (1934) agree well with several air-dried non-cohesive granular materials. According to these solutions the angle of internal friction for a biaxial test depends only on the friction between the grains $f_{g g}$ :
A. Triaxial test, where $\sigma_{2}=\sigma_{3}<\sigma_{1}: \quad \sin \left(\varphi^{\prime}\right)=\frac{15 f_{g g}}{10+3 f_{g g}}$
B. Biaxial test, taking $\sigma_{2}=\frac{\sigma_{1}-\sigma_{3}}{2}: \quad \sin \left(\varphi^{\prime}\right)=\frac{3}{2} f_{g g}$
C. Biaxial test, normal plain strain: $\quad \tan \left(\varphi^{\prime}\right)=\frac{\pi}{2} f_{g g}$

Unfortunately, the following three important facts are not considered in Caquot's solution:

1. Higher density gives higher strength.

2. Less circular shaped grains cause higher strength.

3. An infinite grain friction will not give infinite strength.

This means that Caquot's solution can be called, at best, an incomplete solution. A complete analytical solution for the strength of a non-cohesive granular material will be hard to develop. 

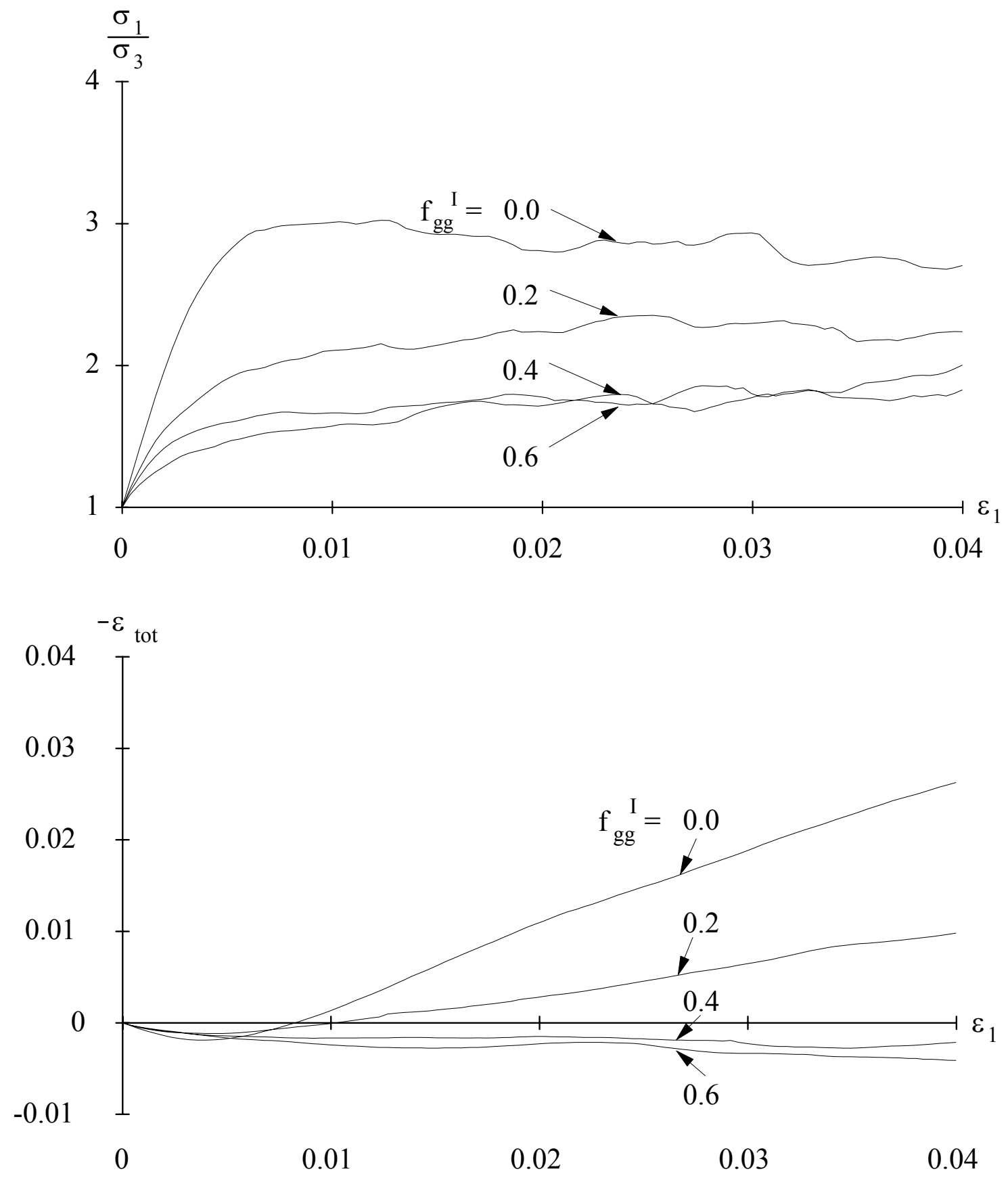

Figure 15. Biaxial test: influence of the density 


\subsubsection{Grain friction}

One of the most important micro parameters is the internal friction between the grains, $f_{g g}^{I I}$, after compaction. This parameter marks the transition between elastic and plastic deformation on micro level.

In figure 17, two macro parameters are strongly influenced by an increase of the internal friction:

1. The strength of the whole structure increases.

2. The dilatancy $\psi$ increases as well.

When the internal friction $f_{g g}^{I I}$ is zero, the grain structure will shear under every circumstance to the maximum relative density. In this way the structure will behave like a fluid and the volume will remain constant. This behaviour is very clear in the numerical simulations.
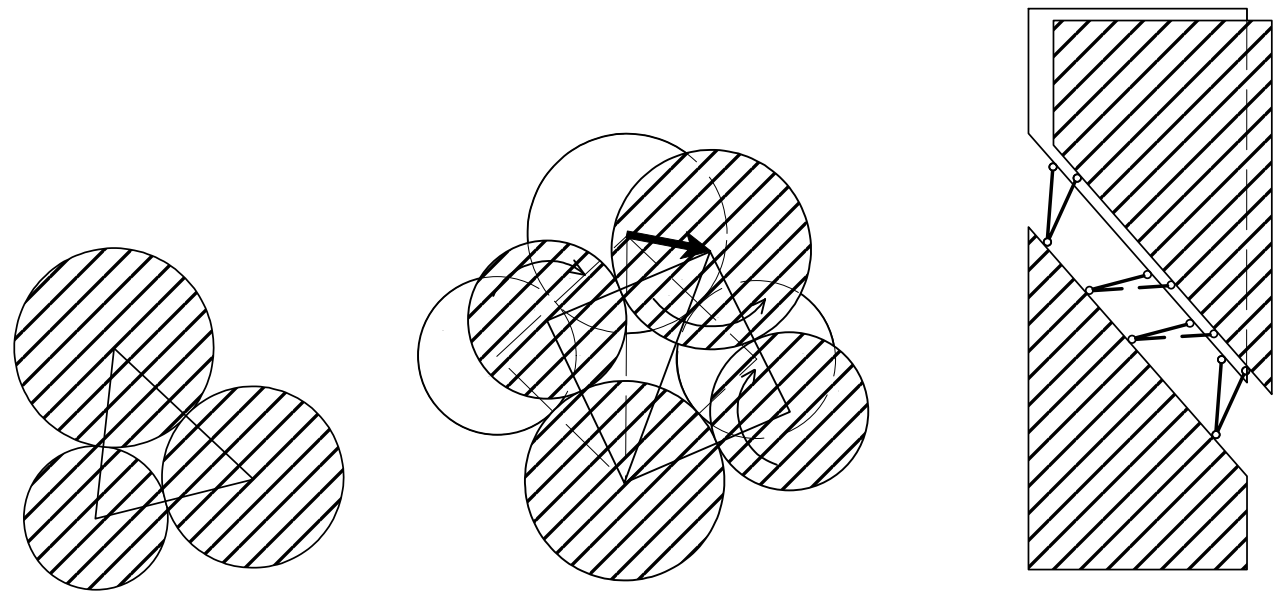

No rolling Rolling without shear Dilatancy and contact breaking

Figure 16. Failure on micro scale

By contrast, a structure with infinite grain friction can collapse only by the rolling of the grains. Triangle contact groups do not roll, but quadrangular and more angular contact groups are able to deform despite the infinite grain friction according figure 16 . These rolling groups will act like rolling wedges, causing an increase in pore volume (dilatancy) and a decrease in the number of (especially lateral) contacts in the shear bands. This dilatancy will be largest for an infinite grain friction, because all wedges will be mobilised, and not one will fail because of shearing. 

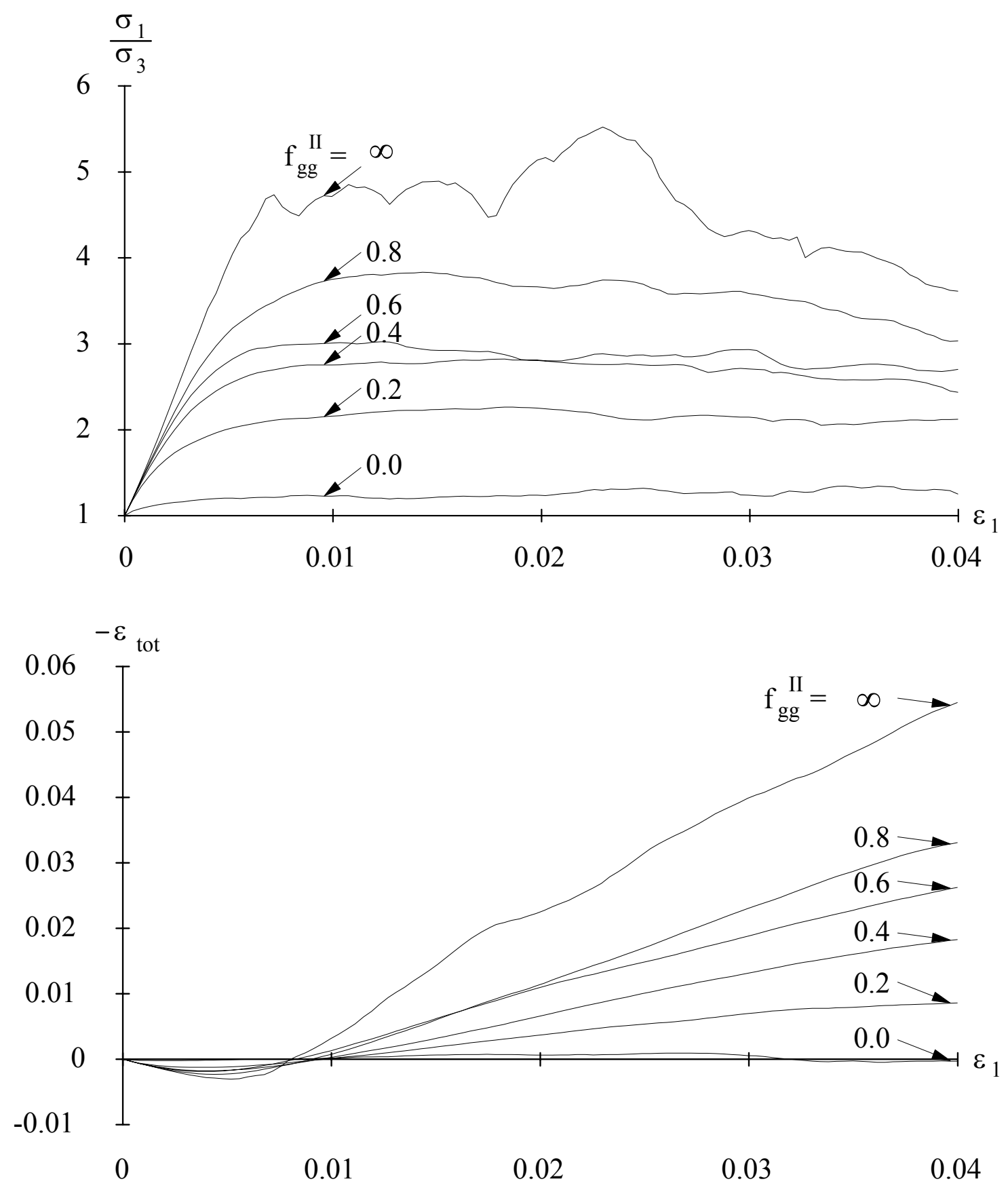

Figure 17. Biaxial test: influence of the internal friction 
Also another conclusion can be drawn from these results. Even if the grain friction is infinite, the strength will not be infinite. This means that for structures with a low grain friction the strength is mainly determined by this friction, but for a high friction the strength is mainly defined by the rolling of the grains. Other tests show that if the rotation of the grains is fixed in combination with an infinite grain friction, then an infinite strength is found, which is in agreement with the previous theory.

It can be concluded that non-cohesive granular materials fail because of both shearing and rolling, but only the rolling of the grains causes dilatancy and contact breaking.

\subsubsection{Poisson's ratio}

The Poisson's ratio of quartz is not the main micro parameter to influence the macro Poisson's ratio of the total granular structure. The rotation of the grains is much more important. Figure 18 shows that a fixed rotation of the grains strongly influences the compression test and the biaxial test.

$$
\Delta \phi=0 \quad \text { versus } \quad \Delta \phi \neq 0
$$

$\sigma_{1}$ and $\sigma_{3}$

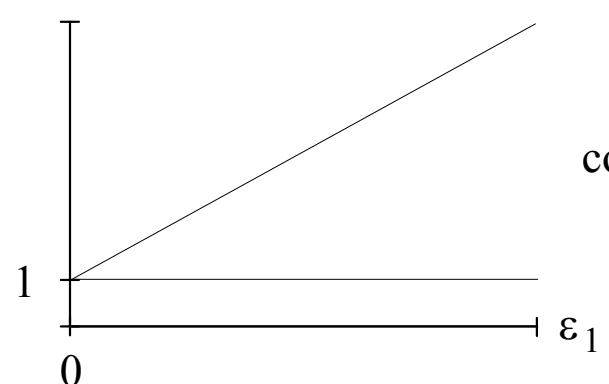

$\frac{\sigma_{1}}{\sigma_{3}}$

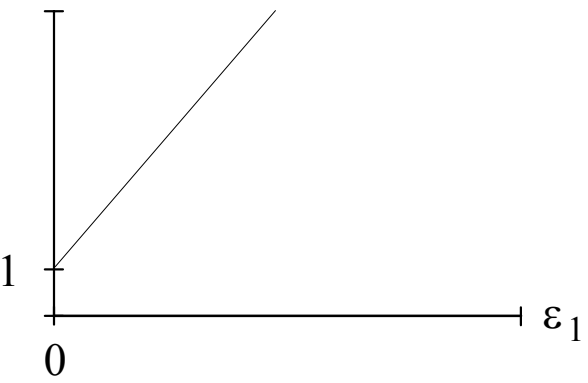

$\sigma_{1}$ and $\sigma_{3}$

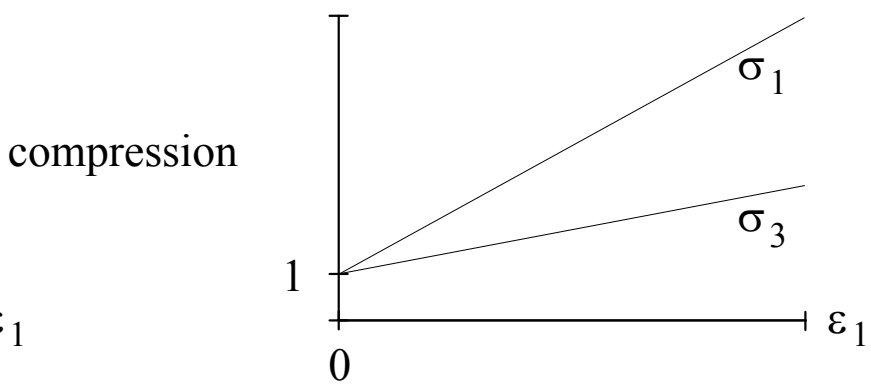

biaxial
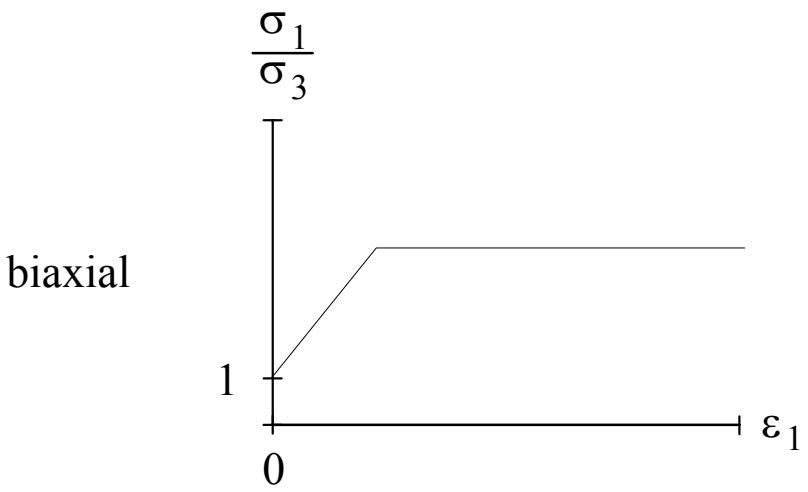

Figure 18. Influence of the rotation of grains 
In reality the rotation of the grains cannot be hindered, but in Grain this is done to show the effect of the rolling of the grains. Without the rotation of these grains there will be no lateral displacement. In this case, there is no failure in a biaxial test and during a one-dimensional compression test the lateral stress will not increase if the rotation of the grains is fixed.

According to the biaxial tests seen in figure 19, the Poisson's ratio has hardly any effect on the results. By an increasing Poisson's ratio, only two parameters are somewhat changed:

1. The Young's modulus $E$ increases slightly.

2. The angle of internal friction $\phi^{\prime}$ and therefore the strength of the sample also increases slightly.

The macro Poisson's ratio or the lateral strain coefficient is not influenced by the micro Poisson's ratio. This macro behaviour is influenced by the rotation of the grains.

\subsubsection{Lateral pressure}

Four tests were done with different lateral pressures on an identical sample. The results are shown in figure 20 . There are only two macro parameters which are influenced by an increase of the lateral pressure:

1. The stiffness $E$ increases.

2. The dilatancy $\psi$ decreases fractionally.

The angle of internal friction $\phi^{\prime}$ and the lateral strain coefficient at the beginning of the test which can also be called the Poisson's ratio $v_{\text {begin }}$, are more or less constant.

\begin{tabular}{||c|c|c|c||}
\hline$\sigma_{3}$ & $\phi^{\prime}$ & $v_{\text {begin }}$ & $\psi$ \\
\hline 1 bar & $30.2^{\circ}$ & 0.17 & $14.2^{\circ}$ \\
\hline 2 bar & $31.6^{\circ}$ & 0.12 & $11.7^{\circ}$ \\
\hline 3 bar & $31.4^{\circ}$ & 0.12 & $10.4^{\circ}$ \\
\hline 4 bar & $31.6^{\circ}$ & 0.12 & $9.8^{\circ}$ \\
\hline
\end{tabular}

Table 3. Biaxial test on sand: influence of the lateral pressure

Despite the non-linear contact behaviour, the results can be described quite well with the advanced Mohr-Coulomb model which is discussed in appendix 5, Twodimensional continuum model. 

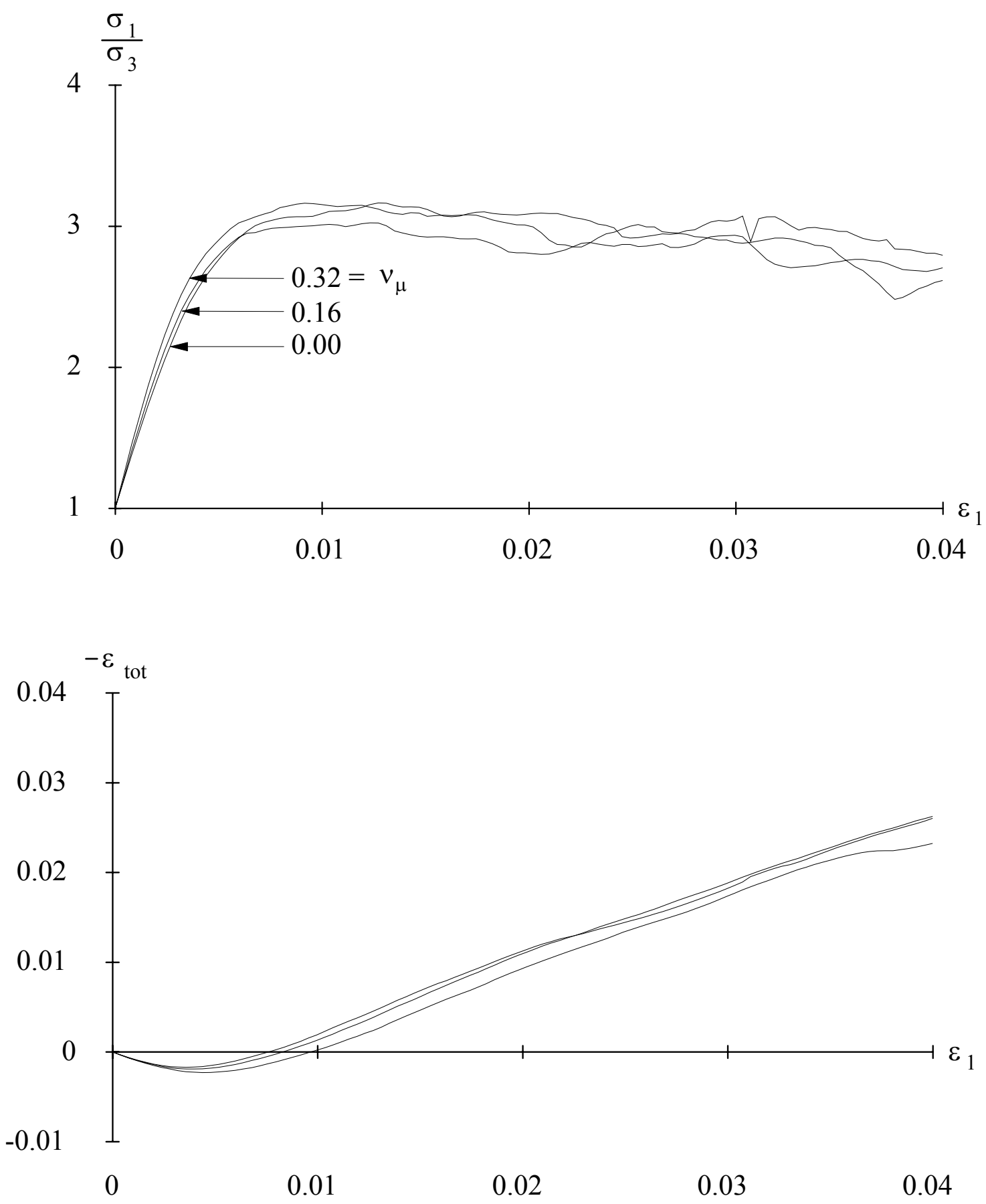

Figure 19. Biaxial test: influence of the Poisson's ratio 

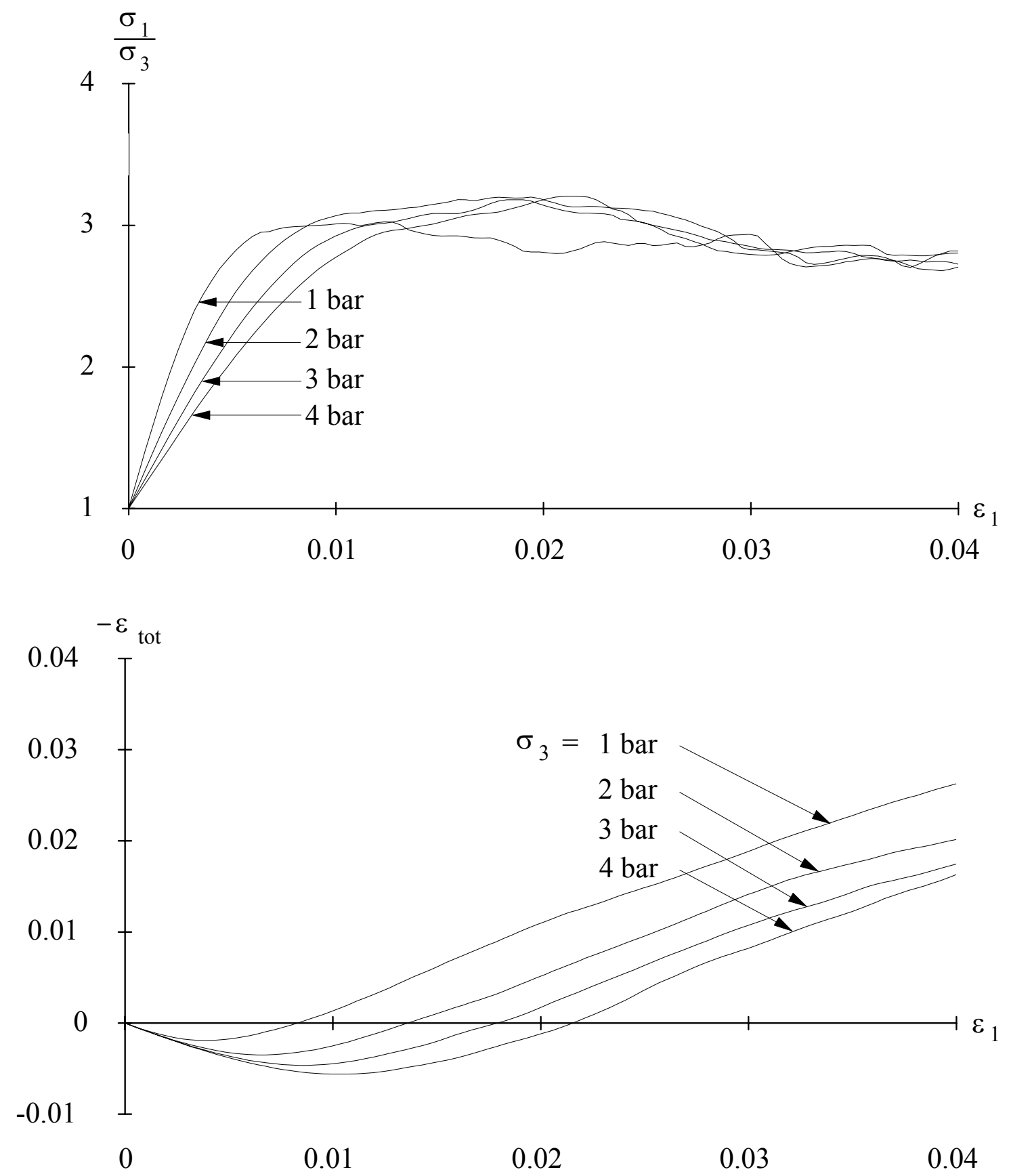

Figure 20. Biaxial test: influence of the lateral pressure 
The Young's modulus is not constant but depends on the stress. This stiffness behaviour of non-cohesive materials has been found in appendix 7, Biaxial test: analytical:

$$
E_{50}=E_{r e f}\left(\frac{\sigma_{0}}{\sigma_{r e f}}\right)^{\beta}
$$

in which:

$$
\begin{aligned}
\beta & =\frac{1}{3} \\
\sigma_{0} & =\frac{\sigma_{1}+\sigma_{3}}{2} \approx 1.5 \sigma_{3}
\end{aligned}
$$

and:

$$
\begin{aligned}
\kappa_{v} & =3 \frac{1-v_{\mu}}{2-v_{\mu}}=3 \times \frac{1-0.16}{2-0.16}=1.37 \\
n_{c / v} & =\frac{n_{c}}{n_{v}}=\frac{\bar{d}^{3} n_{c}}{V}=\frac{(0.0002)^{3} \times 1968}{8.292 \times 10^{-9}}=1.90 \\
E_{r e f} & =\left(\frac{\sqrt{\sigma_{r e f}} G_{\mu}}{3\left(1-v_{\mu}\right)} n_{c / v}\right)^{\frac{2}{3}} \frac{2 \kappa_{v}}{\kappa_{v}+1} \\
& =\left(\frac{\sqrt{10^{5}} \times 10^{9}}{3(1-0.16)} \times 1.90\right)^{\frac{2}{3}} \frac{2 \times 1.37}{1.37+1} \\
& =44.4 \mathrm{MPa} \quad \text { at } \quad \sigma_{r e f}=1 \mathrm{bar}
\end{aligned}
$$

This theoretical solution is in good agreement with the numerical results of the Young's modulus found by Grain, listed in table 4.

\begin{tabular}{||c|c|c||}
\hline \hline$\sigma_{3}$ & $E_{50}(\mathrm{Grain})$ & $E_{50}$ (theory) \\
\hline 1 bar & $48.2 \mathrm{MPa}$ & $50.8 \mathrm{MPa}$ \\
\hline 2 bar & $65.2 \mathrm{MPa}$ & $64.0 \mathrm{MPa}$ \\
\hline 3 bar & $76.4 \mathrm{MPa}$ & $73.3 \mathrm{MPa}$ \\
\hline 4 bar & $84.1 \mathrm{MPa}$ & $80.7 \mathrm{MPa}$ \\
\hline
\end{tabular}

Table 4. Young's modulus versus lateral pressure 


\subsubsection{Average grain size and shear modulus}

There is a direct relation between the average grain size, the stress, the shear modulus (non-cohesive materials) or spring constant and micro cohesion (cohesive materials). In the computer model Grain the grain sizes can be scaled by a factor $n$ without changing the contact forces, but also the forces can be scaled without changing the grain sizes and without any displacements. Table 5 shows the scale factors of the other parameters.

\begin{tabular}{||c|c|c||}
\hline \hline scaling: & $\bar{r}$ & $\bar{F}$ \\
\hline$r$ & $n$ & - \\
\hline$F$ & - & $n$ \\
\hline$\sigma$ & $1 / n^{2}$ & $n$ \\
\hline$G_{\mu}$ & $1 / n^{2}$ & $n$ \\
\hline$k_{n} / d$ & $1 / n^{2}$ & $n$ \\
\hline$c^{\prime}{ }_{\mu}$ & $1 / n^{2}$ & $n$ \\
\hline
\end{tabular}

Table 5. Scale factors for grain or force sizing

This means that the average grain size has absolutely no influence on the macro behaviour of the granular material. It will only influence the forces on micro scale. Hence, the results of non-cohesive tests for other shear moduli can be found by changing the stresses instead.

\subsubsection{Grain size distribution}

Four samples were made with different grain size distributions, but with an identical average grain size. Figure 21 demonstrates that the distribution has hardly any influence on the behaviour of the sample during a biaxial test. Only the strength increases somewhat with a wider grading of the grain sizes.

Two conclusions can be drawn from these curves:

1. The grain size distribution is not very important.

2. A thousand grains are sufficient to make good reproducible samples, especially for the elastic zone. 

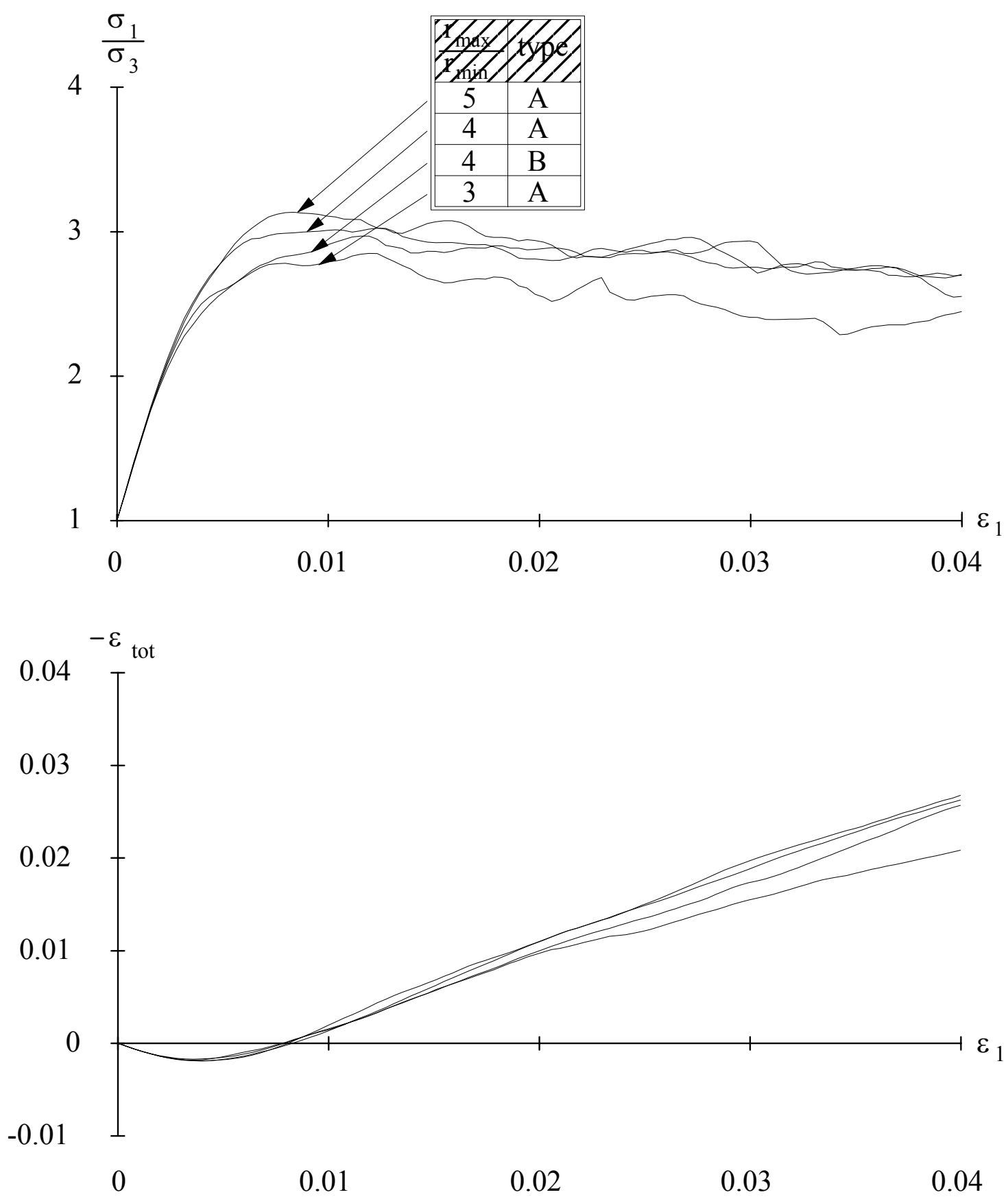

Figure 21. Biaxial test: influence of the grain size distribution 


\subsection{Continuum modelling}

\subsubsection{Compression test}

Since the biaxial test is covered in detail, it is interesting to see if other characteristic tests can be described with the same macro parameters. If the numerical vertical stress $\sigma_{1}$ in a compression test is compared with the vertical stress $\sigma_{1, \text { theory }}$ (dashed line in figure 22) calculated with a Young's modulus depending on the stress:

$$
E_{50}=E_{r e f}\left(\frac{\sigma_{0}}{\sigma_{r e f}}\right)^{\beta}
$$

in which:

$$
\begin{aligned}
\beta & =\frac{1}{3} \\
\sigma_{0} & =\frac{\sigma_{1}+\sigma_{3}}{2} \approx 1.5 \sigma_{3} \\
E_{r e f} & =44.4 \mathrm{MPa} \text { at } \sigma_{\text {ref }}=1 \mathrm{bar}
\end{aligned}
$$

then it is clear that the theory describes the numerical results quite well. Sometimes the Young's modulus is written as a function of vertical stress like this:

$$
E_{50}=\sqrt[3]{\frac{3}{4}} E_{r e f}\left(\frac{\sigma_{v}}{\sigma_{r e f}}\right)^{\beta}
$$

because the vertical stresses are normally better known than the average pressure.

\begin{tabular}{||c|c||c|c||}
\hline \multicolumn{2}{|c||}{ compression test } & \multicolumn{2}{c||}{ biaxial test } \\
\hline$E_{\text {ref }}$ & $44.4 \mathrm{MPa}$ & $44.4 \mathrm{MPa}$ & $E_{\text {ref }}$ \\
\hline$\beta$ & 0.333 & 0.333 & $\beta$ \\
\hline$\left(\dot{\sigma}_{3} / \dot{\sigma}_{1}\right)_{\text {begin }}$ & 0.18 & 0.17 & $\left(\dot{\varepsilon}_{3} / \dot{\varepsilon}_{1}\right)_{\text {begin }}$ \\
\hline$\left(\dot{\sigma}_{3} / \dot{\sigma}_{1}\right)_{\text {end }}$ & 0.35 & 0.33 & $\left(\dot{\varepsilon}_{3} / \dot{\varepsilon}_{1}\right)_{\text {end }}$ \\
\hline
\end{tabular}

Table 6. Compression test versus biaxial test 
For a two-dimensional continuum model the Poisson's ratio is equal to the lateral stress coefficient of the compression test and the lateral strain coefficient of the biaxial test:

$$
v=\left(\frac{\dot{\sigma}_{3}}{\dot{\sigma}_{1}}\right)_{\text {compression }}=\left(\frac{\dot{\varepsilon}_{3}}{\dot{\varepsilon}_{1}}\right)_{\text {biaxial }}
$$

Unfortunately, these coefficients at the beginning of the test are not identical to those at the end of a test, so a constant Poisson's ratio cannot be defined. Nevertheless, the lateral strain coefficient found at the beginning as well as at the end of the compression test are almost equal to the lateral stress coefficients of the biaxial test.

During compression, the stress ratio $\frac{\sigma_{1}}{\sigma_{3}}$ increases constantly, but it can never exceed a certain level according the failure criterion:

$$
\left(\frac{\sigma_{1}}{\sigma_{3}}\right)_{\text {end }}=\frac{1+\sin \left(\phi^{\prime}\right)}{1-\sin \left(\phi^{\prime}\right)} \approx 3.02 \text { with } \quad \phi^{\prime}=30.2^{\circ}
$$

Therefore the lateral stress coefficient in the end is limited by the failure criterion as well:

$$
\left(\frac{\dot{\sigma}_{3}}{\dot{\sigma}_{1}}\right)_{\text {end }} \approx\left(\frac{\sigma_{3}}{\sigma_{1}}\right)_{\text {end }}=0.33
$$

This causes the bending curve of the lateral stress coefficient in figure 22, as it approaches this asymptotic limit. 

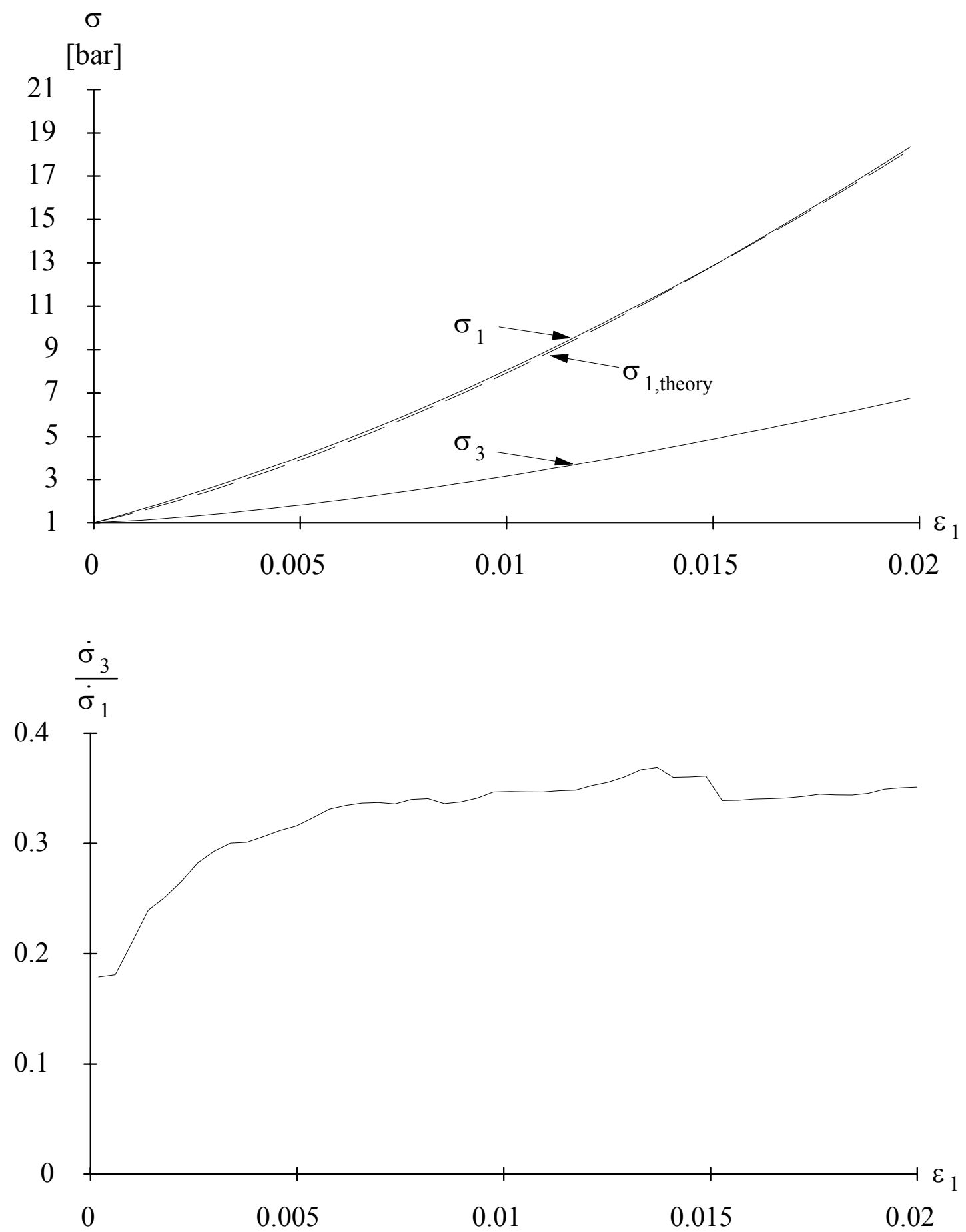

Figure 22. Compression test: Young's modulus and Lateral stress coefficient 
The relative density of the structure in the compression test of figure 23, is very important. Low density samples will react less stiffly and will have continuously irreversible deformation during cyclic loading, which finally leads to a higher density.

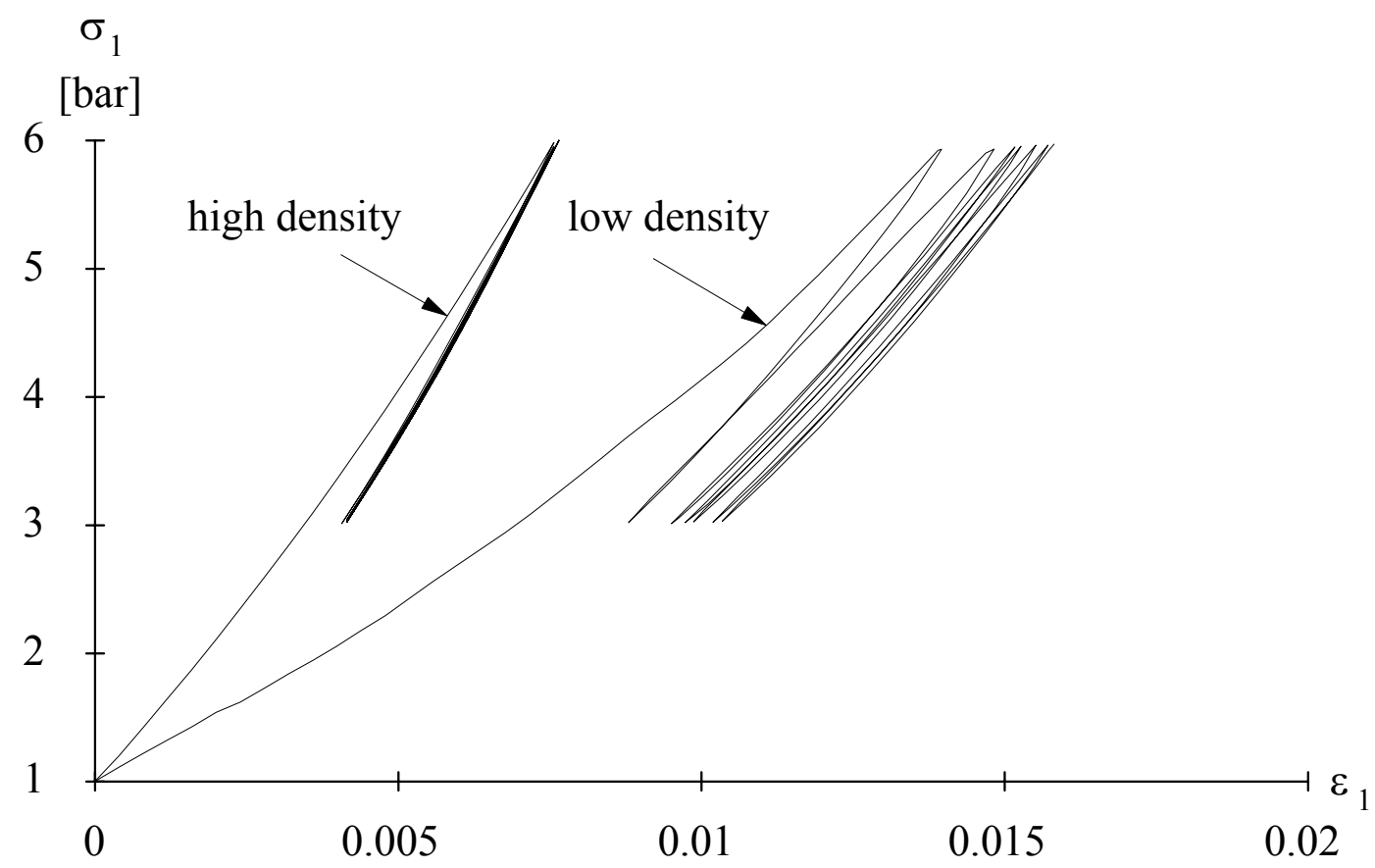

Figure 23. Compression test: influence of the density

What is very interesting, is the lateral stress coefficient in figure 24 . For the virgin load path, as well as for the unload path and the reload path, this coefficient starts low and ends high, which means that there is a jump in between these paths. Because of this, the unload paths are different from the reload paths. Therefore a very small hysteresis loop can be seen in the curve of the lateral stress $\sigma_{3}$. The surface of this loop represents the energy loss during the plastic deformation. 

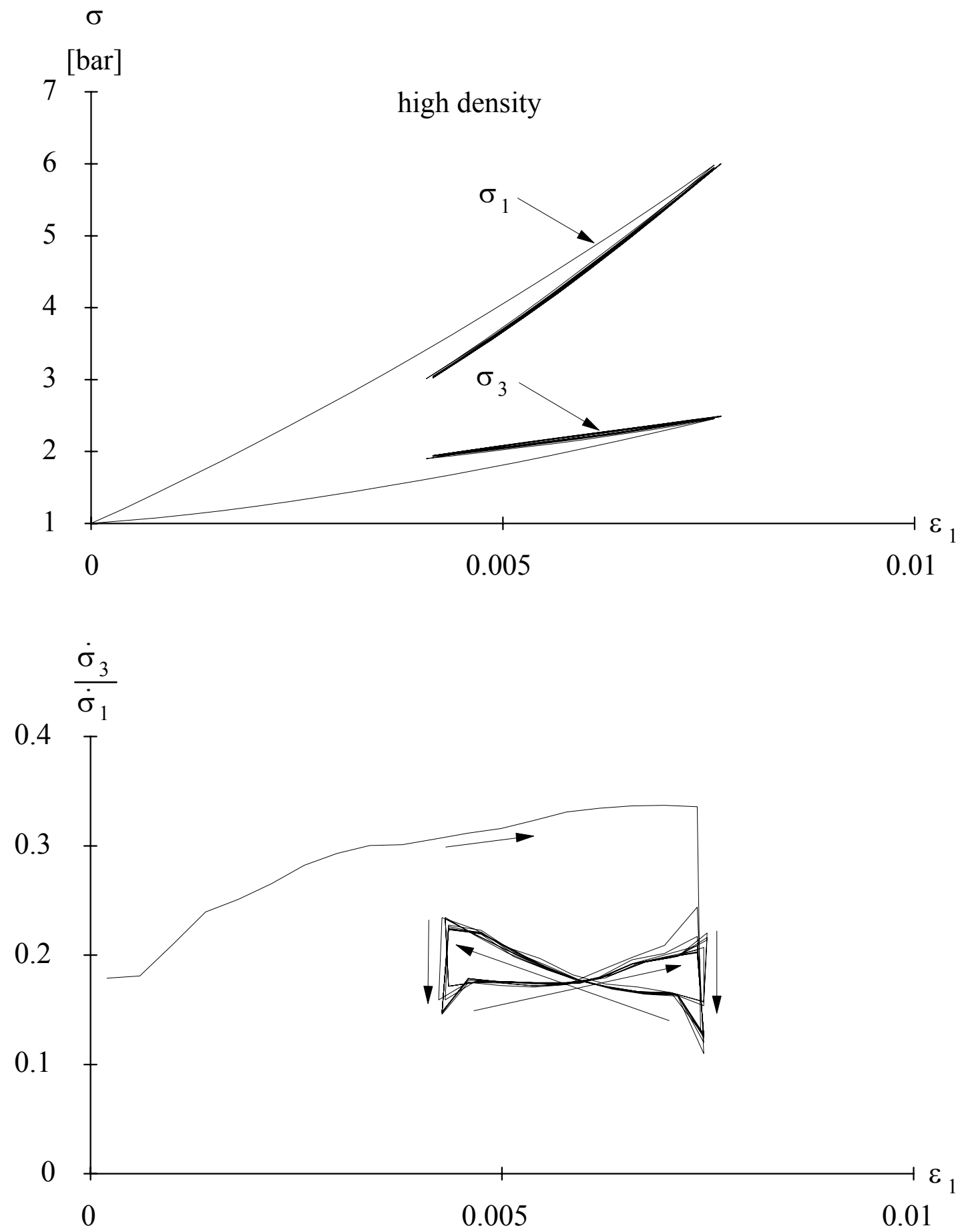

Figure 24. Compression test: Lateral stress coefficient during cyclic loading 


\subsubsection{Confined versus unconfined test}

The unconfined biaxial test is in theory a different test than the confined biaxial test, because the stresses and not the strains are prescribed. Therefore the macroscopic failure mechanisms of both tests can be different, for example, shear bands can influence the stresses in a confined biaxial test. But as figure 25 shows, the curves of the stress behaviour for the confined biaxial test and the unconfined test are almost equal. For an unconfined biaxial test, it is more complicated to measure the volumic deformations, which makes the confined biaxial test more useful for non-cohesive granular materials.

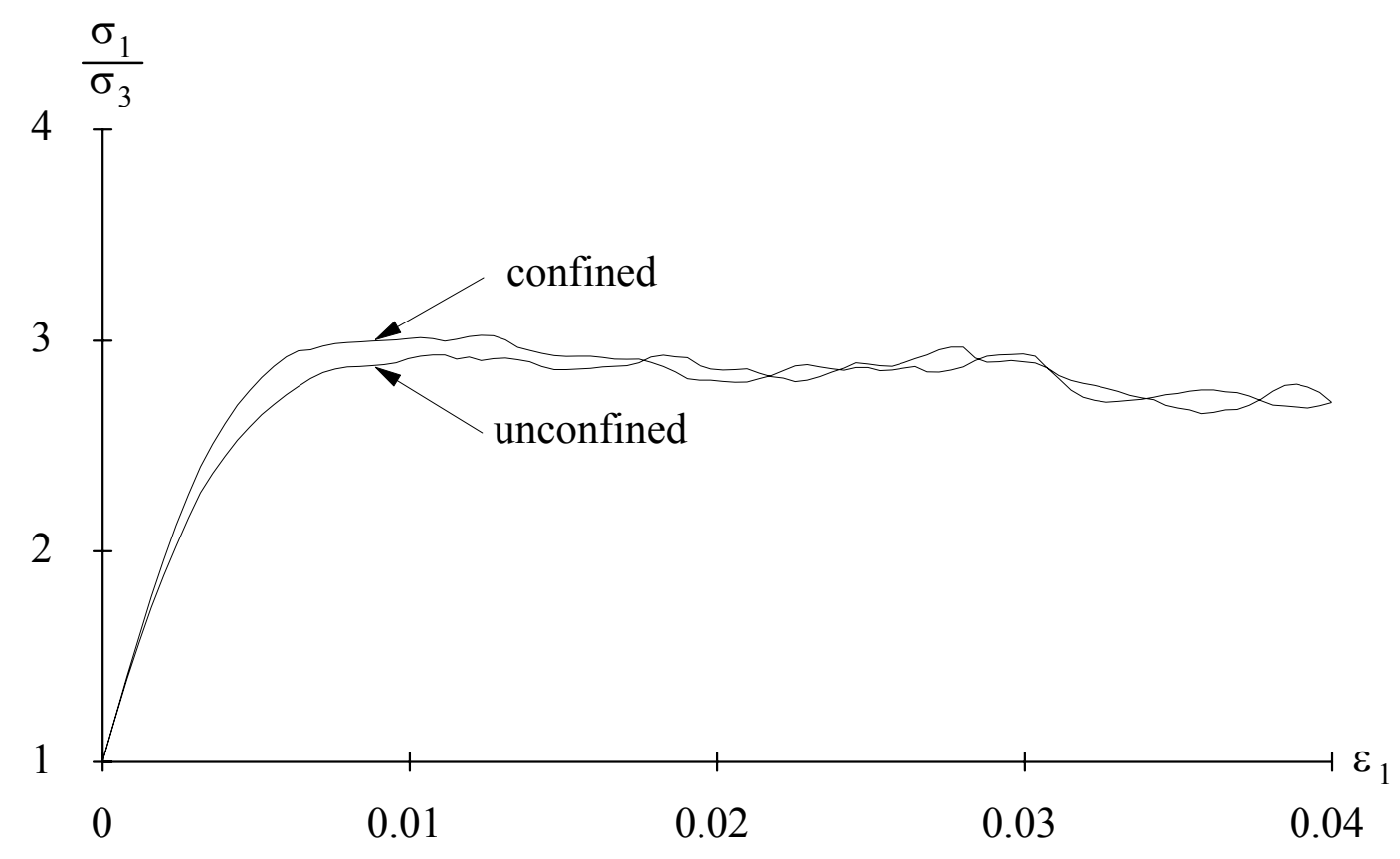

Figure 25. Confined biaxial test and unconfined biaxial test are equal

\subsubsection{Shear band development}

Two questions are often heard in discussions about shear bands. The first is about the thickness and the second about the direction of the shear band.

Mülhaus and Vardoulakis (1987) have measured the width of a shear band with $\mathrm{X}$-ray photographs of a fine sand and a medium sand. They have found values of respectively 18.5 and 13 times the mean particle diameter. Figure 26 shows a numerical simulation of an unconfined biaxial test. The displacements of all four thousand particles are drawn. Here a shear band is found of about 5 times the average grain diameter. Maybe it is only that thin because of the small ratio 
between the diameters of the smallest and largest grains or maybe this is caused by the circle shaped grains instead of a more complex sphere.

A second point of interest is the direction of the shear band. Figure 26 shows the grain displacements of two different unconfined biaxial tests from $5 \%$ to $10 \%$ deformation. The sample on the right had no wall friction, so the weakest areas were at the top and the bottom, only there the grains bend away at failure. The sample on the left had its weakest point in the middle because of the reinforcement caused by the shear stresses at the walls. A clear shear band is formed in the centre with a direction of $\theta=52^{\circ} \pm 2^{\circ}$. This is the same as suggested by the advanced Mohr-Coulomb theory, namely:

$$
\theta=45^{\circ}+\frac{\psi}{2}=45^{\circ}+\frac{14.2^{\circ}}{2} \approx 52^{\circ}
$$

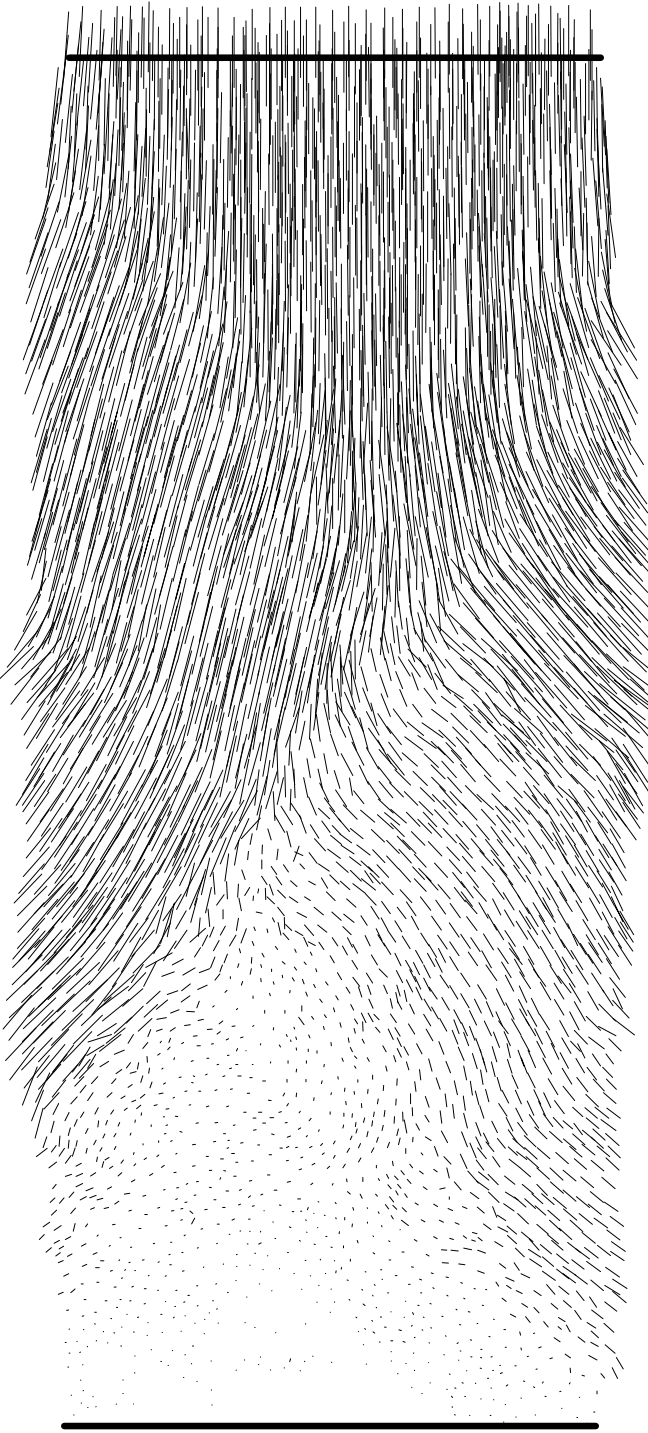

With wall friction

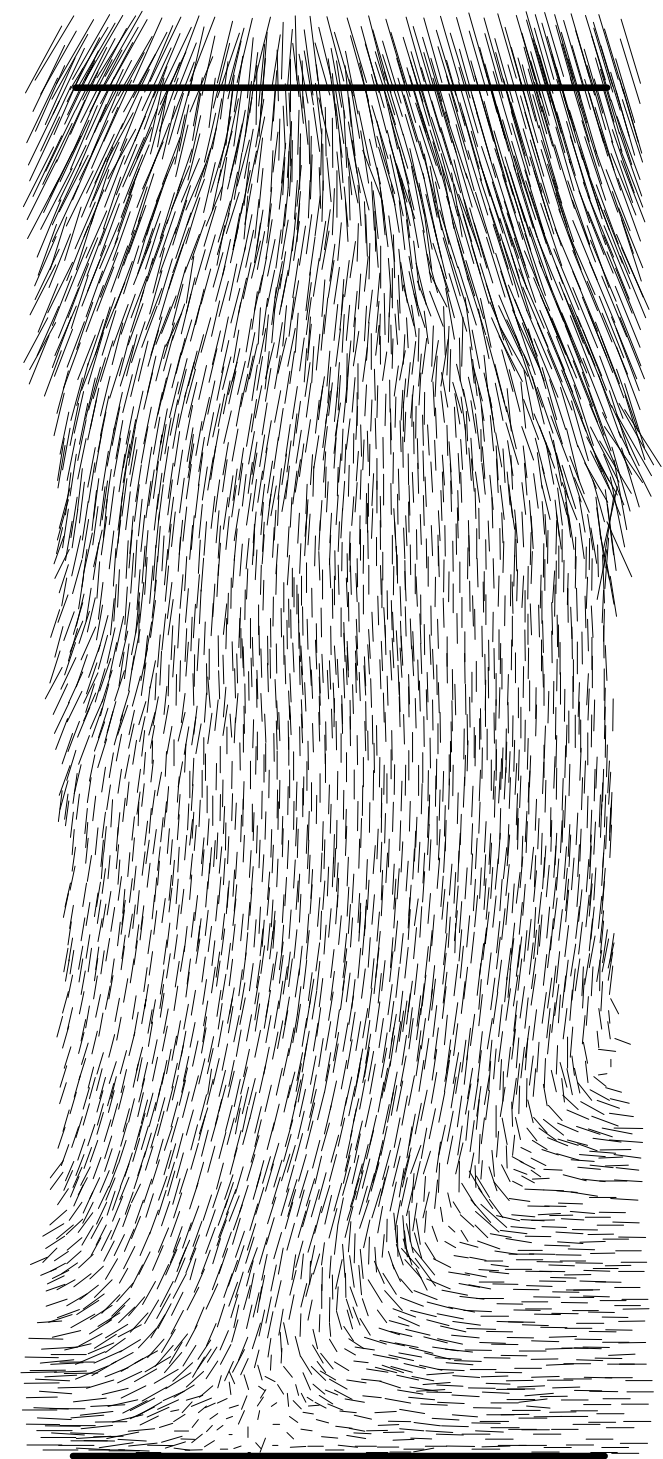

Without wall friction 
Figure 26. Unconfined biaxial test: displacements of the grains 


\subsubsection{Simple shear test}

In Cambridge a shear apparatus was developed by Roscoe (1970) in which (as well as possible) a pure angle deformation was imposed. This test, which is called the simple shear test is described in appendix 5, Two-dimensional continuum model. Three different failure mechanisms have been suggested for this test:

1. Horizontal shearing, by analogy with the shear law of Coulomb.

2. Vertical shearing, according to De Josselin de Jong (1992).

3. Lateral contact failure, according to the author.

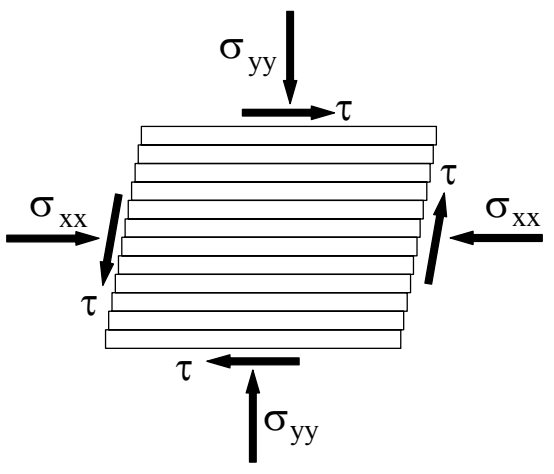

horizontal

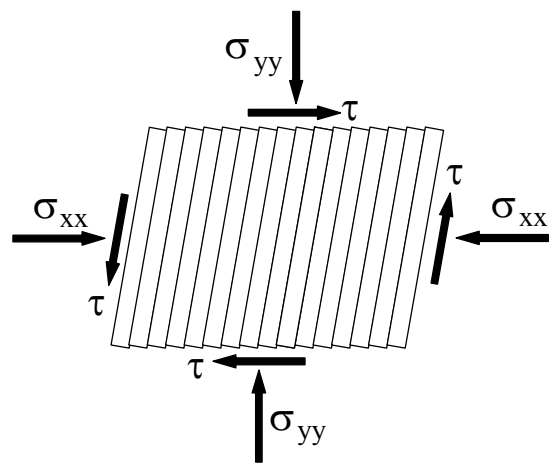

vertical

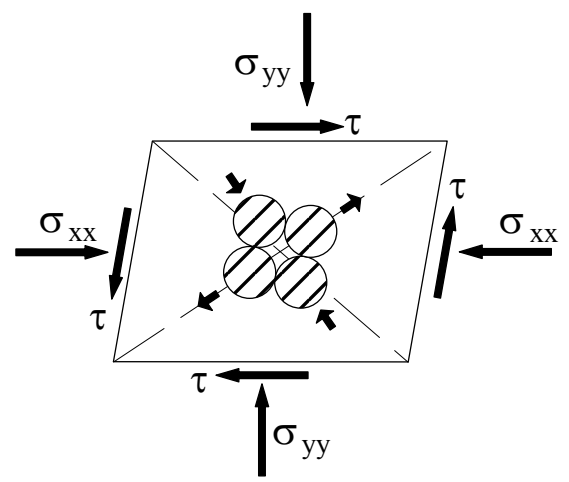

lateral

Figure 27. Failure mechanisms

If failure occurs by exceeding the maximum shear stress in a certain direction, which is suggested by the Coulomb criterion, then only the stress and deformation fields of the horizontal and vertical failure mechanisms can be both static and kinematic admitted. In that case, the horizontal stress during failure has to be, for the horizontal mechanism:

$$
\sigma_{x x}=\frac{1+\sin ^{2}\left(\phi^{\prime}\right)}{1-\sin ^{2}\left(\phi^{\prime}\right)} \sigma_{y y}
$$


and for the vertical mechanism:

$$
\sigma_{x x}=\frac{1-\sin ^{2}\left(\phi^{\prime}\right)}{1+\sin ^{2}\left(\phi^{\prime}\right)} \sigma_{y y}
$$

When the horizontal stress does not meet these particular values in any (artificial) way, no failure can occur according to this Coulomb criterion. This cannot be the case.

If failure takes place by the breaking of the contacts in the direction of the minor principal stress, because tension forces can not be absorbed on micro level, then only lateral contact failure can occur. This also means, that the shear direction can not be obtained from the Coulomb line, because failure does not depend on micro shear failure but on micro lateral contact breaking. This statement can easily be verified with Grain, by comparing the average rotation of the grains $\gamma_{\mu}$ with the rotation of the vertical walls $\gamma$. The ratio of these rotations during failure is for the horizontal, vertical and lateral mechanism respectively equal to:

$$
\frac{\gamma_{\mu}}{\gamma}=0.0 \text { or } 1.0 \text { or } 0.5
$$

The dashed line in figure 29 shows that the lateral failure mechanism is the only correct one $\left(\frac{\gamma_{\mu}}{\gamma} \approx 0.5\right)$. During failure, up to $25 \%$ of the contacts are broken, which fits with this mechanism as well. Also the equal double sliding of the Mohr-Coulomb model will explain the $50 \%$ grain rotation, as suggested in appendix 5, Two-dimensional continuum model, but this model cannot explain the loss of contacts.

For the correct performance of the simple shear test one has to consider two boundary conditions:

1. Because of dilatancy during the plastic phase the horizontal and vertical strains will not remain at zero. A fixed height or width of the shear box will cause increasing wall forces. Therefore the walls have to be stress controlled.

2. A constant shear strain $\left(\varepsilon_{x y}=\varepsilon_{y x}=\frac{1}{2} \gamma\right)$ has to be imposed on the complete wall. This means that the grains are not allowed to shear over the wall, so the friction between grain and wall has to be infinite $\left(f_{g w}=\infty\right)$, but even then the grains can roll away, which must be prevented by glueing the grains to the wall.

The curves in figure 28 show the effect of neglecting this last boundary condition $\left(f_{g w}=0.60\right)$. Because of shearing between grain and wall, moments are developed at the walls (eccentricity of $e \approx 0.1 \times H$ ), which cause a nonhomogeneous stress field in the simple shear apparatus. This was made clear by 
Allersma (1987). In his simple shear tests the normal stress distribution was far from constant. The shear stress inside a sample, however, appeared to be not so much influenced by the incorrect boundary conditions. Therefore much better results are obtained if the stress is measured in the interior of a sample.

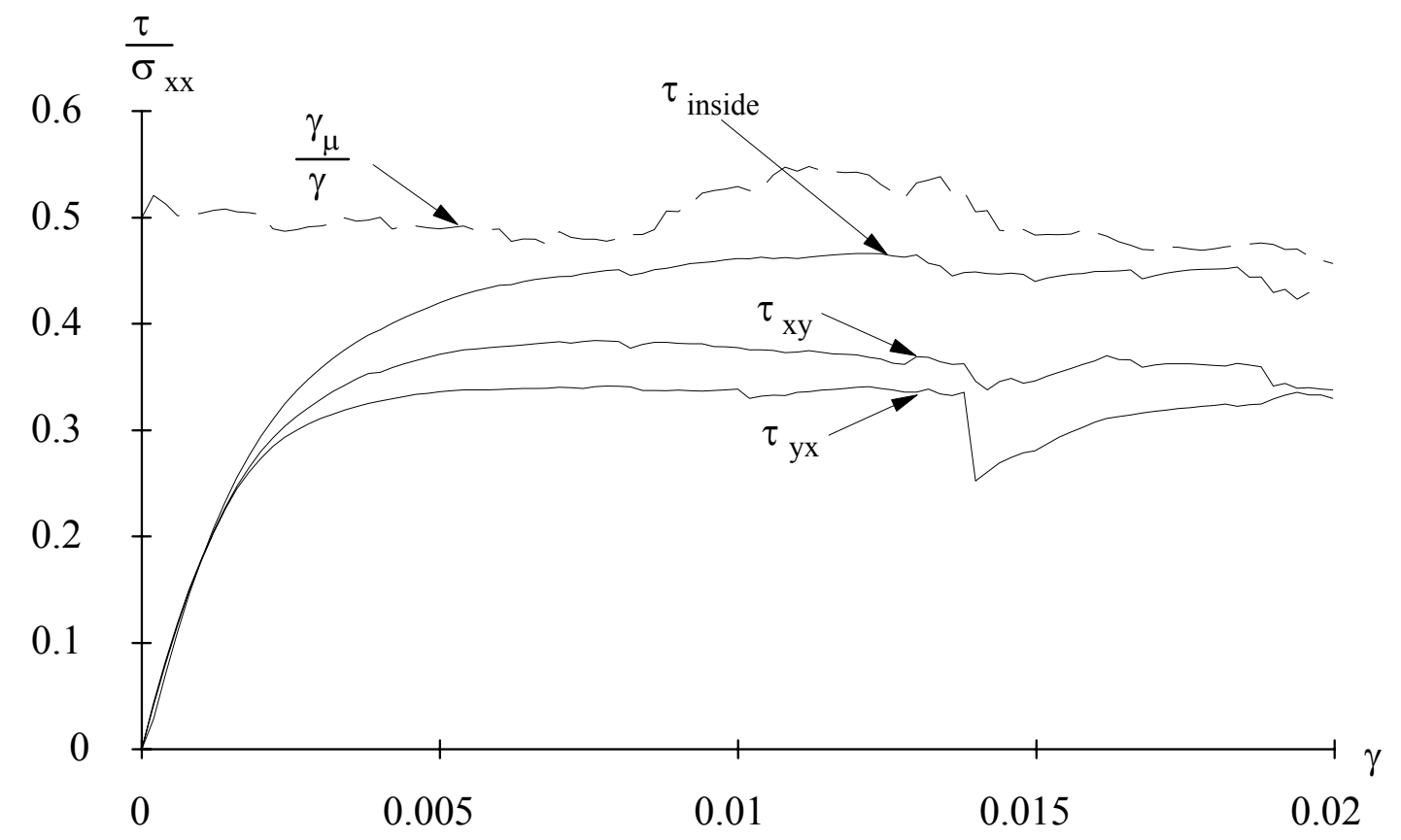

Figure 28. Simple shear test: influence of incorrect boundary conditions

The following table shows the results of the simple shear tests with constant boundary conditions, presented in figures 29 and 30 . The results obtained can be predicted quite accurately with the results of the previous biaxial tests, although the shear modulus is somewhat too small.

\begin{tabular}{||c|c|c|c||}
\hline Test: & $G_{r e f}$ & $\phi^{\prime}$ & $\psi$ \\
\hline Biaxial & $19.5 \mathrm{MPa}$ & $30.2^{\circ}$ & $14.2^{\circ}$ \\
\hline Simple shear I & $18.1 \mathrm{MPa}$ & $28.6^{\circ}$ & $16.9^{\circ}$ \\
\hline Simple shear II & $16.7 \mathrm{MPa}$ & $32.4^{\circ}$ & $14.5^{\circ}$ \\
\hline
\end{tabular}

Table 7. Simple shear versus biaxial test 

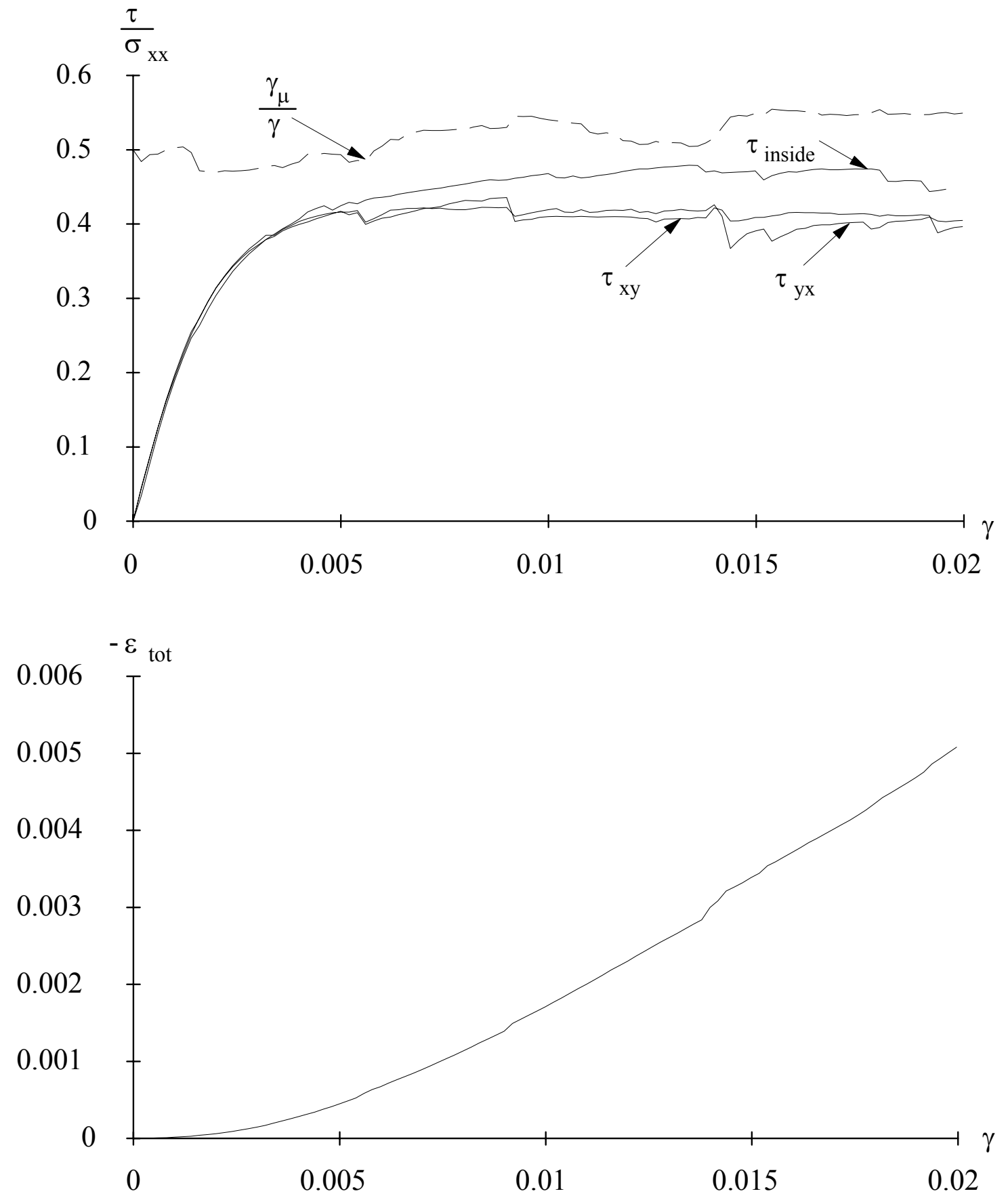

Figure 29. Simple shear test I: $\sigma_{x x}=\sigma_{y y}=1$ bar 

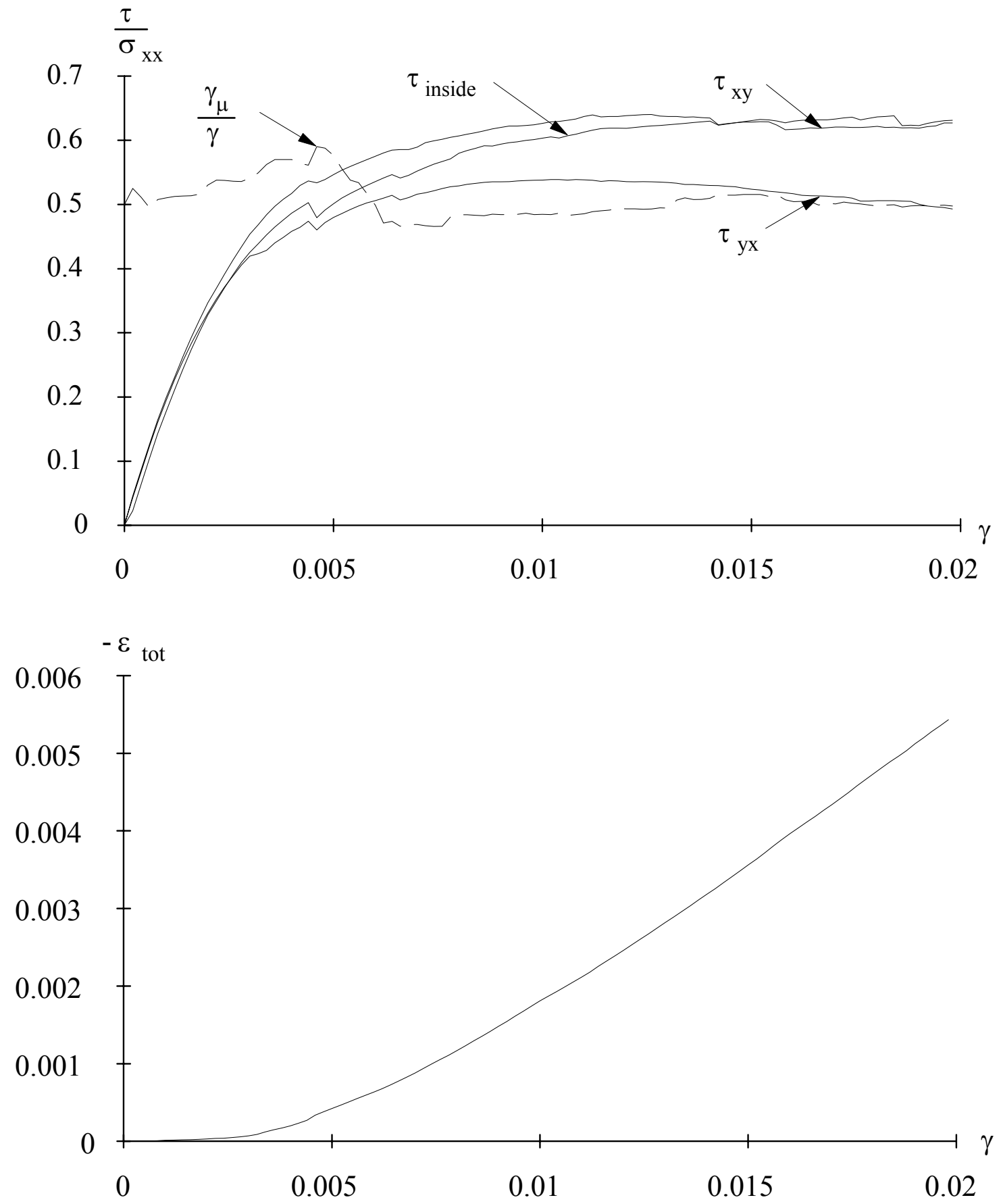

Figure 30. Simple shear test II: $\sigma_{x x}=1$ bar , $\sigma_{y y}=2$ bar 
For the second simple shear test, one phenomenon is more difficult to explain with the continuum theory. The maximum shear stress of the horizontal wall is higher than the maximum shear stress of the vertical wall. According to the continuum theory these should be equal, although the maximum stress of the horizontal wall is expected to be larger than the vertical wall because of the larger lateral pressure.

For both simple shear tests it is found that, during the elastic phase and the plastic phase, the major principal direction is similar for the (inside) stresses and the total strains $\left(\beta_{\sigma}=\beta_{\varepsilon}\right)$. This coaxial behaviour is presented in the figures 31 and 32. In order to calculate the principal direction of the strains, the strains $\varepsilon_{x x, 0}$ and $\varepsilon_{x x, 0}$ at the beginning of the test have to be known. These were calculated with equation (A.9). The theoretical major principal direction during failure, based on the wall stresses, is solved analytically in appendix 5, Two-dimensional continuum model:

$$
\cos (2 \beta)=\frac{-1}{\sin \left(\phi^{\prime}\right)} \frac{\left(\sigma_{y y}-\sigma_{x x}\right)}{\left(\sigma_{y y}+\sigma_{x x}\right)}
$$

So:

$$
\beta=45^{\circ} \quad \text { for simple shear I }
$$

$\beta=64^{\circ}$ for simple shear II

With this coaxial relation between stress and strain for the elastic deformation $\left(\beta_{\dot{\sigma}}=\beta_{\dot{\varepsilon}}\right)$ and the plastic deformation $\left(\beta_{\sigma}=\beta_{\dot{\varepsilon}}\right)$, also the results of a true simple shear test can be predicted. In a true simple shear test the horizontal strain $\left(\dot{\varepsilon}_{x x}=0\right)$ is kept constant, instead of the horizontal stress $\left(\dot{\sigma}_{x x}=0\right)$. In figure 33 the results of a true simple shear test with Grain are compared with the continuum theory, described in appendix 5, Two-dimensional continuum model, using the parameters of simple shear test I. The almost perfect prediction with this bi-linear continuum model suggests that during failure the rolling of the grains will be on average in the direction of the minor principal stress. In other words, granular materials behave coaxial because the grains escape in the direction of the lowest resistance.

The double sliding model of De Josselin de Jong (1971), which is also mentioned in appendix 5, shows that granular materials (can) behave non-coaxial if failure occurs because of shear failure. The fact that non-coaxiality cannot be found agrees with the conclusion earlier made, that granular materials will fail not because of shear failure but because of tension failure. 


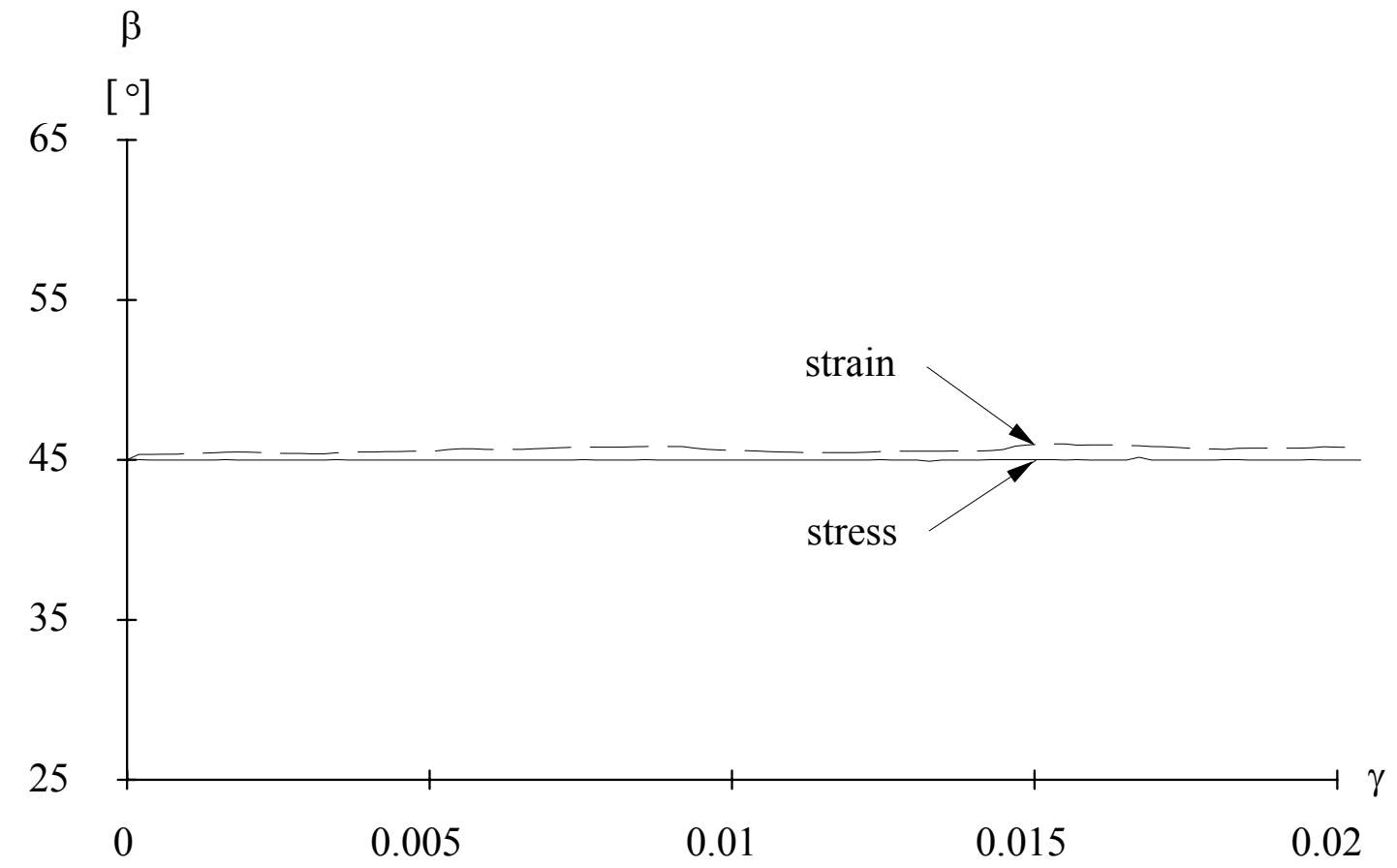

Figure 31. Simple shear test I: principal directions

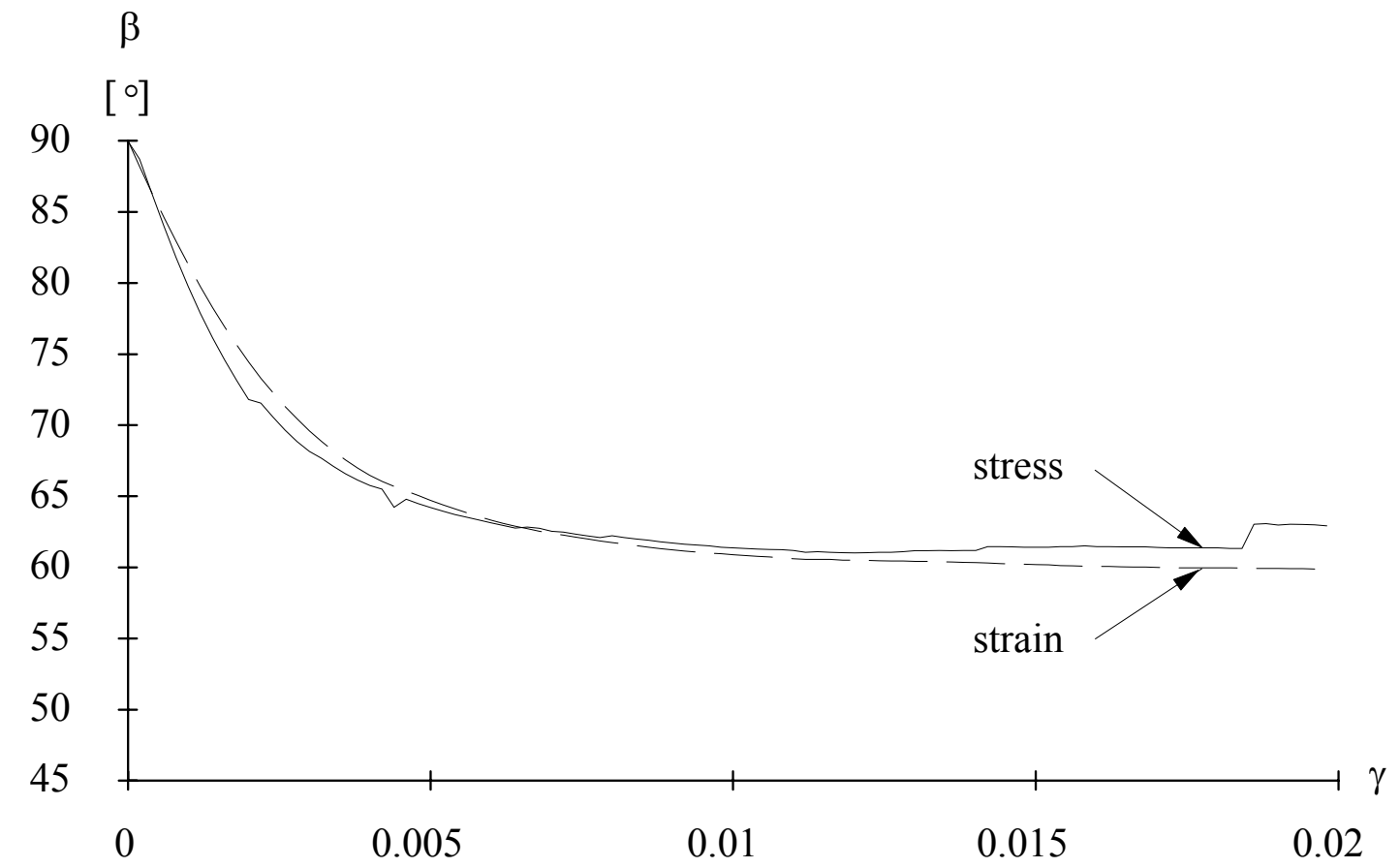

Figure 32. Simple shear test II: principal directions 

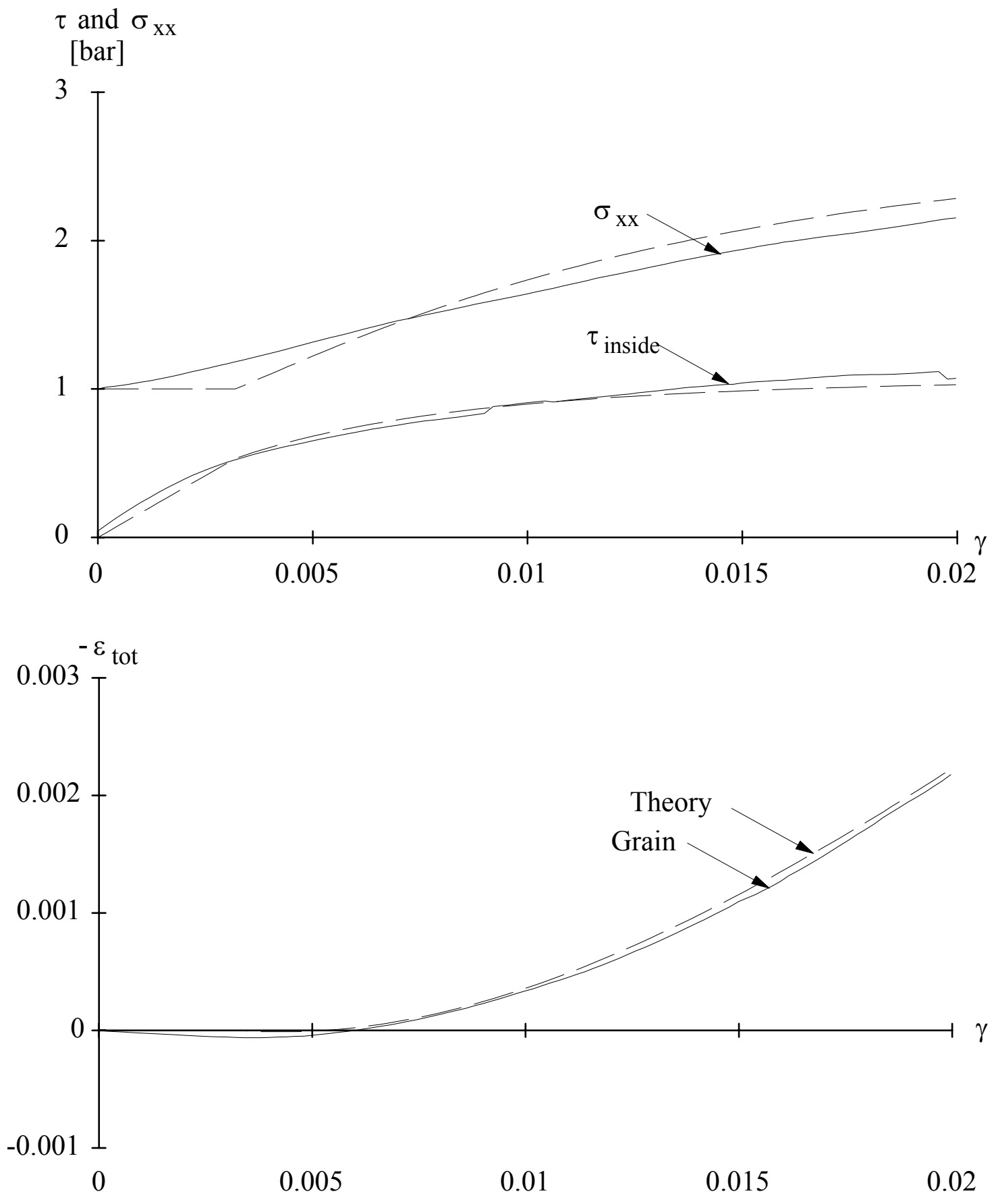

Figure 33. True simple shear test: Theory versus Grain 


\section{COHESIVE GRANULAR MATERIALS}

\subsection{Default parameters}

In order to gain some insight into the failure mechanism and the moment of failure of cohesive granular materials, several unconfined biaxial tests were modelled with Grain. The default micro parameters are chosen as representative for sandstone of dense compaction, as listed in the following table:

\begin{tabular}{||c|c||c|c||c|c||}
\hline \hline \multicolumn{2}{|c||}{ soil data } & \multicolumn{2}{c||}{ grain size } & \multicolumn{2}{c||}{ test parameters } \\
\hline$k_{n}$ & $1 \mathrm{MN} / \mathrm{m}$ & $\bar{r}$ & $0.1 \mathrm{~mm}$ & $\sigma_{3}$ & $10 \mathrm{bar}$ \\
\hline$G_{\mu}$ & - & type & $\mathrm{A}$ and B & $\frac{\Delta H}{H}$ & $4.0 \times 10^{-5}$ \\
\hline$v_{\mu}$ & 0.16 & $\frac{r_{\max }}{r_{\min }}$ & 4.00 & $n_{i}$ & 20 \\
\hline$f_{g g}$ & 0.60 & $\frac{H}{W}$ & $\begin{array}{c}2.50 \\
(3.00)\end{array}$ & - & - \\
\hline$f_{g w}$ & 0.00 & & & - & - \\
\hline$c^{\prime}{ }_{\mu}$ & $100 \mathrm{MPa}$ & $n_{g}$ & $\begin{array}{c}1000 \\
(4000)\end{array}$ & & \\
\hline \hline
\end{tabular}

Table 8. Default micro parameters for sandstone

\subsubsection{Soil data}

The tests on sandstone are based on the linear contact equations, so the linear spring constant $k_{n}$ is used for all contacts. In practice this spring constant is very difficult to measure. Therefore an arbitrary value is chosen. The Poisson's ratio of quartz is about $v_{\mu} \approx 0.16$. The friction angle is about $\phi_{\mu} \approx 30^{\circ}$, so the friction coefficient between two grains will be $f_{g g}^{I I}=\tan \left(\phi_{\mu}\right) \approx 0.60$. Before cementation, this friction coefficient will be temporarily decreased to zero $f_{g g}^{I}=0.0$ to obtain a sample of high density. The friction coefficient between grain and wall, for all tests, is zero $f_{g w}=0$. The cohesion $c^{\prime}{ }_{\mu}$ is unknown and is chosen to be $100 \mathrm{MPa}$ in order to give the sample more or less the same strength as Castlegate sandstone. 


\subsubsection{Grain size}

Both the exponential (Type A) and the linear (Type B) grain size distributions of the previous chapter (about non-cohesive granular materials), were used for the modelling of cohesive granular materials. The shape of the sample for all tests was rectangular, $\frac{H}{W}=2.50$, except for the thick-walled cylinder test in which the ratio between the radii of the inner surface and outer surface $\frac{r_{1}}{r_{3}}=3.00$. Most of the tests were done on a sample of a thousand grains, because this number was more than sufficient to get identical test results for different samples created with identical micro parameters. A few tests were carried out on four thousand or ten thousand grains.

\subsubsection{Test parameters}

The default lateral pressure was chosen to be $\sigma_{3}=10 \mathrm{bar}=1 \mathrm{MPa}$. The total deformation of $2 \%$ was reached in half an hour on a normal personal computer with 500 load steps: $\frac{\Delta H}{H}=4.0 \times 10^{-5}$. Twenty iterations per loading step were sufficient, most of the time, to iterate accurately enough to the equilibrium state. In all cases, the depth of the sample was chosen to be equal to the average diameter of the grain $(D=\bar{d}=2 \bar{r})$ in order to calculate the stresses.

\subsection{Micro behaviour versus macro behaviour}

\subsubsection{Number of grains and shape influence}

Several biaxial tests were done to find out how many grains are necessary to describe a representative part of a sandstone sample with homogeneous boundary conditions. These are registered in table 9. Figure 34 shows that the stress-strain behaviour of sample A with 250 grains differs from the samples B, I and C with more grains, so at least 500 grains are necessary to describe a homogeneous loaded sample. The stiffness and the strength of the samples with at least 500 grains are all quite similar. To minimise error, all biaxial tests in this report were carried out on at least a thousand grains. The percentage of broken contacts is reflected by the dashed line in the same figure. 
A stout sample shows in figure 35 identical stress-strain behaviour in comparison to the three different slender samples I, II and III. This means that the shape of a sample does not influence the failure behaviour.

\begin{tabular}{||c|c|c||}
\hline Sample & $n_{g}$ & $H / W$ \\
\hline $\mathrm{A}$ & 250 & 2.5 \\
\hline $\mathrm{B}$ & 500 & 2.5 \\
\hline $\mathrm{I}$ & 1000 & 2.5 \\
\hline II & 1000 & 2.5 \\
\hline III & 1000 & 2.5 \\
\hline stout & 1000 & 0.4 \\
\hline C & 4000 & 2.5 \\
\hline
\end{tabular}

Table 9. Different samples

The results of the compression tests, confined biaxial tests and unconfined biaxial tests can be described with the Mohr-Coulomb theory and these tests all give comparable results for the Young's modules and the Poisson's ratio. These parameters are listed in the table below. At the beginning of a test, the measured values are slightly lower than just before failure, because new (non-cohesive) contacts are formed during the compression of a sample. These contacts cause an increase in the total stiffness. The elastic parameters listed in the table below are measured both for type A and type B grain size distributions.

\begin{tabular}{||l|c|c||}
\hline \multicolumn{1}{|c|}{ Test: } & $E[\mathrm{GPa}]$ & $v$ \\
\hline Compression & $3.9-4.2$ & $0.11-0.13$ \\
\hline Confined Biaxial & $3.8-4.2$ & $0.04-0.19$ \\
\hline Unconfined Biaxial & $3.9-4.2$ & - \\
\hline
\end{tabular}

Table 10. Young's modules and Poisson's ratio 


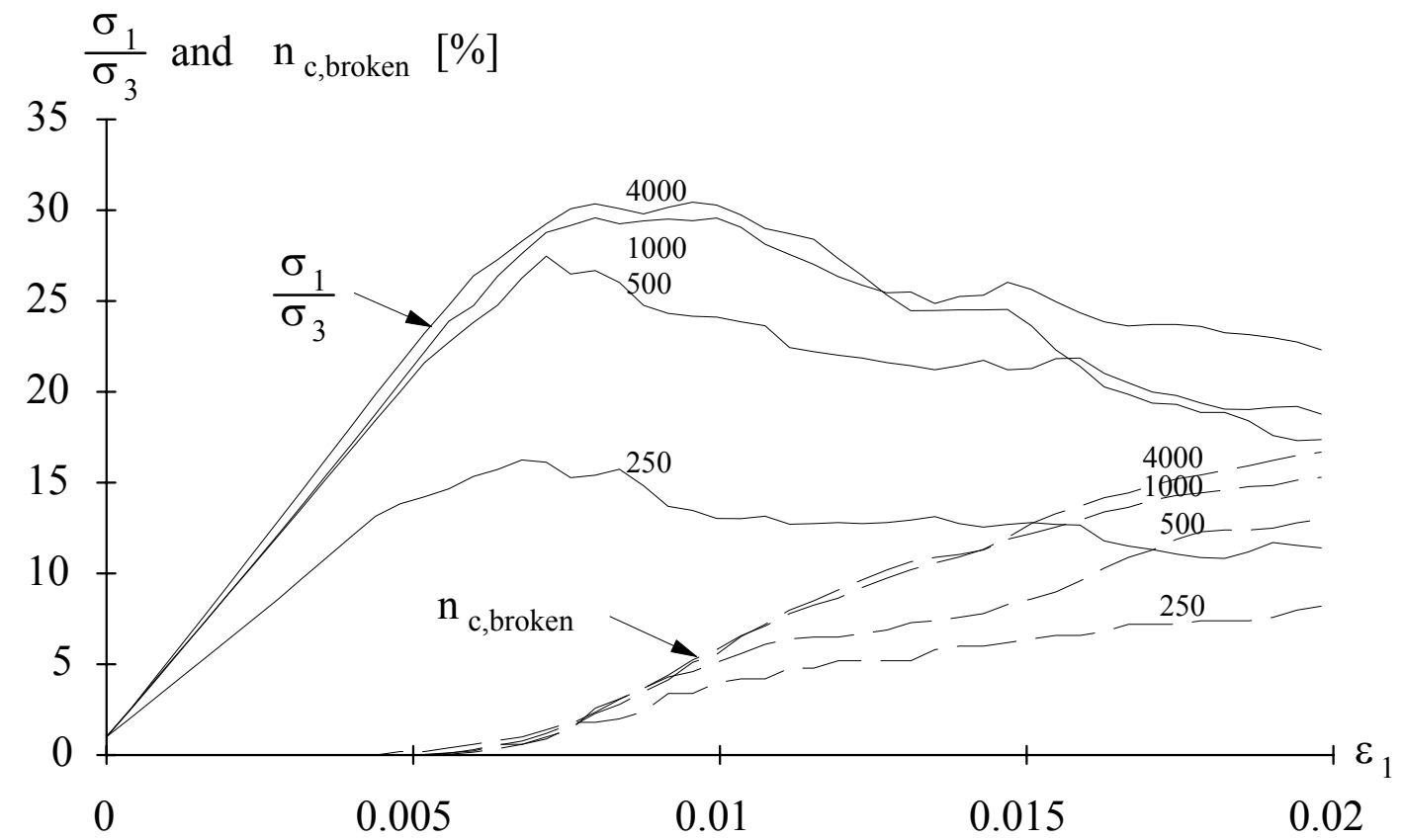

Figure 34. Biaxial test: different number of grains

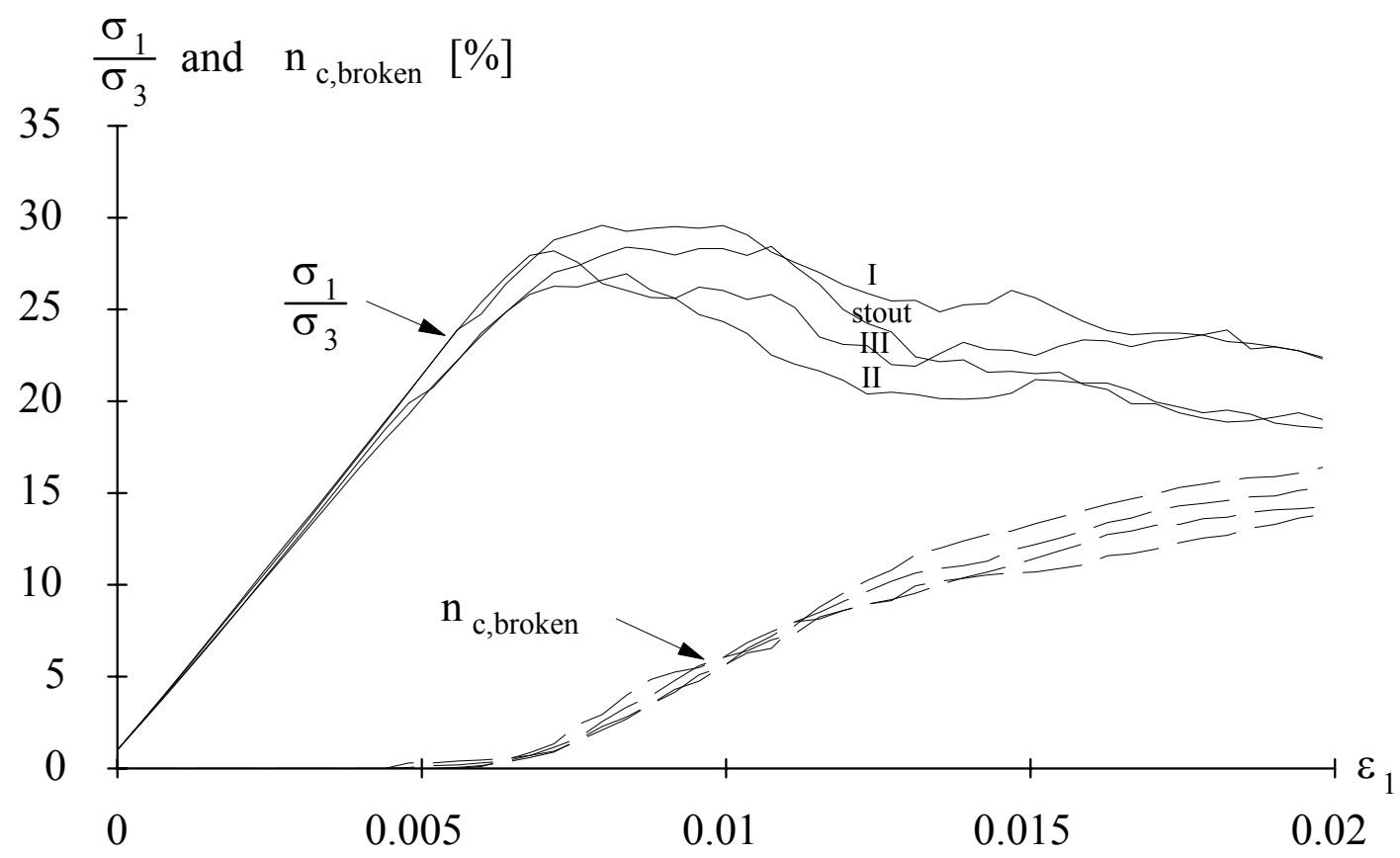

Figure 35. Biaxial test: different shapes 


\subsubsection{Grain size distribution}

In reality, it is complicated to make two identical sandstone samples with only different grain size distributions. This is modelled with Grain to study the influence of the distribution. Figure 36 shows the Mohr circles at failure for the two different distribution types.

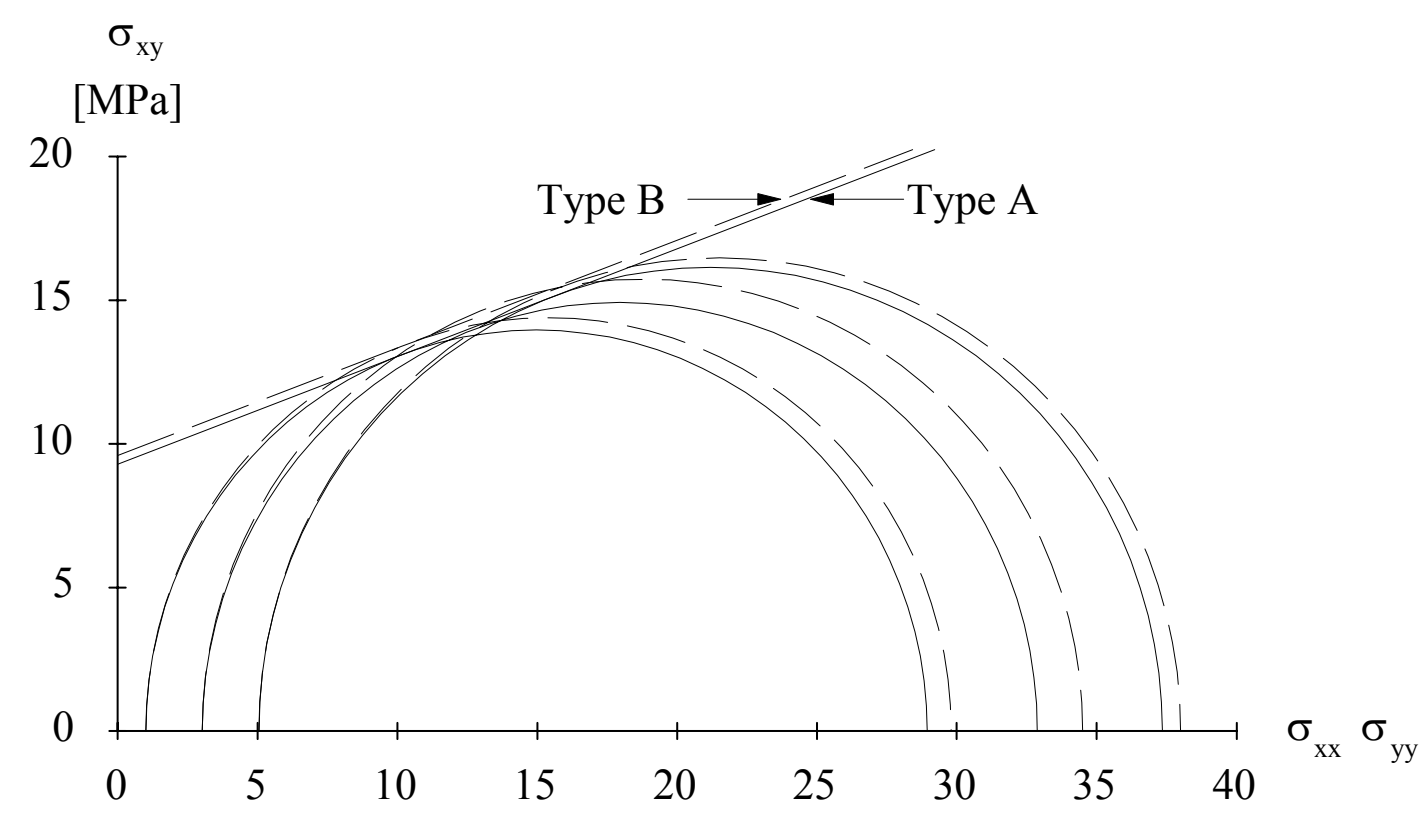

Figure 36. Mohr-Coulomb lines

Distribution type A contains more small grains than large grains, while distribution type B is linear. For both grain size distributions the moment of failure of the samples can be accurately described by the Mohr-Coulomb parameters $c^{\prime}$ and $\phi^{\prime}$. The different distributions cause only a negligible difference in the strength of the samples. This means that both the average force and the deviation of the forces do not depend on the grain size distribution, because the formation of micro cracks depends on this average contact force and its deviation .

\begin{tabular}{||c|c|c||}
\hline \hline Type & $c^{\prime}$ & $\phi^{\prime}$ \\
\hline $\mathrm{A}$ & $9.3 \mathrm{MPa}$ & $22^{\circ}$ \\
\hline $\mathrm{B}$ & $9.6 \mathrm{MPa}$ & $22^{\circ}$ \\
\hline
\end{tabular}

Table 11. Cohesion and angle of internal friction 


\subsubsection{Contact forces}

In the appendix 7, Biaxial test: analytical, it can be seen that the average normal and shear forces for biaxial tests are given by the equations A.73:

$$
\begin{aligned}
& \bar{F}_{n, \alpha}^{I I}=\bar{F}_{n}^{I}\left(c^{2}+\frac{\sigma_{1}}{\sigma_{3}} s^{2}\right) \\
& \bar{F}_{s, \alpha}^{I I}=\bar{F}_{n}^{I}\left(1-\frac{\sigma_{1}}{\sigma_{3}}\right) c s
\end{aligned}
$$

in which:

$$
\bar{F}_{n}^{I}=2 \frac{\sigma_{3} V}{n_{c} \bar{d}}
$$

or:

$$
\bar{F}_{n}^{I}=2 \frac{\bar{d}^{2} \sigma_{3}}{n_{c / v}}
$$

These analytical solutions for the average normal and shear forces (dashed lines in the figure below) in relation to the angle between the contact and the horizontal axis, are in good agreement with the average forces found by simulating a sandstone sample of 1000 grains at $10 \mathrm{MPa}$ loading pressure with Grain.

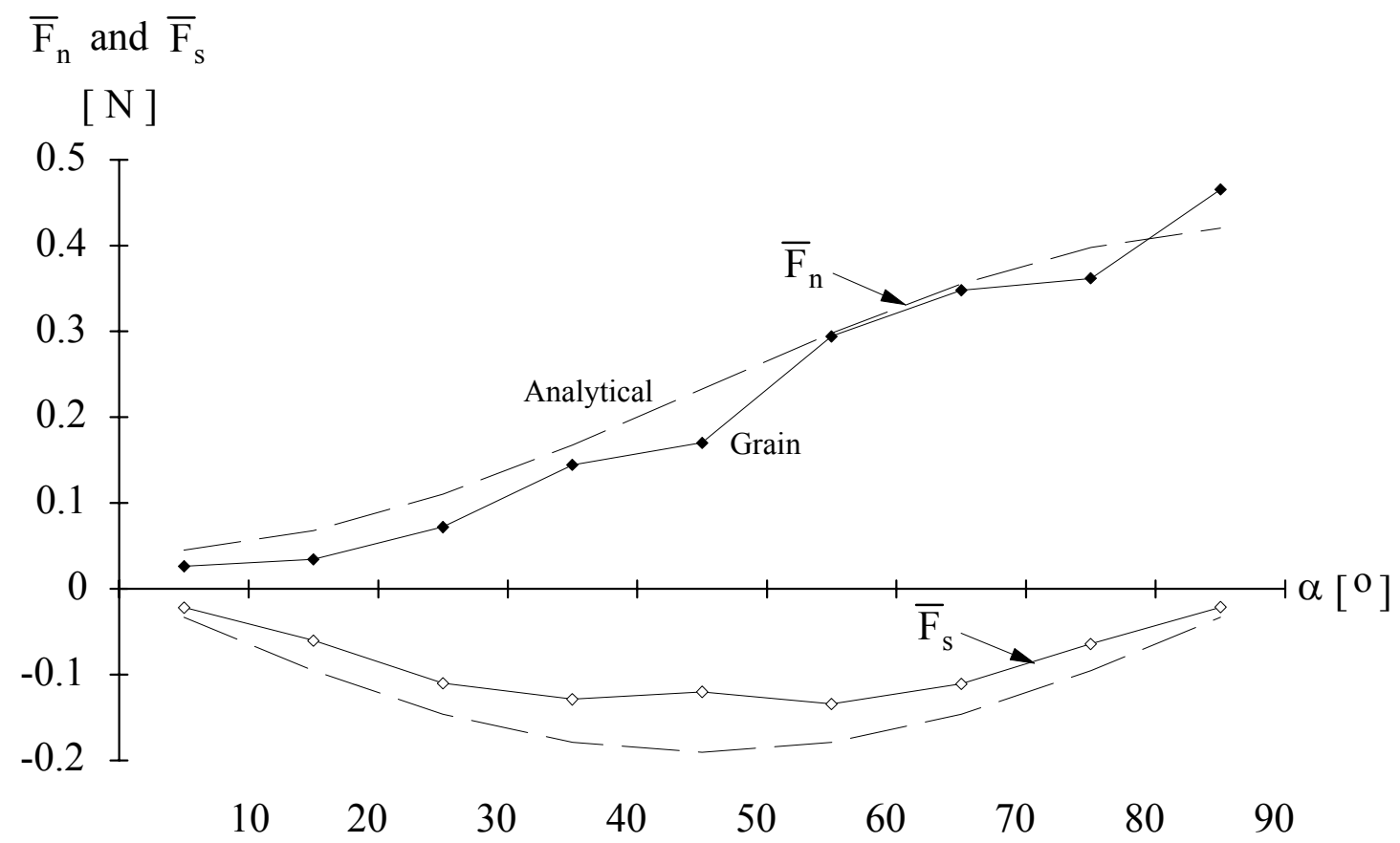

Figure 37. Biaxial test: average normal and shear forces 
The radar plot of these forces in figure 38 shows that the normal forces measured are almost identical to the analytical solution, however the average normal force of the vertical contacts seems to be somewhat too large. This is because there are relatively more vertical contacts due to the horizontal walls. The shape of the curve of the shear forces is correct, but the forces are in general $20 \%$ too low. This is probably because of the high correlation $(r=0.44)$ between the shear forces and the square of the contact length, whereas the analytical solution assumes no correlation.

The average normal force will always be positive i.e. pressure forces. Still, it is found that failure always occurs due to local tension failure. This means that not only the average value of the normal force is important, but also the deviation of the forces. So, to determine the moment of failure, the influence of the deviation of the forces should also be determined.

The normal forces are, especially for the lateral (horizontal) contacts, very small. During loading the deviation of the forces increases, while the average normal force of the horizontal contacts remains constant. So the lateral contacts are expected to collapse first due to tension failure. This means that mainly axial (vertical) micro cracks are expected, since the cracks are perpendicular to the broken contacts.

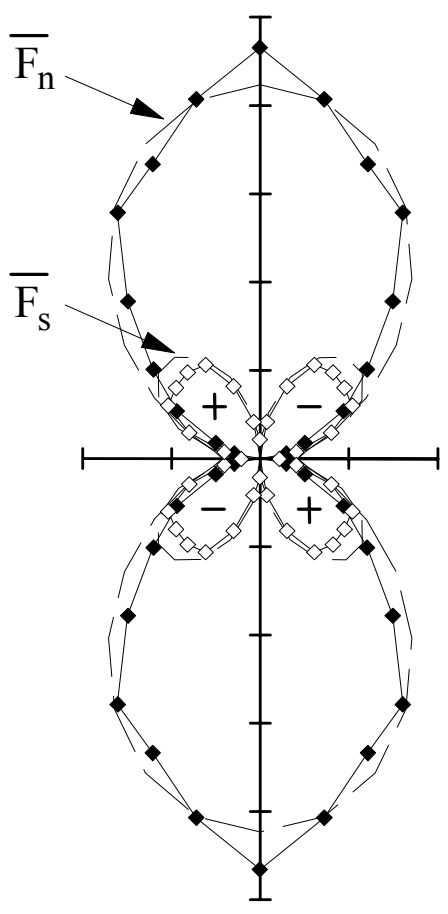

Figure 38. Biaxial test: average normal and shear forces 


\subsubsection{Failure mechanism}

One of the most interesting phenomena of the failure of a sandstone sample is the nucleation and growth of a crack. Therefore this is made visible with Grain. Figure 39 shows the failure mechanism of a cohesive granular material during a biaxial test in detail. If cemented contacts are broken, then a thick line perpendicular to the contact is drawn. The horizontal walls are also represented by thick lines, the rubber vertical membranes are not shown.

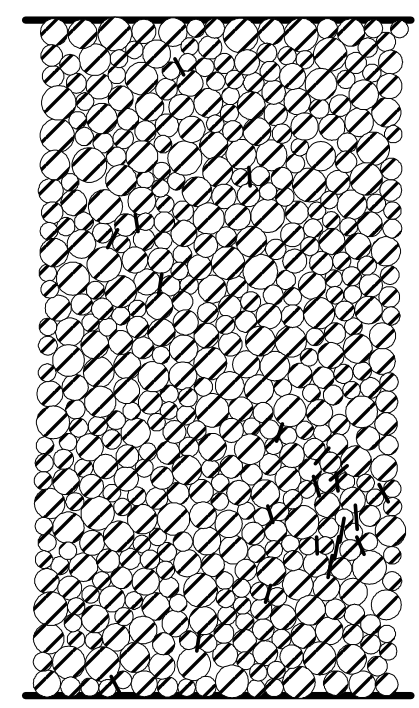

Phase A

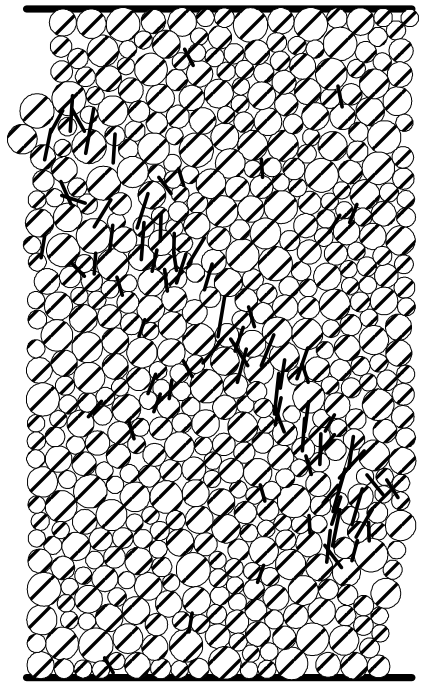

Phase B

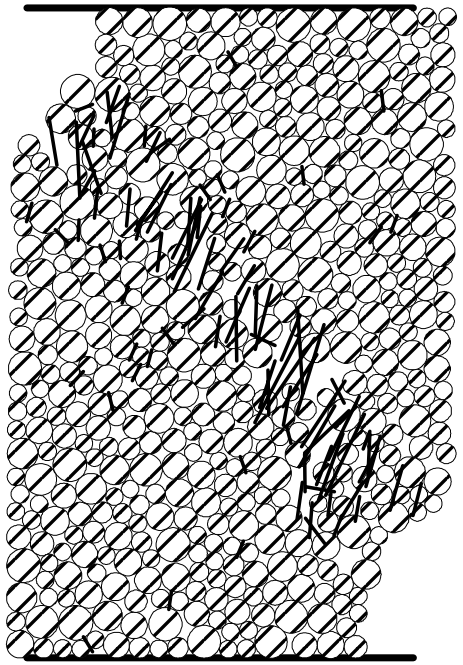

Phase C

Figure 39. Failure mechanism of a cohesive granular material

The failure mechanism of this cohesive granular material can be divided into three phases:

A. During loading more and more contact forces become negative as predicted in the previous paragraph. The contacts do not break due to shear failure as Coulomb suggests but due to tension failure, because the deviation of the forces increases during loading, while the average force of the horizontal contacts remains constant.

B. A crack weakens the surrounding area and increases the probability of a new crack in this area (second order effect). In this way a failure surface is formed. Although this surface is diagonal, the micro cracks are mainly vertical, which means that mainly horizontal contacts are broken. This phenomenon was also found for concrete and mortar by Stroeven (1973). Failure was caused for these materials by axial tensile (cleavage) cracks.

C. Grains with broken contacts act as rollers between the lower and upper part of the sandstone. The resistant vertical force becomes less and less. 
During the failure of a sample, several failure surfaces can also be formed as presented in figure 40 .

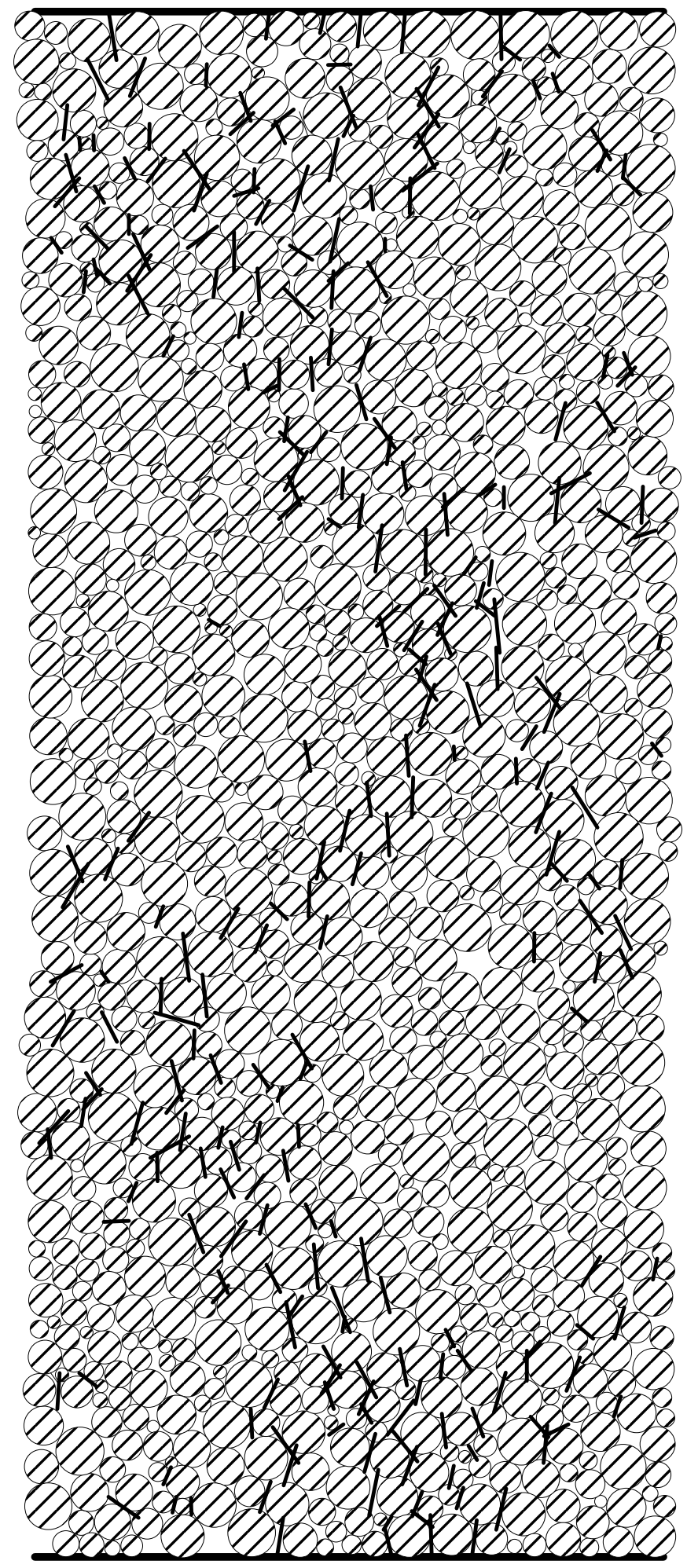

Figure 40. Micro cracks during a biaxial test 
Figure 41 shows the displacements of the 2000 grains of a sandstone structure after failure. A second failure surface can also be seen, as in most cases, one surface is dominant.

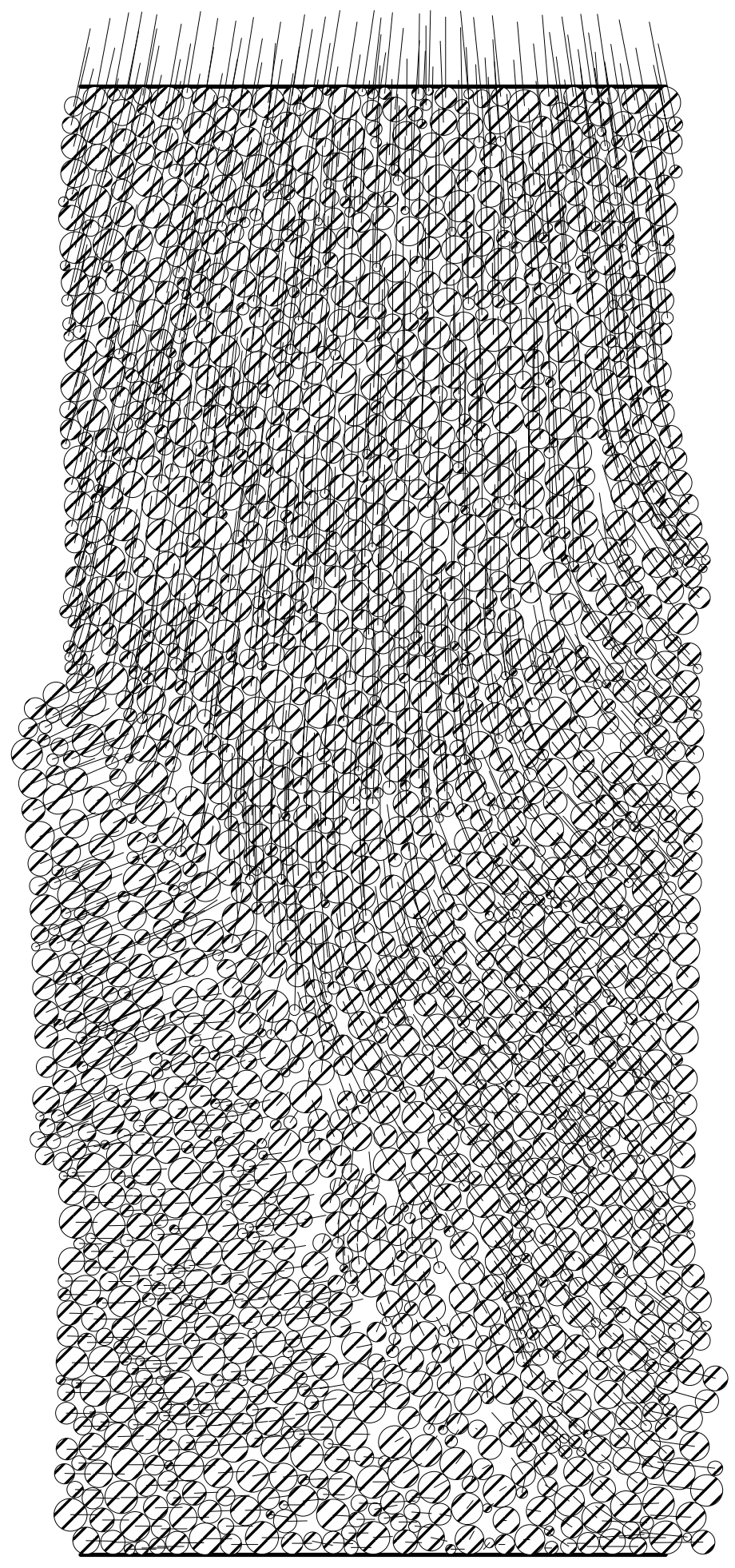

Figure 41. Displacements during a biaxial test on 2000 grains 
Figure 42 presents the rotations of the grains in a sample of 4000 grains. Before the test all the radial lines on the grains were pointing upwards. These lines indicate that only the broken grains within the shear band(s) are rolling.

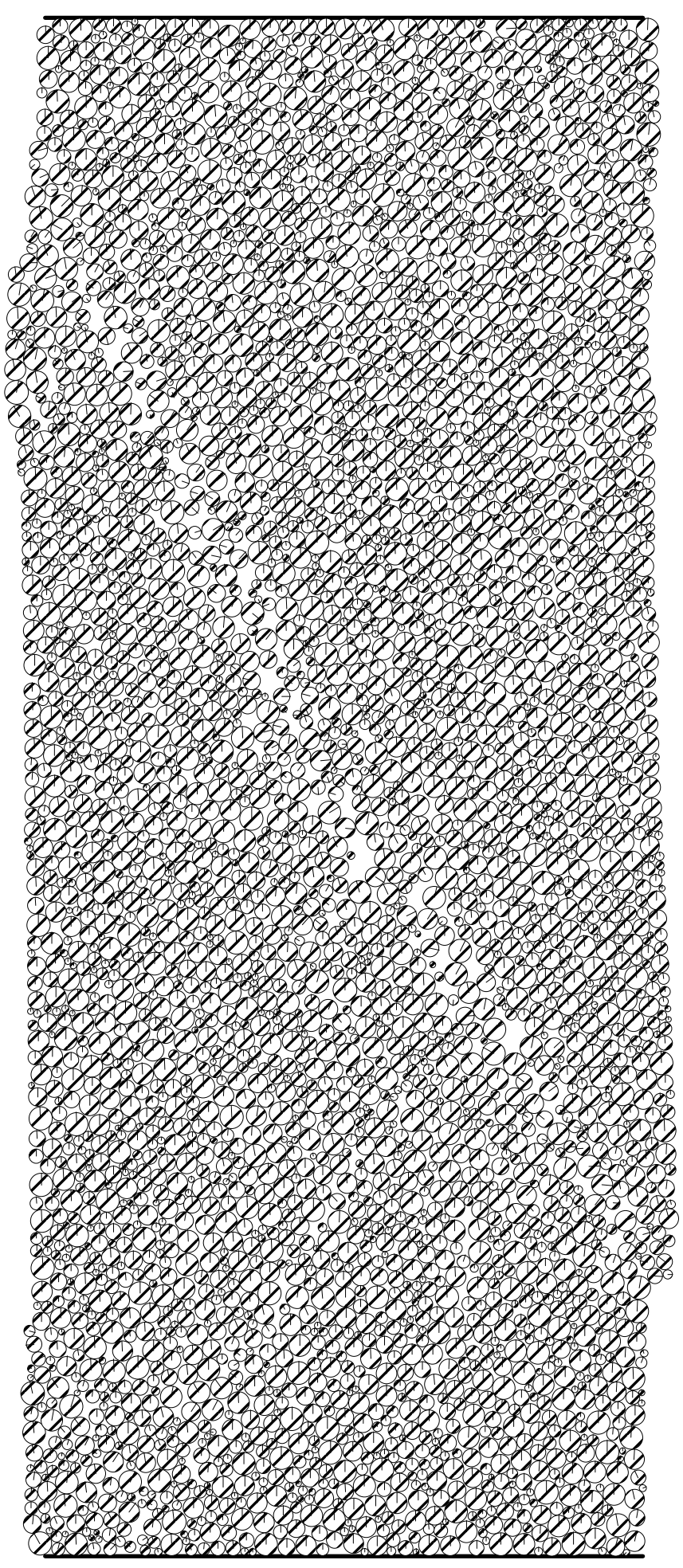

Figure 42. Failure surface during a biaxial test on 4000 grains 


\subsection{Continuum modelling}

The appendix 7, Biaxial test: analytical, shows that both the stiffness behaviour and the strength behaviour of cohesive granular materials can be described with the Mohr-Coulomb model. With the analytical solution of the average forces, the stiffness behaviour of rock samples has been solved. The Young's modulus and the Poisson's ratio of cohesive granular materials are given by:

$$
\begin{aligned}
E & =n_{c / v} \frac{k_{n}}{\bar{d}} \frac{\kappa_{v}}{\kappa_{v}+1} \text { with } n_{c / v}=\frac{\bar{d}^{3} n_{c}}{V} \\
\nu & =-\frac{\kappa_{v}-1}{\kappa_{v}+1}
\end{aligned}
$$

This yields for the default situation:

$$
\begin{aligned}
& n_{c / v}=\frac{\left(2 \times 10^{-4}\right)^{3} \times 1908}{8.48 \times 10^{-9}} \quad=1.80 \\
& E=1.80 \times \frac{10^{6}}{2 \times 10^{-4}} \times \frac{1.37}{1.37+1}=5.20 \mathrm{GPa} \\
& v=-\frac{1.37-1}{1.37+1} \quad=-0.16
\end{aligned}
$$

The elastic behaviour of the numerical sandstone simulations registered in table 9. can be described by:

$$
\begin{aligned}
E & =4.13 \mathrm{GPa} \\
v & =0.1
\end{aligned}
$$

The analytical values are based on the assumption that the grains do not rotate, which is only the case on average. Therefore, the prediction for the Young's modulus is $26 \%$ too high, and the Poisson's ratio $26 \%$ too low. If the rotations are fixed in Grain, then indeed a negative Poisson's ratio of $v=-0.07$ is found. This means that also the rotations of the grains influence the elastic behaviour of the sample in an important way. For some sands with a high density, a negative Poisson's ratio is found, which is officially possible. This means that in these particular cases the grains will hardly rotate.

Using the numerically measured Poisson's ratio a more accurate Young's modulus is found:

$$
\frac{E}{1-v}=n_{c / v} \frac{k_{n}}{2 \bar{d}}
$$

So,

$$
\begin{aligned}
E & =(1-0.1) \times 1.80 \times \frac{10^{6}}{2 \times 2 \times 10^{-4}} \\
& =4.05 \mathrm{GPa}
\end{aligned}
$$


The strength of a cohesive material depends on the contact strength and the normal force distribution. This distribution at isotropic compression $\left(\frac{\sigma_{1}}{\sigma_{3}}=1\right)$ is far different from the distribution during loading $\left(\frac{\sigma_{1}}{\sigma_{3}}>1\right)$. At a certain moment, even a small number of forces becomes negative (tension). These are the forces causing the final failure. These tension forces only occur in the lateral contacts $\left(|\alpha|<10^{\circ}\right)$. For a certain axial and lateral stress level the amount of broken contacts becomes too large to bear the axial load. This is the beginning of failure.

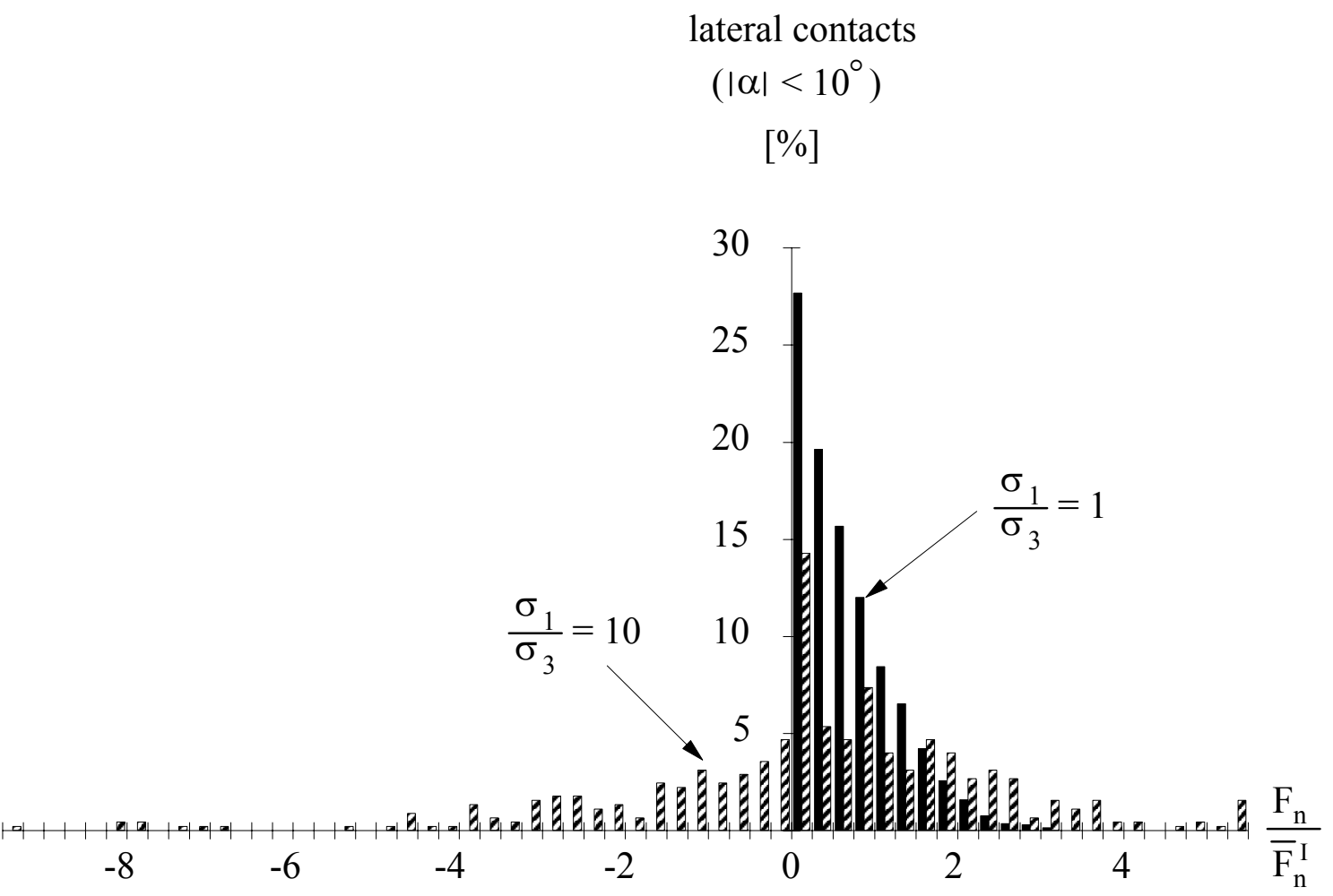

Figure 43. Biaxial test: normal force distribution

Appendix 7, Biaxial test: analytical, shows that the failure behaviour of the cohesive granular materials can also be described with Mohr-Coulomb. The angle of internal friction is constant and does not even depend on the contact force distribution. The cohesion depends only on the strength of a single contact and on the number of contacts per micro volume:

$$
\begin{aligned}
\sin \phi^{\prime} & =\frac{1}{3} \\
c^{\prime} & =\frac{c_{\mu} n_{c / v}}{16 \sqrt{2}} \quad \text { with: } \quad n_{c / v}=\frac{\bar{d}^{3} n_{c}}{V}
\end{aligned}
$$


So, in this case:

$$
\begin{aligned}
& \phi^{\prime}=19.5^{\circ} \\
& c^{\prime}=\frac{100 \mathrm{MPa} \times 1.80}{16 \sqrt{2}}=8.0 \mathrm{MPa}
\end{aligned}
$$

The deviation with the measured angle of internal friction $\left(\phi^{\prime}=22^{\circ}\right)$ and cohesion $\left(c^{\prime}=9.6 \mathrm{MPa}\right)$ of table 11 is not too large. So, an analytical relation between the micro parameters and the macro parameters is found for cohesive granular materials.

To summarise, it is analytically demonstrated that both the elastic behaviour and the moment of failure can be described with a Mohr-Coulomb model, though failure does not occur due to shear failure as Coulomb suggests, but due to the tension failure of the lateral contacts. So, the "angle of internal friction" can better be called "angle of lateral tension". 


\subsection{Cylinder test}

\subsubsection{Grain versus reality}

During radial compression tests on real thick-walled cylinders four phenomena were found which could not be explained by the Mohr-Coulomb continuum model described in appendix 5:

1. Failure occurs on micro level due to tension cracks.

2. These cracks are not diagonal to but parallel to the borehole surface.

3. These cracks cause two diametrically opposite breakouts.

4. Functional failure starts at a higher radial pressure than predicted.

One of the goals of the present research is to find the reasons for these anomalies. Therefore both the cylinder test and the biaxial test were simulated with Grain. All cylinder tests were carried out on exactly the same material as the former biaxial tests. The only difference with the previous samples is the number of grains which in this case were, one, four or ten thousand.

Just like real cylinder tests, the phenomena mentioned also occurred in the cylinder tests with Grain. The following figure shows the micro cracks in a thickwalled cylinder sample of a thousand cohesive grains made by Grain.

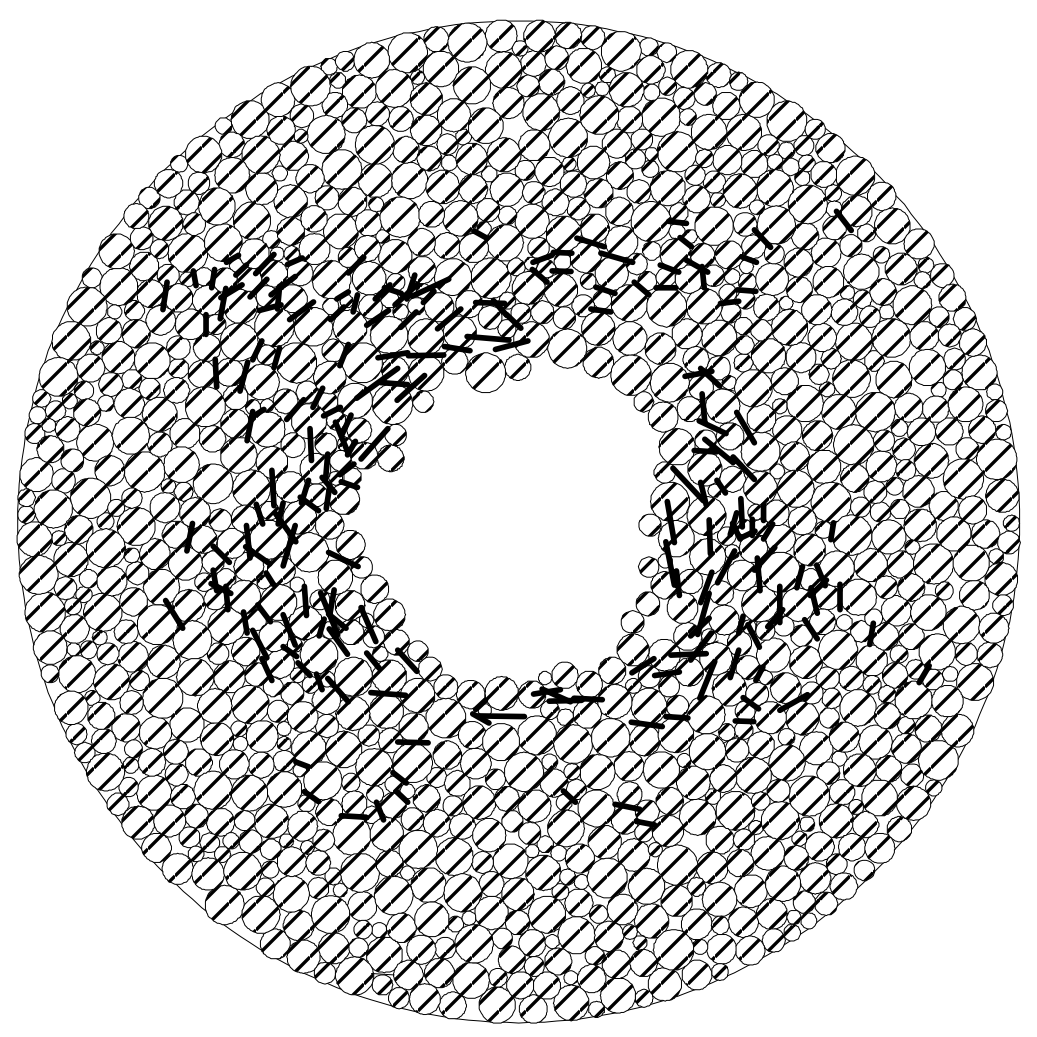

Figure 44. Tension cracks in a cylinder of 1000 grains 
After failure many micro cracks (thick lines) parallel to the inner surface are found. These are all caused by tension failure.

The first two phenomena, the tension cracks and their direction, are already explained in the previous chapter. Local tension forces can be created only by pressure forces and, especially for the contacts in the direction of the minor principal stress, the average normal force is relatively very low. Therefore mainly micro cracks in the direction of the major principal stress are expected, which means parallel tension cracks. In this chapter, the reason why thick-walled cylinders fail at a higher compressive stress than predicted will be explained.

\subsubsection{Radial pressure at failure}

The stresses in the sandstone sample during the cylinder test depend on the axial and radial pressures. This has been solved analytically in the appendix 8, Cylinder test: analytical, for a continuum model with a constant Young's modulus. The axial, tangential and radial stresses are found to be:

$$
\begin{aligned}
& \sigma_{z z}=P_{z} \\
& \sigma_{t t}=\left(\frac{b^{2}}{b^{2}-a^{2}}\right)\left(1+\frac{a^{2}}{r^{2}}\right) P_{r} \\
& \sigma_{r r}=\left(\frac{b^{2}}{b^{2}-a^{2}}\right)\left(1-\frac{a^{2}}{r^{2}}\right) P_{r}
\end{aligned}
$$

With these equations the radial pressure at failure can be calculated using the failure criterion of Mohr-Coulomb:

$$
\sin \phi^{\prime}\left(\sigma_{1}+\sigma_{3}\right)+2 c^{\prime} \cos \phi^{\prime}=\left(\sigma_{1}-\sigma_{3}\right)
$$

The strength parameters $c^{\prime}=9.3 \mathrm{MPa}$ and $\phi^{\prime}=22^{\circ}$ (Type $\mathrm{B}$ grain size distribution) were already determined with biaxial tests. For the cylinder test, the lateral stress at the inner surface is zero $\left(\sigma_{3}=0\right)$, so the tangential stress at failure will be:

$$
\sigma_{t t, r=a}=\sigma_{1}=\frac{2 c^{\prime} \cos \phi^{\prime}}{1-\sin \phi^{\prime}}=27.6 \mathrm{MPa}
$$

The ratio between the radii of the inner surface and the outer surface remains constant:

$$
\frac{a}{b}=\frac{1}{3}
$$

The radial pressure at failure depends both on this ratio and the tangential stress at the inner surface:

$$
P_{r}=\frac{\sigma_{t t, r=a}}{2}\left(1-\left[\frac{a}{b}\right]^{2}\right)
$$


So, the radial pressure at failure of this cylinder (Type B) is expected to be:

$$
P_{r}=12.3 \mathrm{MPa}
$$

However, the cylinder test on four thousand grains with Grain seems to fail at a pressure of about $29.7 \mathrm{MPa}$, which is much higher than the predicted value.

This happened also with a sample of ten thousand grains (Type A) where $P_{\text {breakout }}=30.2 \mathrm{MPa}$ (figure 45) instead of $12.7 \mathrm{MPa}$.

There are two reasons for this large deviation. Firstly, the influence of edge effects is neglected. Secondly, there is a definition difference between local failure and functional failure.

Local failure is the moment the strength of a material in a certain area starts to reduce. Because the pressure-strain relation of a cylinder test has no maximum, the moment when the first cluster of grains starts to break out of the inner surface wall, is normally assumed to mark the radial pressure at failure. This is the moment the borehole looses its function. This functional failure happens at a much higher pressure because of the large rest capacity of a thick-walled cylinder test.

$$
\begin{array}{cc}
\mathrm{P}_{\mathrm{r}} & {[\mathrm{MPa}]} \\
\mathrm{n}_{\mathrm{c}, \text { broken }} & {[\%]}
\end{array}
$$

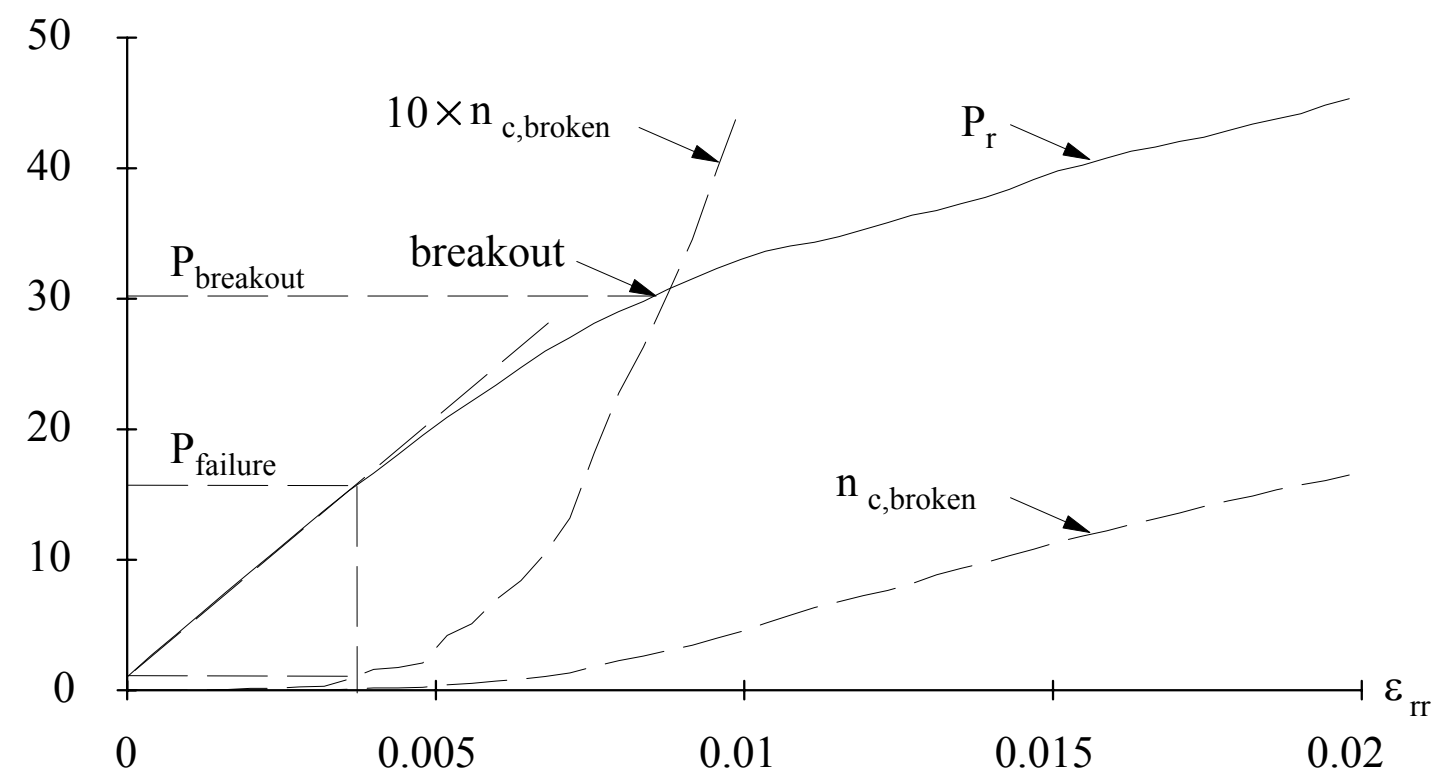

Figure 45. Cylinder test on 10,000 grains: Radial pressure and percentage of broken contacts 
But, in fact, this is not the real moment of failure of a cylinder. In the former biaxial tests failure occurred at a percentage of broken contacts of about $n_{c, \text { broken }}=1 \%$. In a cylinder, cracks occur only near the borehole in an area of about $10 \%$ of the total cylinder surface. The cylinder has failed when $1 \%$ of the contacts in this particular area is broken. From this point $P_{\text {failure }}$ on, more and more contacts start to break and the cylinder stiffness and the gradient of the curve start to decrease. Therefore this point has to be the radial pressure at failure.

If a borehole is loaded with a radial pressure which is in between this local failure pressure and the functional failure pressure, no breakouts can be seen, but much lasting damage is done to the borehole.

\subsubsection{Surface stresses}

Figure 46 shows the tangential and radial stresses in a cylinder of four thousand grains at a radial pressure of $P_{r}=14.2 \mathrm{MPa}$. The lines with the markers represent the stresses measured by Grain, with the sum of the contact forces as mentioned in the appendix 6, Micro-macro relation:

$$
\sigma_{i j}=\frac{1}{V} \sum_{k=1}^{n_{c}}\left(d_{i, k} F_{j, k}\right)
$$

Unfortunately, local strains cannot be measured in this way, by summation of the contact displacements over the contacts, according to the same appendix.

The dotted line in figure 46 is the analytical solution for a sample of constant elasticity. The dashed line shows the numerical solution based on the local (not constant) elasticities.

If the stresses of this analytical solution for a sample of constant elasticity are compared with the results of Grain then the analytical solution seems to predict the stresses quite accurately, except for the fall in the tangential stress at the surfaces. This fall can also be seen in the numerical simulation work of Thallak (1992).

This fall occurs because there are less contacts at the surface of a sandstone sample than average. Only at a distance of two times the average grain radius can this edge effect be considered negligible. In theory the number of contacts per volume $n_{c / v}$ is zero at the surface, $50 \%$ of the average value at a distance of one grain radius, and at a distance of two radii (one diameter), the amount of contacts is almost average. Figure 47 shows this in a cross-section of the cylinder of 4,000 grains, with a gauge of 51 times the average grain radius. 


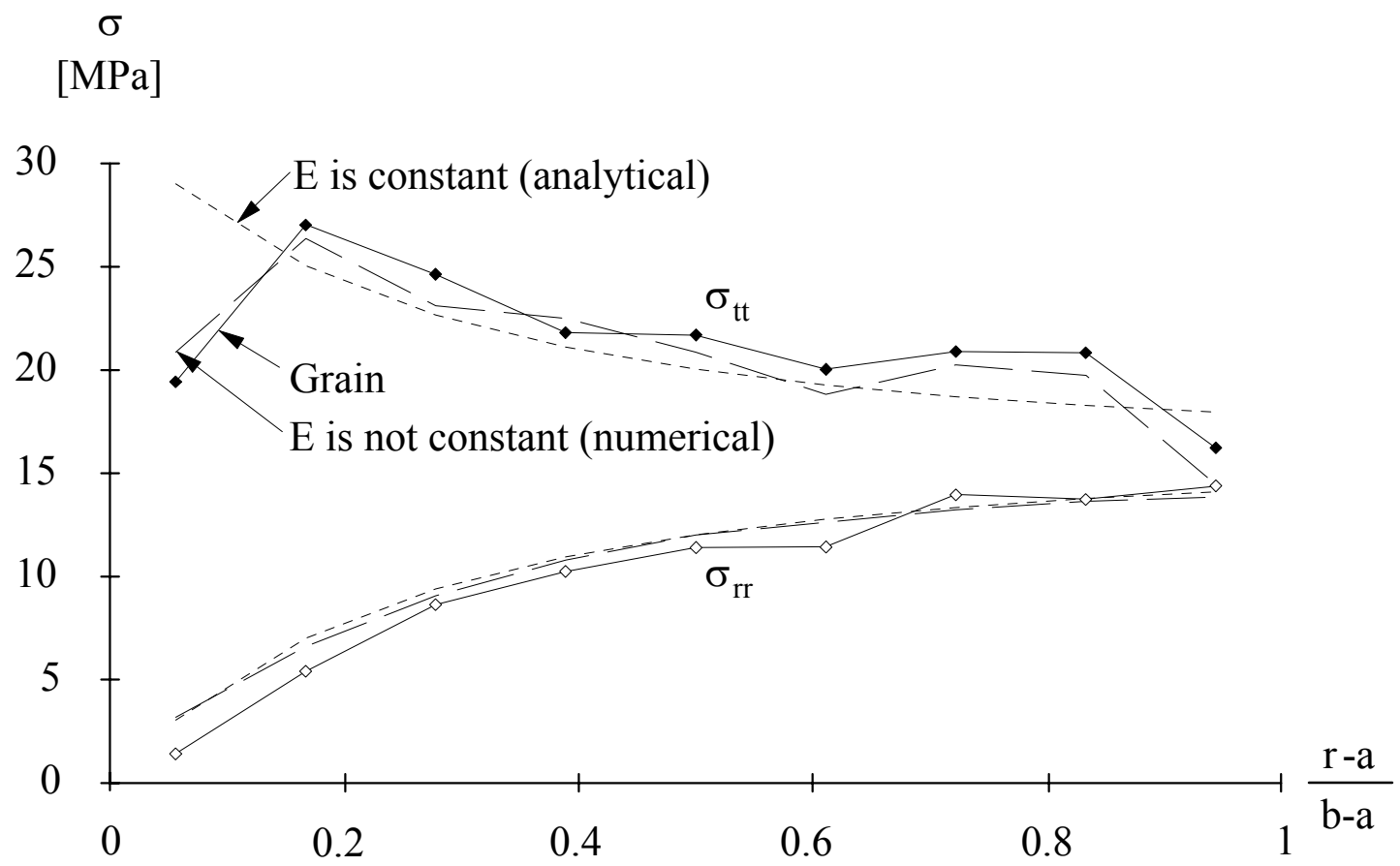

Figure 46. Tangential and radial stresses in the cylinder

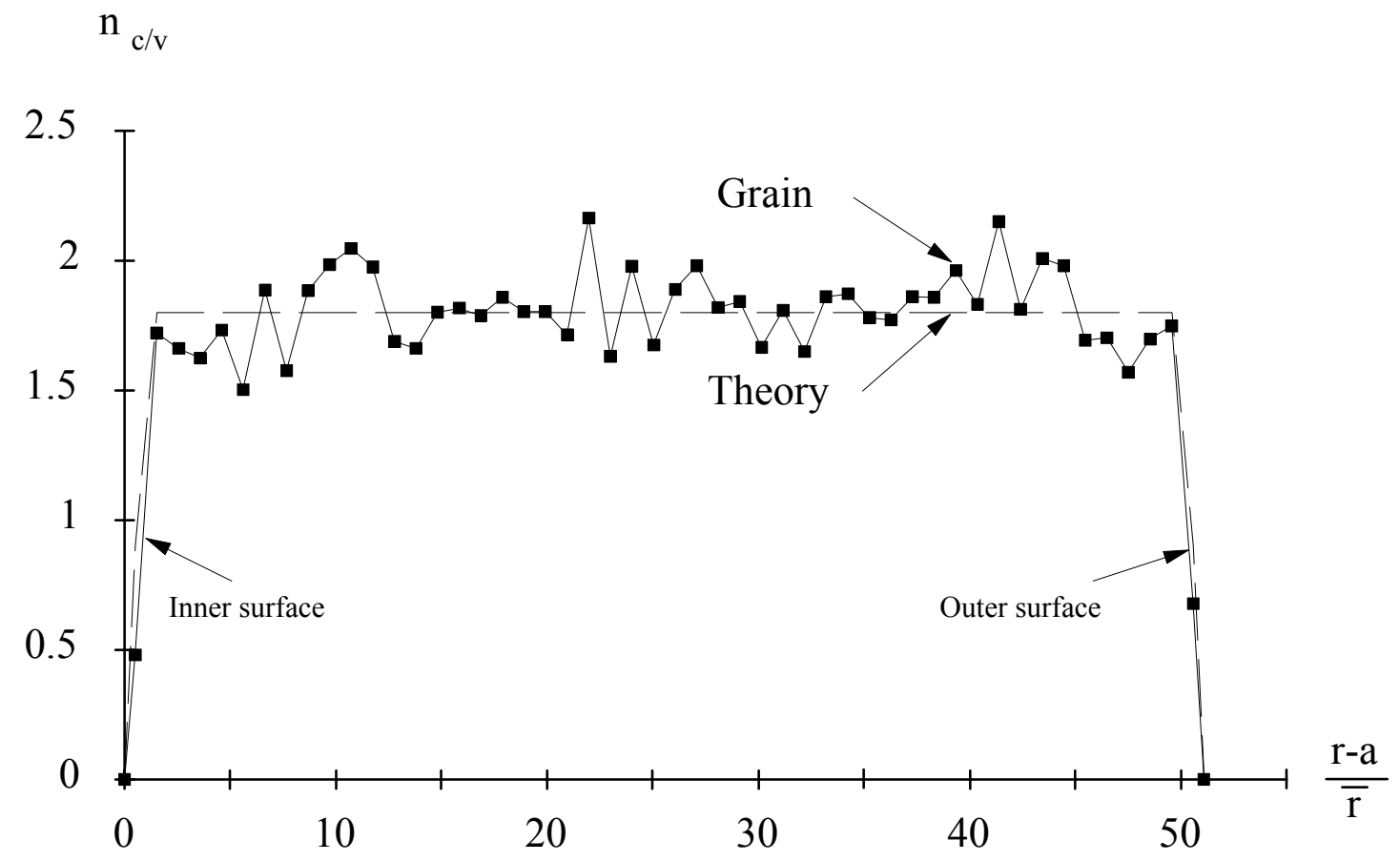

Figure 47. Number of contacts per volume from the inner surface to the outer surface 
In appendix 7, Biaxial test: analytical, a linear relation between the Young's modulus and this number of contacts per volume is found:

$$
E=n_{c / v} \frac{k_{n}}{d} \frac{\kappa_{v}}{\kappa_{v}+1}
$$

This relation has been used to calculate the local Young's moduli. With a numerical finite element model, the stresses in the cylinder can be calculated using these moduli. Because of the lack of contacts at the surface, the Young's modulus will be lower, which explains the fall in the stresses. The numerical prediction of the stresses in figure 46, is almost equal to the stresses in Grain, even at the surfaces. So, because of a lack of contacts at the boundaries the Young's modulus and therefore also the tangential stress will be lower. This effect will take place only in a thin layer near the inner surface: $a<r<a+\bar{d}$. In this area not only are the stresses lower but there are also hardly any lateral contacts to break, so failure does not start at the surface $(r \neq a)$ but just underneath $(r=a+d)$. This layer of lower tangential stress is so thin, that it will only increase the strength of the cylinder with 4,000 grains by about 34 percent and the cylinder of 10,000 grains by about eighteen percent:

$$
\frac{P_{r, a+d}}{P_{r, a}} \approx \frac{1-\sin \phi^{\prime}}{1-\sin \phi^{\prime}-2 \frac{\bar{d}}{a}} \approx 1.18
$$

In reality the borehole is relatively large $(a>>\bar{d})$ so most of the times this edge effect can be neglected.

This theoretical prediction of the radial pressure at failure $P_{r, a+d}$ is quite close to the pressure $P_{r, \text { failure }}$ found by Grain. The first breakout will be found at a higher

\begin{tabular}{|c|c|c|c|c|c|}
\hline & & & Theory & Grain & \\
\hline$n_{c}$ & Type & $\bar{P} P_{r, a}$ & $\overline{P_{r, a+d}}$ & $P_{r, \text { failure }}$ & $P_{r, \text { breakout }}$ \\
\hline 4,000 & $\mathrm{~B}$ & $12.3 \mathrm{MPa}$ & $16.5 \mathrm{MPa}$ & $15.3 \mathrm{MPa}$ & $29.7 \mathrm{MPa}$ \\
\hline 10,000 & A & $12.7 \mathrm{MPa}$ & $15.0 \mathrm{MPa}$ & $15.7 \mathrm{MPa}$ & $30.2 \mathrm{MPa}$ \\
\hline
\end{tabular}
pressure.

\section{Table 12. Pressure at failure: Prediction versus Grain}

Although the bi-linear Mohr-Coulomb model predicts the radial pressure at local failure quite well, this model is inappropriate for predicting the radial pressure at functional failure, because it can not handle hardening and softening behaviour. According Papamichos and Van den Hoek (1995) a tri-linear Cosserat-MohrCoulomb model with hardening and softening gives much better predictions concerning functional failure than the conventional continuum models. 


\subsubsection{Cylinder wall breakouts}

Laboratory observations of borehole breakouts in several sandstones show very often stable breakout shapes, according to Zheng et all (1989) and Ewy and Cook (1990 II). In the default cylinders made with Grain, breakouts occur all along the borehole surface, but the two diametrically opposite breakouts never occur. Maybe this phenomenon depends on the history of a natural sandstone. During formation of sandstone the vertical effective stress is about two times higher than the horizontal stresses and sometimes also the stress of one horizontal direction is larger than the stress of the other perpendicular horizontal direction. These different stresses cause different contact forces. Thus, the horizontal contact forces will be smaller than the vertical ones. Therefore a horizontal contact will form in time a smaller cemented contact surface. In other words, the found macro cohesion will be smaller for triaxial samples loaded in the direction of gravity than for samples loaded perpendicular to this direction. This can be an explanation for the mentioned breakouts. In figure 48 the micro cohesion of the horizontal contacts is made two times smaller than the micro cohesion of the vertical contacts. A uniform radial pressure of $11.2 \mathrm{MPa}$ is sufficient to create two opposite breakouts in this anisotropic sample.

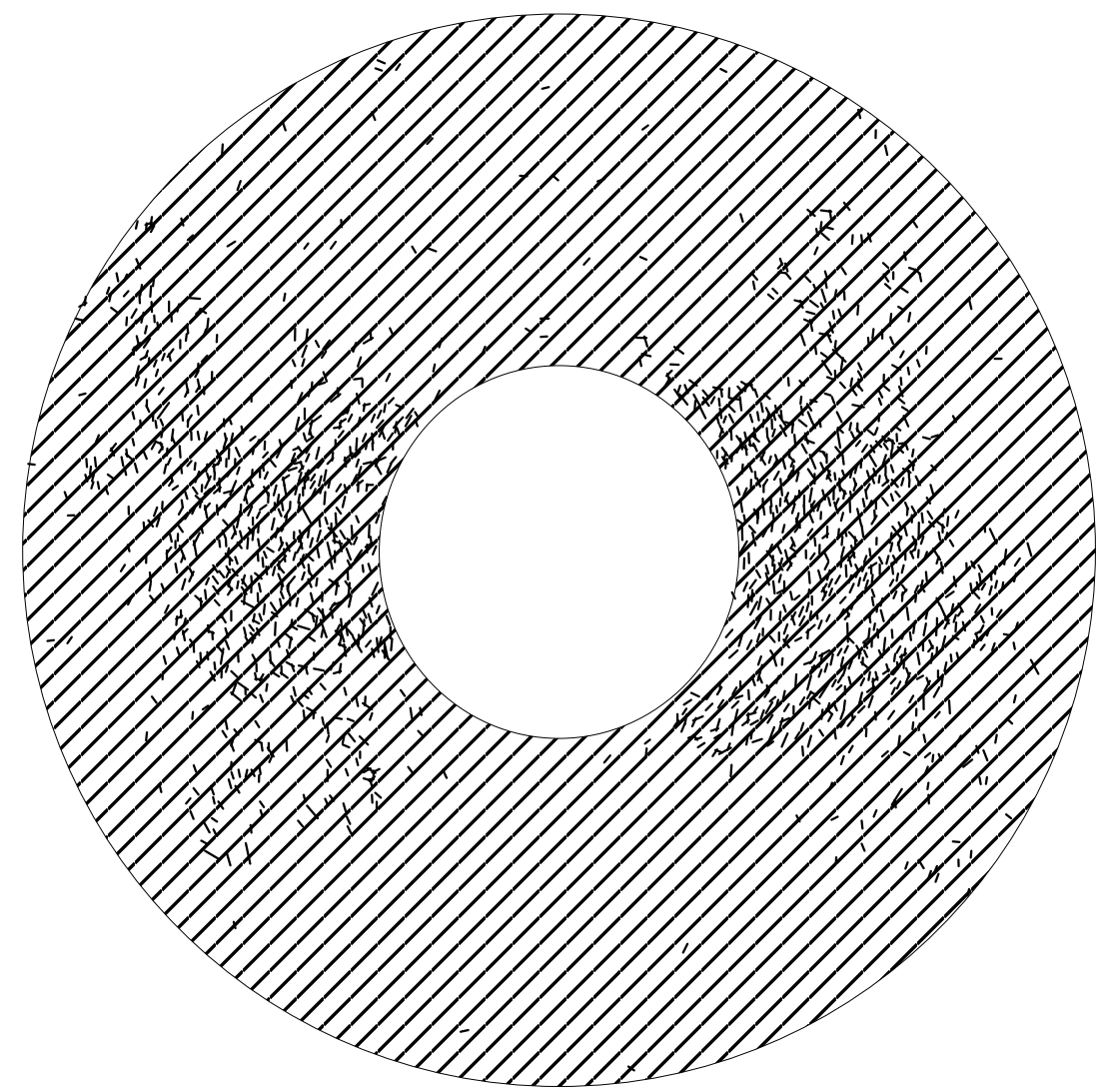

Figure 48. Two opposite breakouts in a cylinder of 10,000 grains 


\subsection{Three point bend test}

A familiar test to measure the strength of a concrete beam is the three point bend test. This test is simulated in Grain with a small beam $(h \times l \times d=39.8 \mathrm{~cm} \times 102.5 \mathrm{~cm} \times 2.00 \mathrm{~cm})$ containing a thousand grains. Just like the cylinder test the beam will fail on the edge but this beam has no rest capacity, so a sudden failure will occur.

One of the problems of a real concrete beam is the small number of (gravel) particles and contacts so the assumption of a homogeneous material, which is necessary for a continuum approach, is not completely valid. The smaller the number of particles, the larger the deviation of a group of test results will be. As the results of table 13 show, the predicted vertical load at failure is indeed far from the numerical simulated value.

\begin{tabular}{||c|c|}
\hline Bending test & vertical load \\
\hline predicted (analytical) & $27 \mathrm{kN}$ \\
\hline measured (numerical) & $43 \mathrm{kN}$ \\
\hline
\end{tabular}

\section{Table 13. Vertical load at failure}

Just before failure, the compressive forces (black lines) in the beam in figure 49, show a very clear arch from the left support upwards to the vertical load and downwards to the right support. The underside of the beam shows mainly horizontal tensile forces (grey lines) with small vertical compressive forces, which is analogous with the formation of local lateral tensile forces in the biaxial test. In other words, the results are as expected.

In addition, the crack (thick black lines) in the beam in figure 50, formed during failure, starts at the bottom of the beam and grows from weaker area to weaker area, which are the larger pores. A crack can also lead to a dead end if the area above the crack is too strong. A nice detail is the last remaining contact in the failure surface causing a few high tensile and compressive forces on the right of the failure surface.

It is remarkable, that the micro cracks have the same direction as this failure surface, which is also the case for the cylinder test but which is definitely not the case for biaxial tests. Nevertheless, the micro cracks are always in the direction of the major principal stress, i.e. the axial direction. 


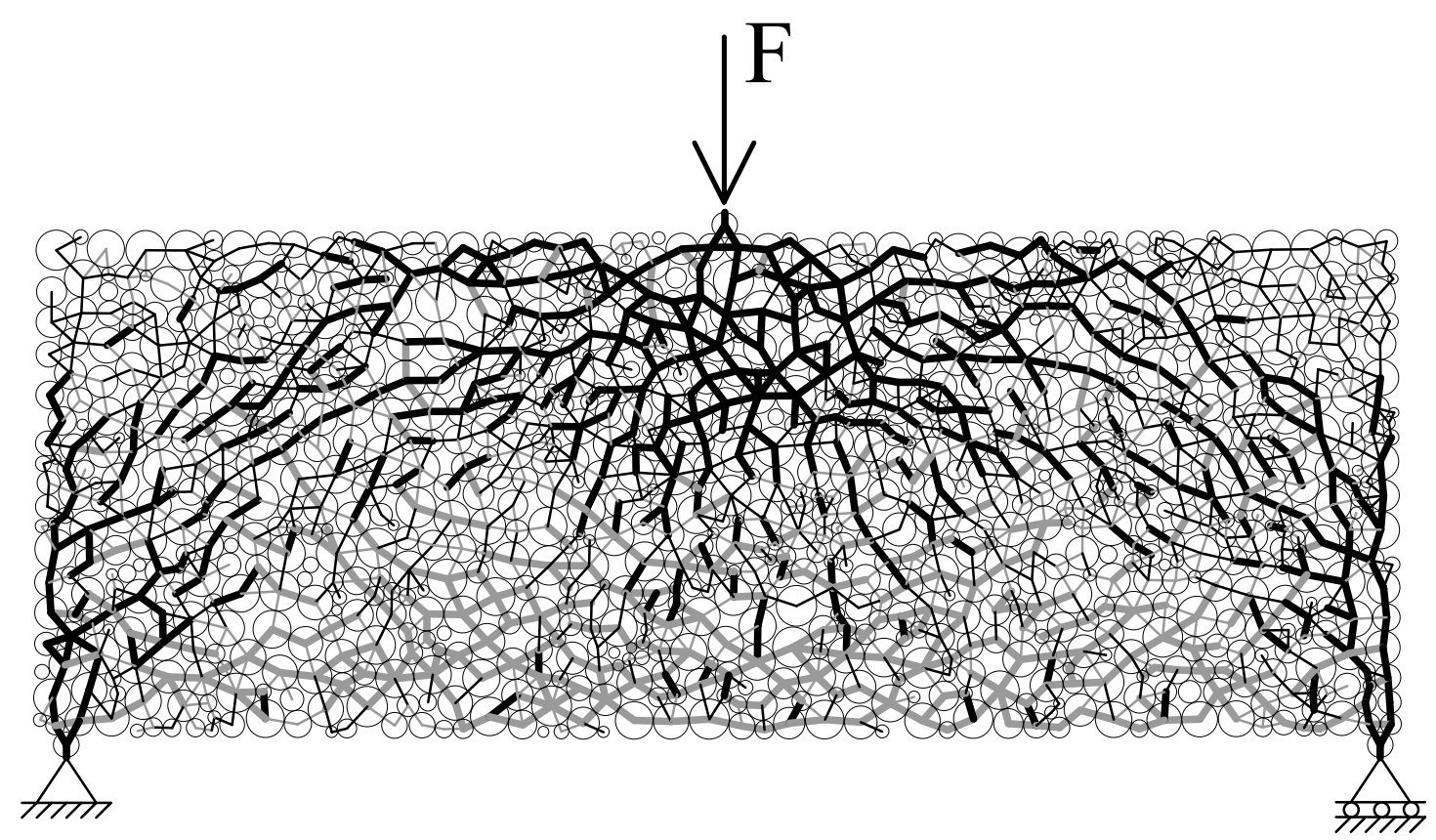

Figure 49. Concrete beam before failure

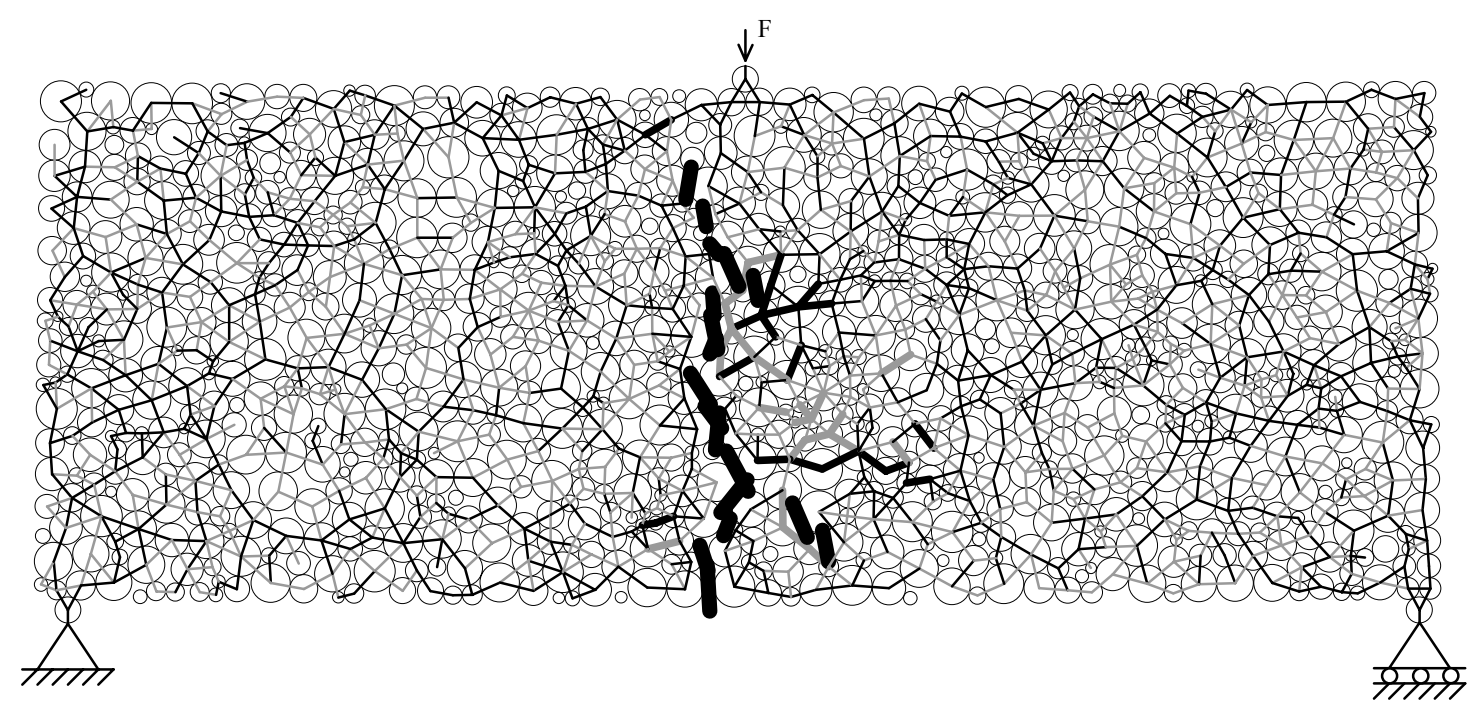

Figure 50. Concrete beam after failure 


\section{CRYSTAL STRUCTURES}

A particular case in cohesive granular materials is the crystal structures in which all the grains are having the same size. Because of this, these materials have a completely regular structure, which causes different behaviour than normal cohesive granular materials.

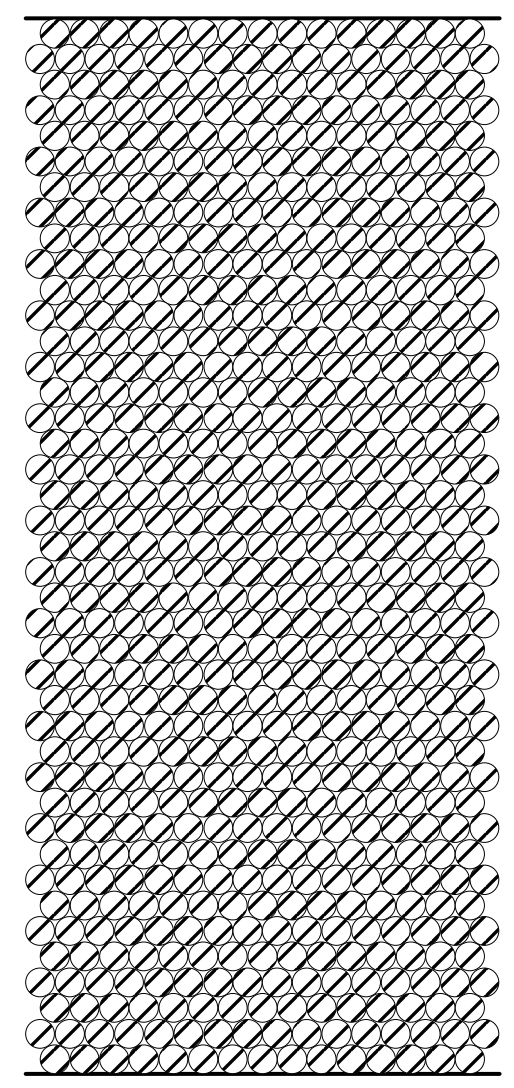

Figure 51. Crystal structure

On a crystal structure of $15 \times 21+16 \times 20=635$ grains, a biaxial test was done to show this behaviour. The structure has almost the same parameters as sandstone. The only difference with the previous tests on cohesive granular materials is that in this case all grains have the same size, so $\frac{r_{\max }}{r_{\min }}=1$. Because of this, crystal structures belong both to the logarithmic grain size distribution (Type A) and the linear distribution (Type B).

The grains all have six contacts in specific directions. All contacts form triangular micro structures, so not one quadrangular structure is formed. These quadrangular structures were the fundament of failure of non-crystalline structures, because they caused tension failure in the contacts in the direction of the minor principle direction. That is the reason why crystal structures fail at 
higher axial stress and via a different failure mechanism. Even though all micro parameters are equal to those of sandstone, this crystal structure is extremely strong. Figure 52 shows that the sample fails only at $417 \mathrm{MPa}$ !

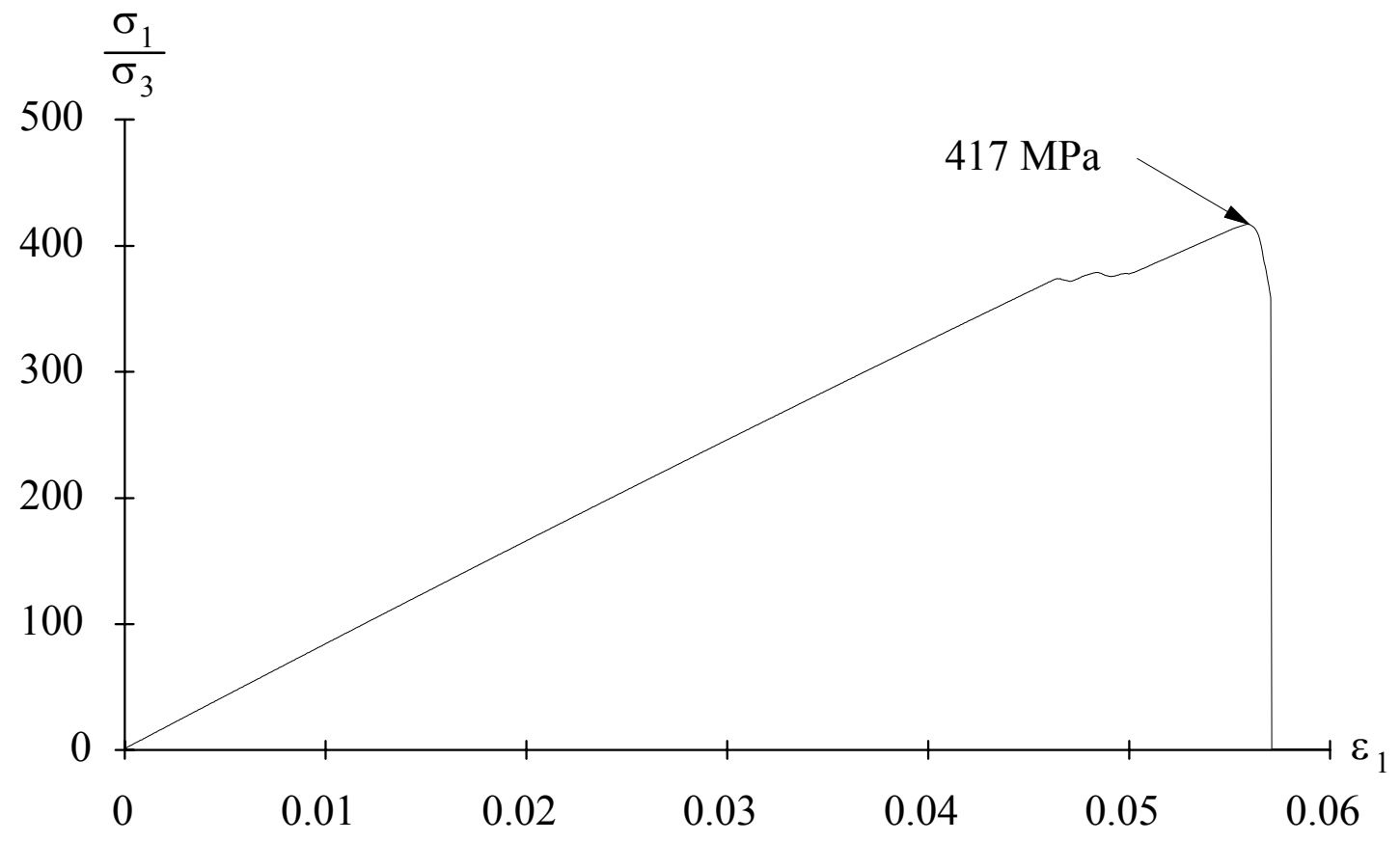

Figure 52. Biaxial test on a crystal structure of 635 grains

In appendix 9, Crystal: analytical, it is found that during the elastic phase of a biaxial test there are only three types of contact forces in this crystal, and these are solved by:

$$
\begin{aligned}
& F_{n}^{\prime}=\frac{1}{6 C} \frac{\left(\kappa_{v}+2\right) \sigma_{1}-\kappa_{v} \sigma_{3}}{\left(\kappa_{v}+1\right)} \\
& F_{s}^{\prime}=\frac{1}{6 C} \frac{\kappa_{v}\left(\sigma_{1}-\sigma_{3}\right)}{\left(\kappa_{v}+1\right)} \sqrt{3} \\
& F_{t}^{\prime}=\frac{1}{6 C} \frac{\left(\kappa_{v}-1\right) \sigma_{1}+\left(\kappa_{v}+3\right) \sigma_{3}}{\left(\kappa_{v}+1\right)}
\end{aligned}
$$

in which:

$$
\begin{aligned}
& C=\frac{1}{4 \sqrt{3} r^{2}} \\
& \kappa_{v}=3 \frac{1-v_{\mu}}{2-v_{\mu}}=1.37
\end{aligned}
$$


The following figure shows that the numerical results of the contact forces is close to the analytical prediction (dashed lines).

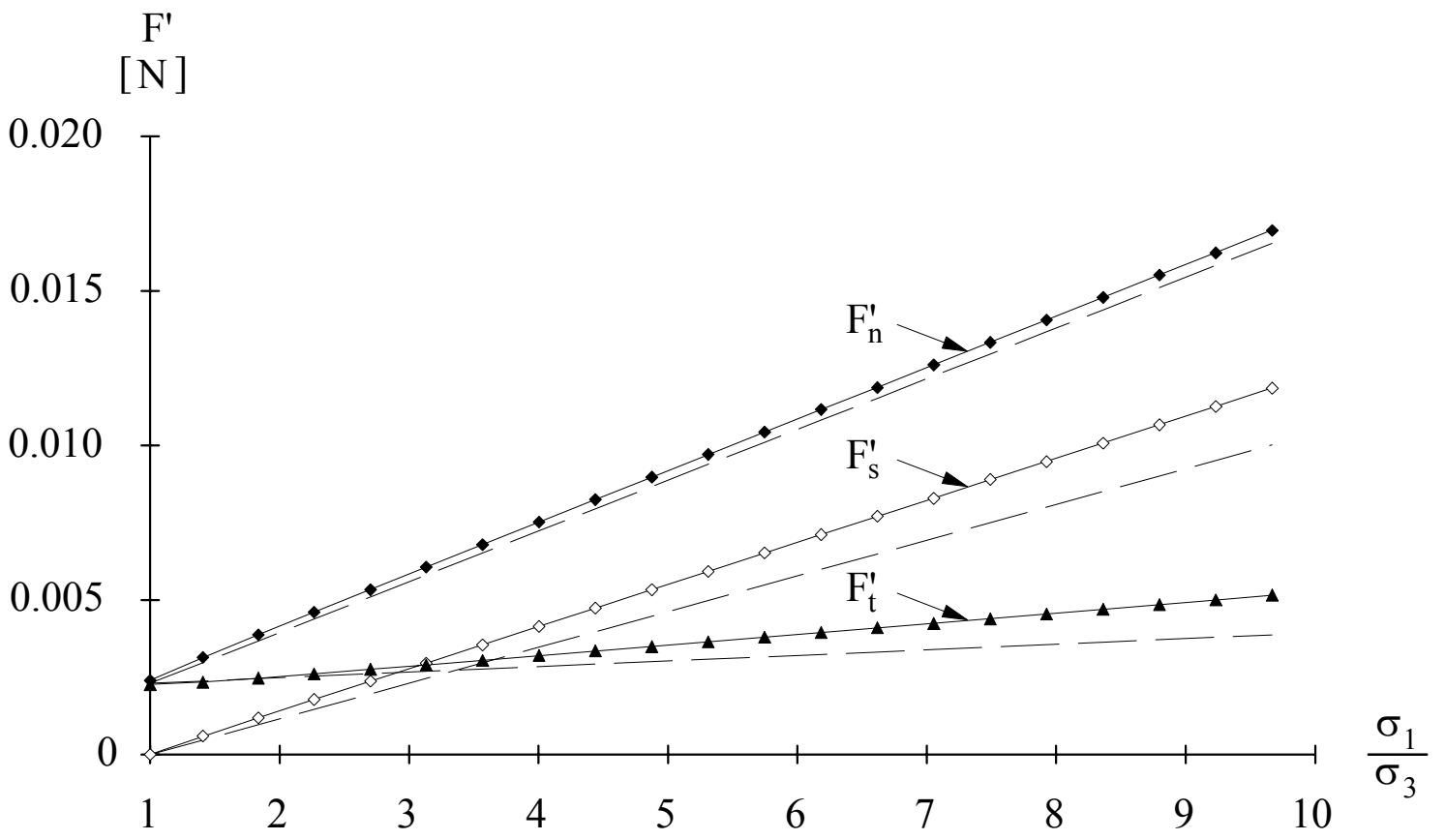

Figure 53. Biaxial test: Contact forces in a crystal structure

The stiffness ratio, $\kappa_{v}$, is just above one so the horizontal force $F_{t}^{\prime}$ will never become negative, and as a result of this, tension failure can never occur. The second criterion for failure is the shear failure, but since the shear force increases even more slowly during loading than the normal force, this will happen at a very high axial pressure. Therefore this crystal is much stronger than a non-crystal sample with identical micro parameters. 


\section{CONCLUSIONS AND RECOMMENDATIONS}

\subsection{Conclusions}

1. Models based on equilibrium will give the same results for quasi-static problems as models based on motion.

2. Models based on equilibrium will iterate faster, but cannot be used for dynamic problems unlike models based on motion.

3. The results for non-cohesive granular materials can be described with an advanced Mohr-Coulomb model.

4. The results for cohesive granular materials can be described with a MohrCoulomb model, but due to softening behaviour only until the plastic phase (breaking).

5. An analytical relation between the micro behaviour and the macro behaviour is found for cohesive granular materials.

6. Although the Coulomb line describes the moment of failure of a granular material quite well, the failure does not occur due to shear failure as described, but due to local tensile failure on a microscopic level, which is causing micro cracks in the axial direction.

7. Diametrically opposite breakouts near the borehole surface are probably caused by anisotropy in the strength behaviour of the sandstone.

8. Boreholes fail at a higher radial pressure than predicted, because of the definition difference between local failure and functional failure and the large rest capacity of a thick-walled cylinder test. 


\subsection{Recommendations}

It was never meant to model a complete geotechnical construction like a dike or a tunnel with discrete elements. One hand filled with sand contains one billion grains already, so the present computational facilities will always be insufficient to model this. Discrete element modelling has been developed to obtain insight into the micro behaviour of granular materials, in order to improve the continuum models of these materials. A few thousand grains are sufficient to model a homogeneous loaded sample. Since several tens of thousands of grains can be handled on a normal computer, it has no meaning to increase this number of grains. A more fruitful approach would be to improve the three simplifications made at the beginning of this research:

- A three-dimensional model will probably not gain many additional insights, but will make the results more realistic.

- A non-cohesive grain structure with more complex grain shapes reacts more strongly than a structure with circular grain shapes.

- A better description of the contact relation, which can perhaps be obtained from laboratory tests, will give more accurate simulations.

These improvements will cost much work, but may not gain that many additional insights. Besides, the behaviour of the discrete models can quite accurately be described by an advanced Mohr-Coulomb model. Therefore the question whether this amount of work can be justified must be settled first. 


\section{REFERENCES}

Allersma, H.G.B. (1987).

Optical analysis of stress and strain in photoelastic particle assemblies.

Dissertation, Delft University of Technology, pp. 100-103.

Baars, van S. (1995).

Discrete element analysis of granular materials. Communications on Hydraulic and Geotechnical Engineering, report 95-4, ISSN 0169-6548.

Bathurtst, R.J. and Rothenburg, L. (1988).

Micro mechanical aspects of isotropic granular assemblies with linear contact interactions. Journal of Applied Mechanics, volume 55, pp. 17-23.

Bishop, A.W. (1954).

Correspondence. Géotechnique, volume 4, pp. 43-45.

Caquot, A. (1934).

Equilibre des massifs à frottement interne. Stabilité des terres pulvérulents et cohérentes. Gauthier-Villars, Paris.

Cundall, P.A. and Strack, O.D.L. (1979).

A discrete numerical model for granular assemblies. Géotechnique, volume 29, pp. 47-65.

David C. and Darot M. (1993).

Pore structures and transport properties of sandstone. Transport in Porous Media, volume 11, figure 4-9, pp. 161-177.

Deresiewicz, H. (1958).

Reprinted from: Mechanics of granular matter. Advances in Applied Mechanics, volume 5, Academic press inc., New York, pp. 254-261.

Drescher, A. and Josselin de Jong, de G. (1972).

Photo-elastic verification of a mechanical model for the flow of a granular material. Journal of Mechanics and Physics. Solids 20, pp. 337-351.

Ewy, R.T. and Cook, N.G.W. (1990 I).

Deformation and fracture around cylindrical openings in rock I. International Journal of Rock Mechanics. Min. Science and Geomechanics, volume 27 , no. 5, pp. 387-407.

Ewy, R.T. and Cook, N.G.W. (1990 II).

Deformation and fracture around cylindrical openings in rock II. International Journal of Rock Mechanics. Min. Science and Geomechanics, volume 27, no. 5, pp. 409-427.

Hertz, H. (1881).

Journal of Mathematics, volume 92.

Or: Timoshenko, S. and Goodier, J.N. (1951): Theory of elasticity. McGraw-Hill Book Company, Inc. pp. 372-383.

Josselin de Jong, de G. and Verruijt A. (1969).

Etude photo-élastique d'un empilement de disques. Cahiers du Group 
Français de Rhéologie, Janvier 1969, volume II, pp. 73-86.

Josselin de Jong, de G. (1971).

The double sliding, free rotating model for granular assemblies.

Géotechnique, volume 21, no. 2, pp. 155-163.

Josselin de Jong, de G. (1992).

Co-rotational solution in simple shear test. Proceedings of the Wroth

Memorial Symposium 1992, Predictive Soil Mechanics, Thomas, Telford, London, pp. 254-260.

Kruyt, N.P. (1994).

Aspects of constitutive relations for cohesionless granular materials.

Dissertation, University Twente, pp. 126-127.

Lindhout, P.H. (1992).

Use of distinct element method in soil and rock mechanics. student report 92.048, Shell, March 1992, pp. 39-41.

Mindlin, R.D. and Deresiewicz, H. (1953).

Elastic spheres in contact under varying oblique forces. Journal of Applied

Mechanics, volume 20, September 1953, pp. 327-344.

Papamichos, E. and Hoek, van de P.J. et all. (1995).

Size dependency of Castlegate and Berea sandstone hollow-cylinder strength on the basis of bifurcation theory. Rock Mechanics, Daemen and Schultz, Balkema, Rotterdam, ISBN 90-5410552-6.

Roscoe, K.H. (1970).

The influence of strains in soil mechanics. Géotechnique, volume 20, no 2, pp. $132-141$.

Rothenburg, L. and Bathurtst, R.J. (1992).

Micromechanical features of granular assemblies with planar elliptical particles. Géotechnique, volume 42, no. 1, pp. 79-95.

Stroeven, P. (1973).

Some aspects of the micromechanics of concrete. Dissertation, University of Technology Delft, February 21st 1973, pp. 156-165.

Thallak, S. (1992).

Particulate mechanics simulation of borehole stability in unconsolidated media. In Situ, volume 16, no. 3, pp. 203-227.

Ting, T.M. (1989).

Discrete numerical model for soil mechanics. Journal of Geotechnical Engineering, volume 115, no. 3, March 1989, p. 381.

Yamamuro, J.A. et all. (1996).

One-dimensional compression of sands at high pressures. Journal of Geotechnical Engineering, volume 122, no. 2, ASCE, ISSN 0733-9410, February 1996, pp. 147-154.

Zheng, Z. et all. (1989).

Analysis of borehole breakouts, Journal of Geophysical Research, volume 94, no. B6, June 10th 1989, pp. 7171-7182. 


\section{APPENDIX}

1. SYMBOL LIST 94

2. HERTZIAN CONTACT 96

3. DISCRETE ELEMENT BOOK-KEEPING 97

4. GRAIN SIZE DISTRIBUTION 99

5. TWO-DIMENSIONAL CONTINUUM MODEL 101

5.1. Stress-strain relation $\quad 101$

5.2. Characteristic tests 103

5.3. Double sliding 106

6. MICRO-MACRO RELATION 109

6.1. Stress 109

6.2. Strain 110

7. BIAXIAL TEST: ANALYTICAL 112

7.1. Normal and shear forces 112

7.2. Elastic behaviour of cohesive materials $\quad 116$

7.3. Elastic behaviour of non-cohesive materials 119

7.4. Failure of cohesive materials $\quad 120$

8. CYLINDER TEST: ANALYTICAL 122

9. CRYSTAL: ANALYTICAL 126 


\section{Symbol list}

$$
\begin{aligned}
& D: \text { Depth of structure } \quad=\bar{d}=2 \bar{r} \\
& E \quad \text { : Young's modulus } \\
& F \text { : Force } \\
& G \quad \text { : Shear modulus } \\
& H \text { : Height of structure } \\
& O \text { : Surface of structure } \\
& P \text { : Pressure } \\
& \text { R.D.: Relative density } \quad=\frac{e_{\max }-e}{e_{\max }-e_{\min }} \quad \text { in which: } e=\frac{V_{\text {pores }}}{V_{\text {grains }}} \\
& V \quad \text { : Volume of structure } \\
& W \quad \text { : Width of structure } \\
& \text { c : } \operatorname{Cos}(\alpha) \\
& c^{\prime}: \text { Cohesion } \\
& d \text { : Distance between centres of two grains } \\
& e \text { : Total volumic strain }=\varepsilon_{\text {tot }} \\
& f_{g g}: \text { Friction between two grains }=\tan \left(\phi_{\mu}\right) \\
& f_{g w}: \text { Friction between grain and wall } \\
& k \text { : Contact stiffness, spring constant } \\
& n \text { : Normal displacement } \\
& n_{c}: \text { Number of contacts } \\
& n_{g}: \text { Number of grains } \\
& n_{c / g} \text { : Number of contacts per grain } \\
& n_{c / v}: \text { Number of contacts per micro volume }\left(\bar{d}^{3}\right) \\
& n_{i} \text { : Number of iteration per load step } \\
& n_{v}: \text { Number of micro volumes per total volume }=V / \bar{d}^{3} \\
& r \quad \text { : Radius of grain } \\
& s \quad: \operatorname{Sin}(\alpha) \\
& s_{h}: \text { Shear displacement } \\
& u \text { : Displacement }
\end{aligned}
$$


$\alpha$ : Angle between contact and $\mathrm{x}$-axis

$\beta$ : Angle between major principal direction and $\mathrm{x}$-axis

$\gamma:$ Angle deformation or rotation

$\varepsilon \quad:$ Strain

$\kappa_{v}:$ Ratio between stiffness in normal and shear direction

$v \quad:$ Poisson's ratio

$\sigma:$ Stress

$\phi^{\prime} \quad$ : Angle of internal friction

$\psi \quad$ : Angle of dilatancy

$x_{n}:$ In normal direction

$x_{s}:$ In shear direction

$x_{x x}:$ In horizontal direction

$x_{y y}:$ In vertical direction

$x_{r r}:$ In radial direction

$x_{t t}:$ In tangential direction

$x_{t o t}:$ In total

$x_{0}:$ Average value, so: $=\frac{x_{1}+x_{3}}{2}$

$\times_{1}$ : In major principal direction, often: $\times_{y y}$

$x_{3}$ : In minor principal direction, often: $x_{x x}$

$x_{\mu}$ : Of grain material itself, not whole structure

$\bar{x} \quad$ : Average value or expectation value

$\dot{x}$ : Derivative value

$x_{I}$ : During first phase (i.e. isotropic compression)

$x_{I I}$ : During second phase (e.g. biaxial test)

$x_{e}$ : During elastic phase

$\times_{p}$ : During plastic phase 


\section{Hertzian contact}

To verify the contact equation by Hertz, a compression test was done on a ball of hard polystyrene foam with a radius of $r=74.6 \mathrm{~mm}$. The elasticity parameters are measured with a triaxial test $\left(\sigma_{3}=0\right)$ on a cube of the same material:

$$
\begin{aligned}
E_{\text {virgin }} & =7.59 \mathrm{MPa} \\
E_{\text {non-virgin }} & =9.21 \mathrm{MPa} \\
v & =0.22
\end{aligned}
$$

The Young's moduli remain very constant during the test. The figure below shows that the prediction of non-virgin compression by Hertz is about $30 \%$ too high all the time, but the shape of the non-linear behaviour is correct.

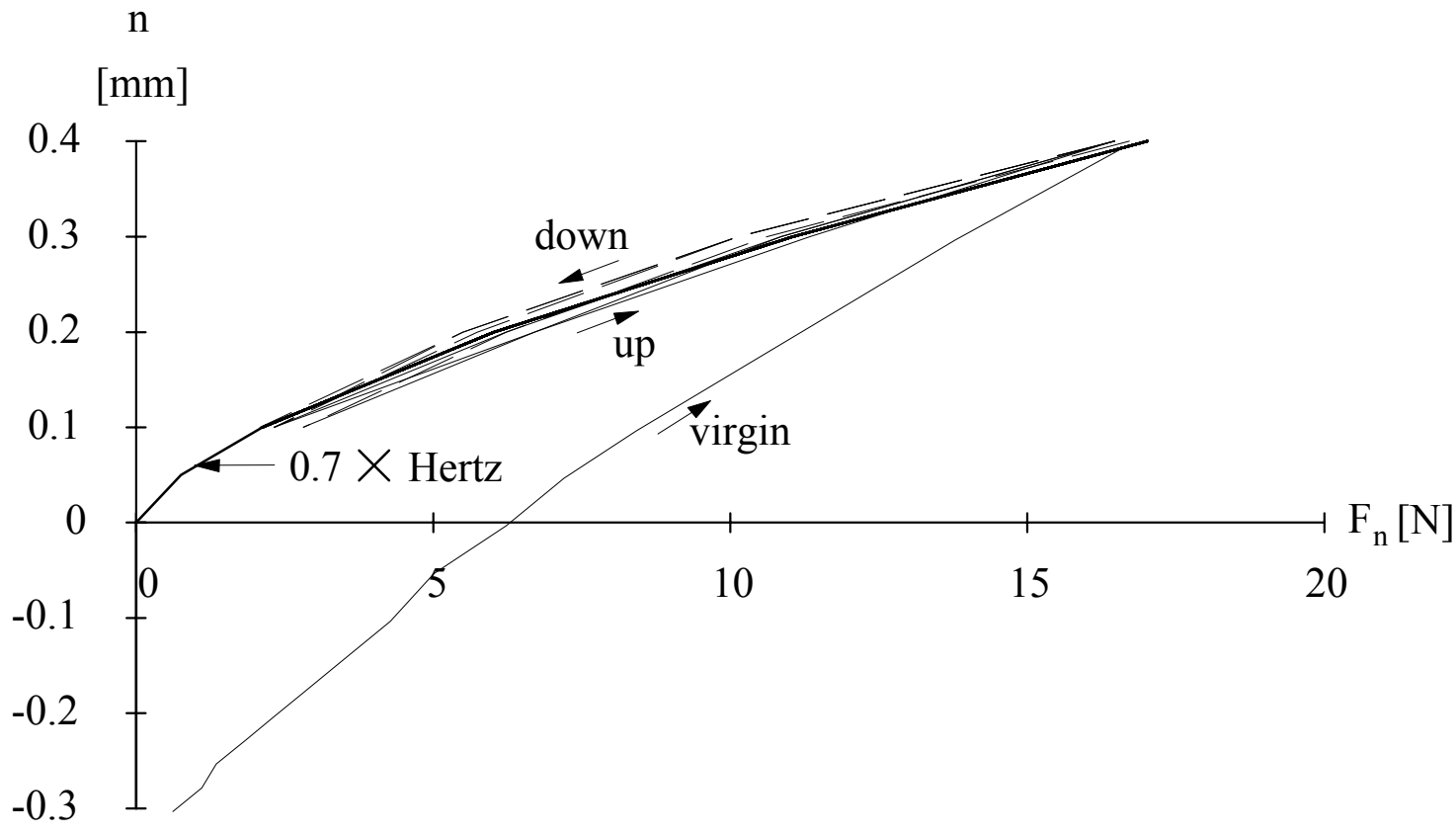

Figure A.1. Hertzian contact relation of a polystyrene ball 


\section{Discrete element book-keeping}

A complex part of discrete element modelling is the book-keeping of all grains, walls, contact numbers and their corresponding data. During simulation of a granular material new contacts can be made and other contacts can be lost, what leads to continuous updating of all information. The method which is used in Grain will be explained here.

In general there are two types of arrays: one for the contact information and another for the grain and wall information. In the contact arrays the state of the contact (off, shear, non-cohesive or cohesive), the numbers $n_{\text {low }}$ and $n_{\text {high }}$ of both grains on both sides of the contact, the forces $F_{n}$ and $F_{s}$ and the shear deformation $s_{h}$ are stored. For instance the array of contact number 3 in figure A.2. will be:

\begin{tabular}{||c|c|c|c|c|c|c||}
\hline \hline contact & state & $n_{\text {low }}$ & $n_{\text {high }}$ & $F_{n}$ & $F_{s}$ & $s_{h}$ \\
\hline 3 & shear & -1 & 3 & $+\ldots$ & $+/-\ldots$ & $+/-\ldots$ \\
\hline
\end{tabular}

Table A.1 Information on contact 3
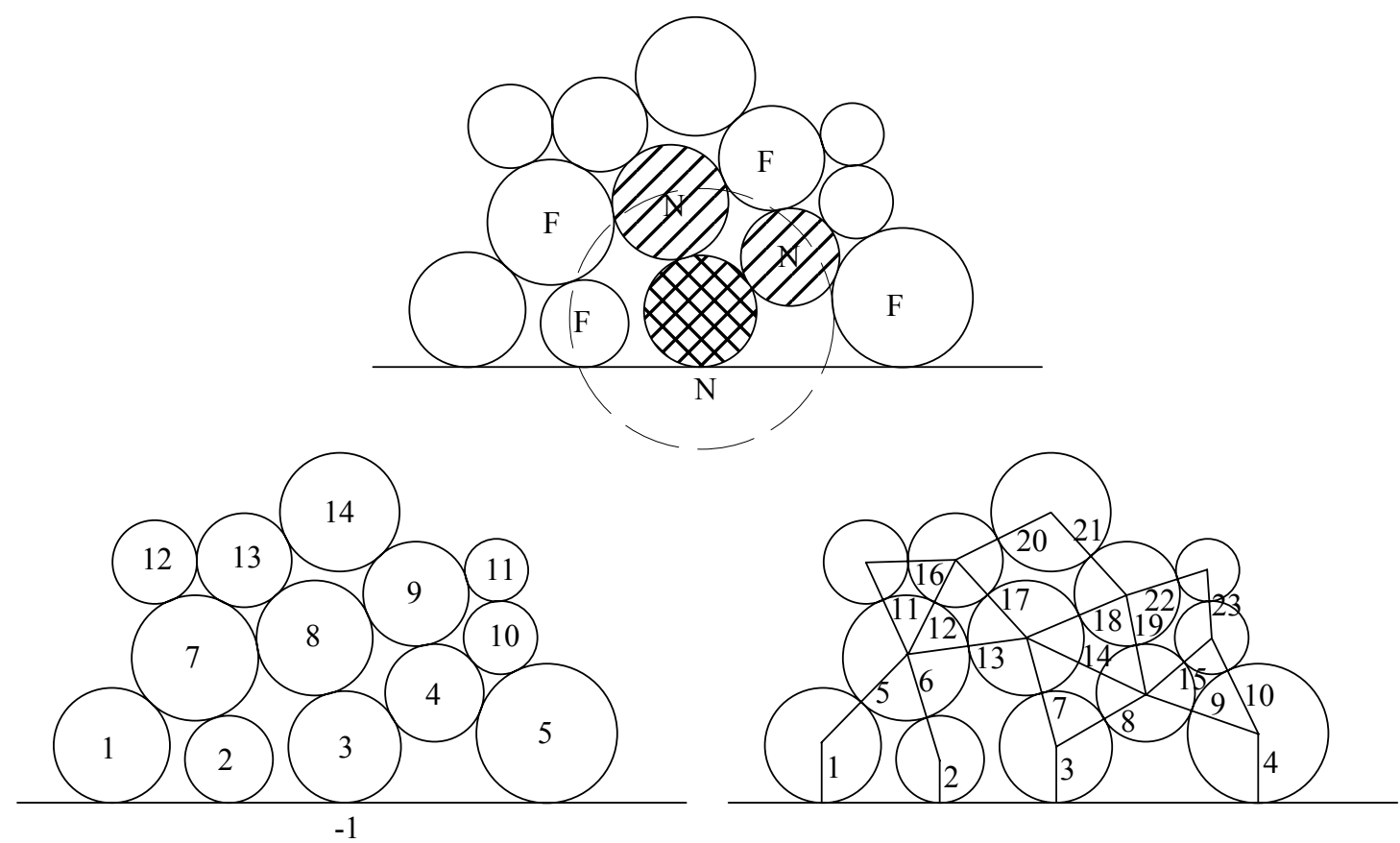

Neighbours and Friends

Grain numbers Contact numbers

Figure A.2. 
The grain and wall arrays contain two parts. In the first part, the data of the grain itself are stored: the present position co-ordinates $x, y, \phi$ and size $r$ of the grain, the position $x_{0}, y_{0}$ of the grain, when the last friends backup $(\mathrm{F})$ has been made. The second part contains the contact numbers towards the neighbour grains $(\mathrm{N})$ and the friend grains which are the grains nearby but not connected $(F)$ to this grain. For grain 3 this last part will be:

\begin{tabular}{|c|c|c|c|c|c|c||}
\hline neighbours & 3 & 7 & 8 & & & $n_{c}=3$ \\
\hline friends & 2 & 7 & 9 & 5 & & $n_{f}=4$ \\
\hline
\end{tabular}

Table A.2 Information on grain 3

Notice that for the neighbours, not the neighbour numbers are registered, but the number of contacts between the grain and its neighbour. In this way, the contact data can be found. When a contact is broken, the contact number must be removed from the arrays of the grain and its neighbour and both grain numbers must be placed in each other's friend arrays. Only the neighbours have to be checked for contact breaking and the friends for contact making. The friend array will be updated in the procedure check village when a grain moves too far away from its original position $x_{0}, y_{0}$.

The advantage of this method is that only the necessary data is stored and the contact checking is minimal. 


\section{Grain size distribution}

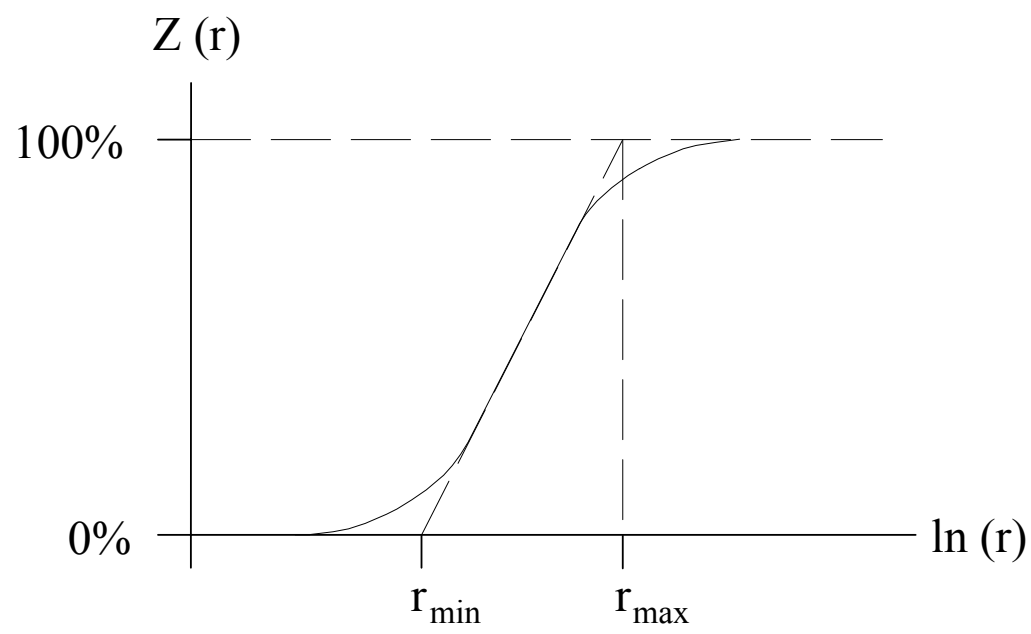

Figure A.3. Sieve curve

In theory an infinite number of grain size distributions can be made, however for most sands the sieve curves show a rather straight line:

$$
\begin{aligned}
& Z(r)=\frac{\text { weight of grains } \leq r}{\text { weight of all grains }} \\
& Z(r) \approx c_{1}+c_{2} \ln (r) \text { for } \quad r_{\min } \leq r \leq r_{\text {max }}
\end{aligned}
$$

The weight of a grain can be described by:

$$
w=c_{3} r^{3}
$$

Therefore the probability density function for these sands will be:

$$
f=\frac{r_{\max }^{3} r_{\min }^{3}}{r_{\max }^{3}-r_{\min }^{3}} \frac{3}{r^{4}} \quad \text { for } \quad r_{\min } \leq r \leq r_{\max }
$$

The corresponding grain size distribution can be described with a random generator:

$$
r=\left[\frac{1}{r_{\min }^{3}}-\left(\frac{r_{\max }^{3}-r_{\min }^{3}}{r_{\max }^{3} r_{\min }^{3}}\right) \tilde{x}\right]^{-3} \quad \text { with } \quad \tilde{x}=\operatorname{random}[0 . .1]
$$

This distribution is specified by only two parameters, such as the minimum $r_{\text {min }}$ and maximum $r_{\max }$ grain size or the grain size ratio $M$ and the average grain size $\bar{r}$ :

$$
\begin{aligned}
M & =\frac{r_{\max }}{r_{\min }} \\
\bar{r} & =r_{\max } \frac{3\left(M^{2}-1\right)}{2\left(M^{3}-1\right)}
\end{aligned}
$$

The average grain size is not necessarily equal to the mean grain size: 


$$
\frac{\bar{r}}{r_{50}}=\frac{M+1}{2 \sqrt{M}}
$$

Beside this exponential distribution "Type A", also a linear distribution "Type B" is used:

$$
r=r_{\min }+\left(r_{\max }-r_{\min }\right) \tilde{x} \quad \text { with } \quad \tilde{x}=\operatorname{random}[0 . .1]
$$

This distribution is also specified by the grain size ratio $M$ and the average grain size $\bar{r}$ :

$$
\begin{aligned}
M & =\frac{r_{\text {max }}}{r_{\text {min }}} \\
\bar{r} & =r_{\min } \frac{M+1}{2}
\end{aligned}
$$




\section{Two-dimensional continuum model}

\subsection{Stress-strain relation}

For comparison of the numerical results obtained with a continuum model, the advanced Mohr-Coulomb model was chosen. The two-dimensional stress-strain definitions are a little bit different from the three-dimensional definitions, simply because there is no third dimension $\left(v_{z z}=0\right)$. Therefore the law of Hooke will become:

$$
\left[\begin{array}{l}
\dot{\varepsilon}_{x x} \\
\dot{\varepsilon}_{y y} \\
\dot{\varepsilon}_{x y}
\end{array}\right]=\frac{1}{E}\left[\begin{array}{ccc}
1 & -v & 0 \\
-v & 1 & 0 \\
0 & 0 & 1+v
\end{array}\right]\left[\begin{array}{l}
\dot{\sigma}_{x x} \\
\dot{\sigma}_{y y} \\
\dot{\sigma}_{x y}
\end{array}\right]
$$

(The dot above the symbol implies the material time derivative.)

This means that during the elastic phase the Mohr circle for the strains has the same shape as the one for the stresses, although its size is $\frac{1+v}{E}$ times larger and the distance to the centre is multiplied by a factor $\frac{1-v}{E}$.

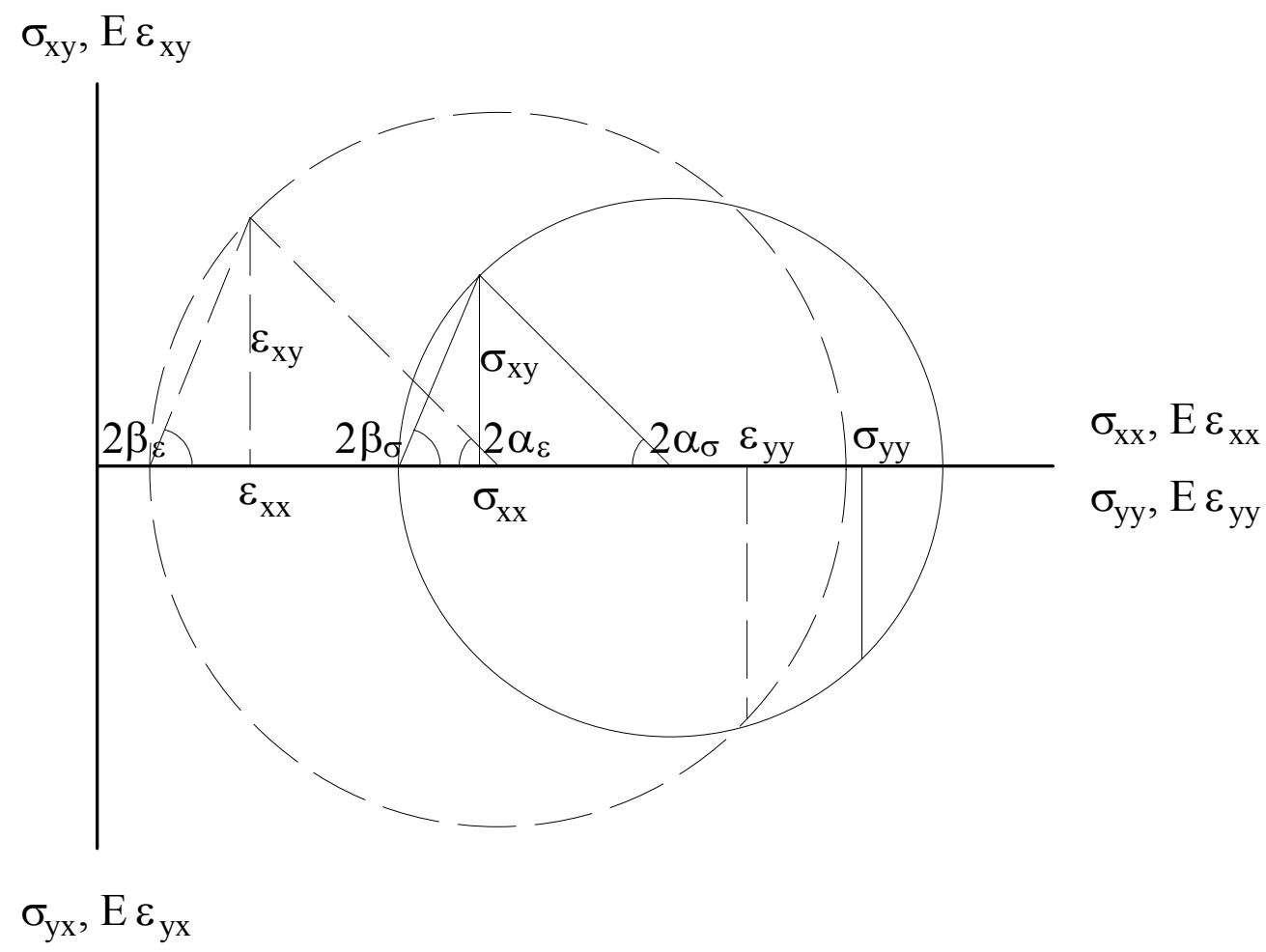

Figure A.4. stresses and strains during the elastic phase 
The stresses can be described by:

$$
\begin{aligned}
& \sigma_{x x}=\frac{1}{2}\left(\sigma_{1}+\sigma_{3}\right)-\frac{1}{2}\left(\sigma_{1}-\sigma_{3}\right) \cos (2 \alpha) \\
& \sigma_{y y}=\frac{1}{2}\left(\sigma_{1}+\sigma_{3}\right)+\frac{1}{2}\left(\sigma_{1}-\sigma_{3}\right) \cos (2 \alpha) \\
& \sigma_{x y}=\frac{1}{2}\left(\sigma_{1}-\sigma_{3}\right) \sin (2 \alpha)
\end{aligned}
$$

The strains can be described in a similar way, thus:

$$
\begin{aligned}
\frac{2 \varepsilon_{x y}}{\varepsilon_{y y}-\varepsilon_{x x}} & =\frac{2 \dot{\varepsilon}_{x y}}{\dot{\varepsilon}_{y y}-\dot{\varepsilon}_{x x}}=\tan \left(2 \alpha_{\varepsilon}\right) \\
& =\frac{2 \sigma_{x y}}{\sigma_{y y}-\sigma_{x x}}=\frac{2 \dot{\sigma}_{x y}}{\dot{\sigma}_{y y}-\dot{\sigma}_{x x}}=\tan \left(2 \alpha_{\sigma}\right)
\end{aligned}
$$

During the elastic phase the principal directions for the (incremental) stresses and for the (incremental) strains are equal which is called coaxiality:

$$
\alpha_{\sigma}=\alpha_{\varepsilon} \text { so: } \alpha_{\dot{\sigma}}=\alpha_{\dot{\varepsilon}} \text { or: } \beta_{\dot{\sigma}}=\beta_{\dot{\varepsilon}}
$$

Failure occurs according to Coulomb:

$$
\sin \phi^{\prime}\left(\sigma_{1}+\sigma_{3}\right)+2 c^{\prime} \cos \phi^{\prime}=\left(\sigma_{1}-\sigma_{3}\right)
$$

At failure of a non-cohesive granular material, the major principal direction will be:

$$
\cos (2 \beta)=\frac{-1}{\sin (\phi)} \frac{\left(\sigma_{y y}-\sigma_{x x}\right)}{\left(\sigma_{y y}+\sigma_{x x}\right)}
$$

During the plastic phase the increments of the strains can be described by:

$$
\begin{aligned}
& \dot{\varepsilon}_{x x}=\frac{1}{2} \dot{\varepsilon}_{1}\left[(1-\mu)-\frac{1}{2}(1+\mu)\right] \cos (2 \alpha) \\
& \dot{\varepsilon}_{y y}=\frac{1}{2} \dot{\varepsilon}_{1}\left[(1-\mu)+\frac{1}{2}(1+\mu)\right] \cos (2 \alpha) \\
& \dot{\varepsilon}_{x y}=\frac{1}{2} \dot{\varepsilon}_{1}(1+\mu) \sin (2 \alpha)
\end{aligned}
$$

in which:

$$
\mu=-\left[\frac{\dot{\varepsilon}_{3}}{\dot{\varepsilon}_{1}}\right]_{p}=\frac{1+\sin (\psi)}{1-\sin (\psi)}
$$

because:

$$
\sin (\psi)=\frac{\dot{\varepsilon}_{3}+\dot{\varepsilon}_{1}}{\dot{\varepsilon}_{3}-\dot{\varepsilon}_{1}}
$$

If the increments of the stresses $\dot{\sigma}$ are zero and the plastic deformation remains coaxial $\left(\beta_{\sigma}=\beta_{\dot{\varepsilon}}\right)$ throughout the plastic phase, like this:

$$
\frac{2 \sigma_{x y}}{\sigma_{y y}-\sigma_{x x}}=\frac{2 \dot{\varepsilon}_{x y}}{\dot{\varepsilon}_{y y}-\dot{\varepsilon}_{x x}}=\tan (2 \alpha)
$$

then the plastic deformations are defined by:

$$
\frac{\dot{\varepsilon}_{x x}}{\dot{\varepsilon}_{y y}}=\frac{\sin (\psi)+\cos (2 \alpha)}{\sin (\psi)-\cos (2 \alpha)} \text { and } \quad \frac{\dot{\varepsilon}_{y y}}{\dot{\varepsilon}_{x y}}=\frac{\sin (\psi)-\cos (2 \alpha)}{-\sin (2 \alpha)}
$$




\subsection{Characteristic tests}

For the confined biaxial test, unconfined biaxial test and the compression test, the orientations of the principal stresses are equal to the $\mathrm{x}$ - and $\mathrm{y}$-axis:

$$
\begin{aligned}
& \times_{1}=\times_{y y} \\
& \times_{3}=\times_{x x}
\end{aligned}
$$

The elasticity parameters can be obtained from the confined or unconfined biaxial test $\left(\dot{\sigma}_{3}=0\right)$ during the elastic phase, as follows:

$$
\begin{aligned}
E & =\frac{\dot{\sigma}_{1}}{\dot{\varepsilon}_{1}} \\
v & =-\frac{\dot{\varepsilon}_{3}}{\dot{\varepsilon}_{1}} \\
& =1-\frac{\dot{\varepsilon}_{t o t}}{\dot{\varepsilon}_{1}}
\end{aligned}
$$

in which:

$$
\dot{\varepsilon}_{\text {tot }}=\dot{\varepsilon}_{1}+\dot{\varepsilon}_{3}
$$
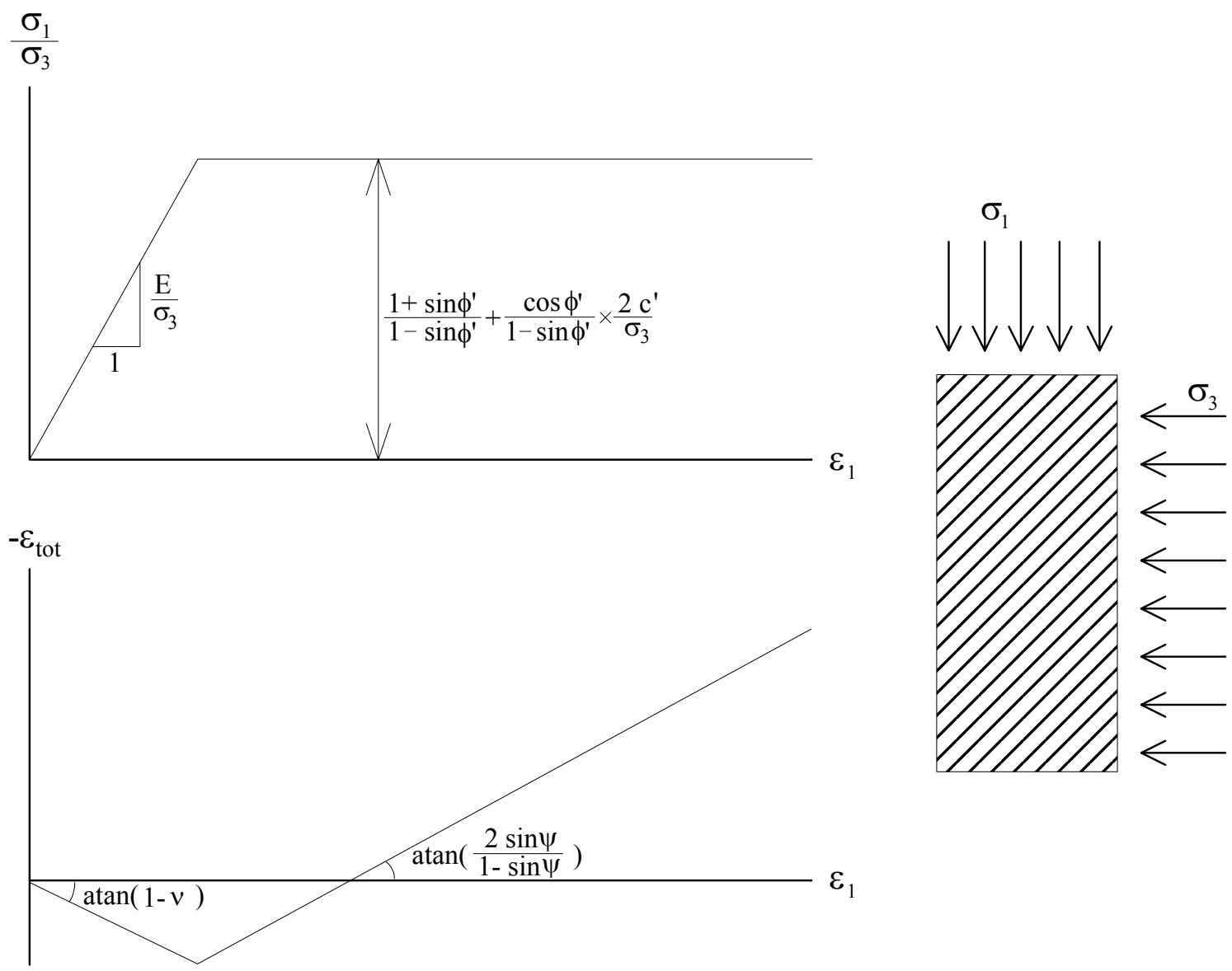

Figure A.5. bi-linear idealisation of a 2-D biaxial test 
In the case of non-cohesive granular materials we also know for the plastic phase that:

$$
\begin{aligned}
\sin \left(\phi^{\prime}\right) & =\frac{\frac{\sigma_{1}}{\sigma_{3}}-1}{\frac{\sigma_{1}}{\sigma_{3}}+1} \\
& =\frac{\sigma_{1}-\sigma_{3}}{\sigma_{1}+\sigma_{3}} \\
\sin (\psi) & =\frac{\dot{\varepsilon}_{\text {tot }}}{\dot{\varepsilon}_{\text {tot }}-2 \dot{\varepsilon}_{1}}
\end{aligned}
$$

The compression test $\left(\dot{\varepsilon}_{3}=0\right)$ remains elastic:

$$
\begin{aligned}
& E=\left(1-v^{2}\right) \frac{\dot{\sigma}_{1}}{\dot{\varepsilon}_{1}} \\
& v=\frac{\dot{\sigma}_{3}}{\dot{\sigma}_{1}}
\end{aligned}
$$

For non-cohesive granular materials the Young's modulus depends on the stress:

$$
E=E_{r e f}\left(\frac{\sigma_{0}}{\sigma_{r e f}}\right)^{\beta}
$$

in which:

$$
\sigma_{0}=\frac{\sigma_{y y}+\sigma_{x x}}{2}
$$

The simple shear test $\left(\dot{\sigma}_{x x}=0\right)$ can be solved with the same parameters:

$$
\begin{aligned}
\tau=G \gamma & \\
\sin \left(\phi^{\prime}\right) & =\frac{\sqrt{\left(\sigma_{y y}-\sigma_{x x}\right)^{2}+4 \tau^{2}}}{\left(\sigma_{y y}+\sigma_{x x}\right)} \\
& =\frac{\tau}{\sigma} \quad \text { if: } \quad \sigma_{y y}=\sigma_{x x}
\end{aligned}
$$

in which:

$$
\begin{aligned}
& G=\frac{E}{2(1+v)} \\
& \gamma=2 \varepsilon_{x y}
\end{aligned}
$$

The true simple shear test $\left(\dot{\varepsilon}_{x x}=0\right)$ is more complicated because the horizontal stress increases during failure. The nine unknown components of the stress, elastic strain and plastic strain $\left(\dot{\vec{\sigma}}, \dot{\vec{\varepsilon}}_{e}\right.$ and $\left.\dot{\vec{\varepsilon}}_{p}\right)$ can be solved with the three elastic equations (A.9), the three test equations: 


$$
\begin{aligned}
\dot{\sigma}_{y y} & =0 \\
\dot{\gamma} & =2\left(\dot{\varepsilon}_{x y, e}+\dot{\varepsilon}_{x y, p}\right) \\
\dot{\varepsilon}_{x x, e}+\dot{\varepsilon}_{x x, p} & =0
\end{aligned}
$$

and the three plastic equations A.13, A.16 and A.15 (Coulomb, coaxiality and dilatancy), in this case:

$$
\begin{aligned}
\dot{\sigma}_{x y} & =D \dot{\sigma}_{x x} \\
\dot{\varepsilon}_{x y, p} & =\frac{F}{2}\left(\dot{\varepsilon}_{y y, p}-\dot{\varepsilon}_{x x, p}\right) \\
\dot{\varepsilon}_{x x, p} & =\frac{J+1}{J-1} \dot{\varepsilon}_{y y, p}
\end{aligned}
$$

in which:

$$
\begin{aligned}
D & =\frac{\sigma_{y y}\left(1+\sin ^{2}\left(\phi^{\prime}\right)\right)-\sigma_{x x}\left(1-\sin ^{2}\left(\phi^{\prime}\right)\right)}{4 \sigma_{x y}} \\
F & =\frac{2 \sigma_{x y}}{\sigma_{y y}-\sigma_{x x}} \\
J & =+\sin (\psi) \sqrt{1+F^{2}} \quad \text { if } \quad \sigma_{y y}>\sigma_{x x} \\
& =-\sin (\psi) \sqrt{1+F^{2}} \quad \text { if } \quad \sigma_{y y}<\sigma_{x x}
\end{aligned}
$$

Which gives us the incremental stresses and strains of the true simple shear test:

$$
\frac{\dot{\varepsilon}_{y y, p}}{\dot{\sigma}_{x y}}=\frac{1}{E D}\left(\frac{1+\sin ^{2}(\psi)+2 F}{1-\sin ^{2}(\psi)-2 F}\right)
$$

and:

$$
\begin{aligned}
& \frac{\dot{\gamma}}{\dot{\sigma}_{x y}}=\frac{2(1+v)}{E}+F\left(\frac{\dot{\varepsilon}_{y y, p}}{\dot{\sigma}_{x y}}+\frac{1}{E D}\right) \\
& \frac{\dot{\varepsilon}_{y y}}{\dot{\sigma}_{x y}}=-\frac{v}{E D}+\frac{\dot{\varepsilon}_{y y, p}}{\dot{\sigma}_{x y}} \\
& \frac{\dot{\sigma}_{x x}}{\dot{\sigma}_{x y}}=\frac{1}{D}
\end{aligned}
$$




\subsection{Double sliding}

The plastic deformation of several soil models is based on sliding. Sliding means essentially that the stresses and therefore also the shapes of the sliding parts remain constant. So, there will be no total volume change, or with other words the dilatancy is zero.

If failure of a soil occurs by shear sliding, then there are, because of symmetry, two directions in which the maximum shear stress is reached. This idea led to the double sliding model proposed in 1959 by De Josselin de Jong. In figure A.6. only the left failure surfaces (type A) are shown.

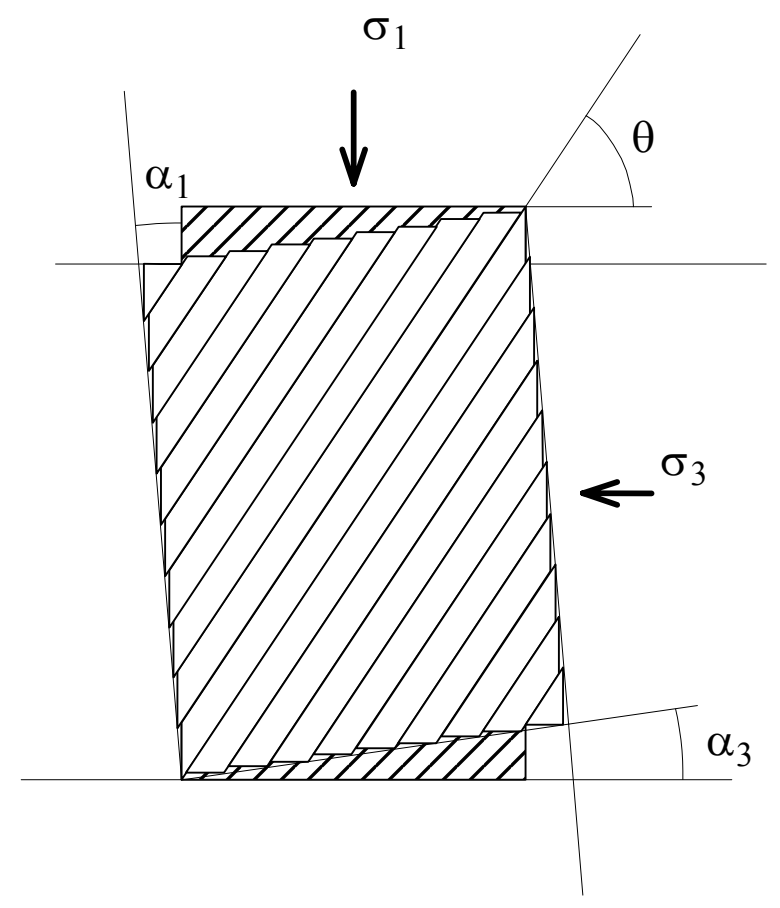

Figure A.6. Sliding causes an axial and lateral rotation

In the same way also a right sliding (type B) can occur. If both the left and the right slidings cause a same amount of deformation $(a=b)$ then the axial rotation and the lateral rotation will be zero:

$$
\text { if } \quad a=b \text { then } \quad \alpha_{1}=\alpha_{3}=0
$$

Figure A.7. shows such a double sliding failure in a simple shear test. To meet the boundary conditions, the sample requires a free rotation of:

$$
\alpha_{\text {free }}=\frac{1}{2} \gamma
$$

In case of equal double sliding, the principal directions of the incremental strains and the principal directions of the stresses are identical $\left(\beta_{\sigma}=\beta_{\dot{\varepsilon}}\right)$. This is called coaxiality. 


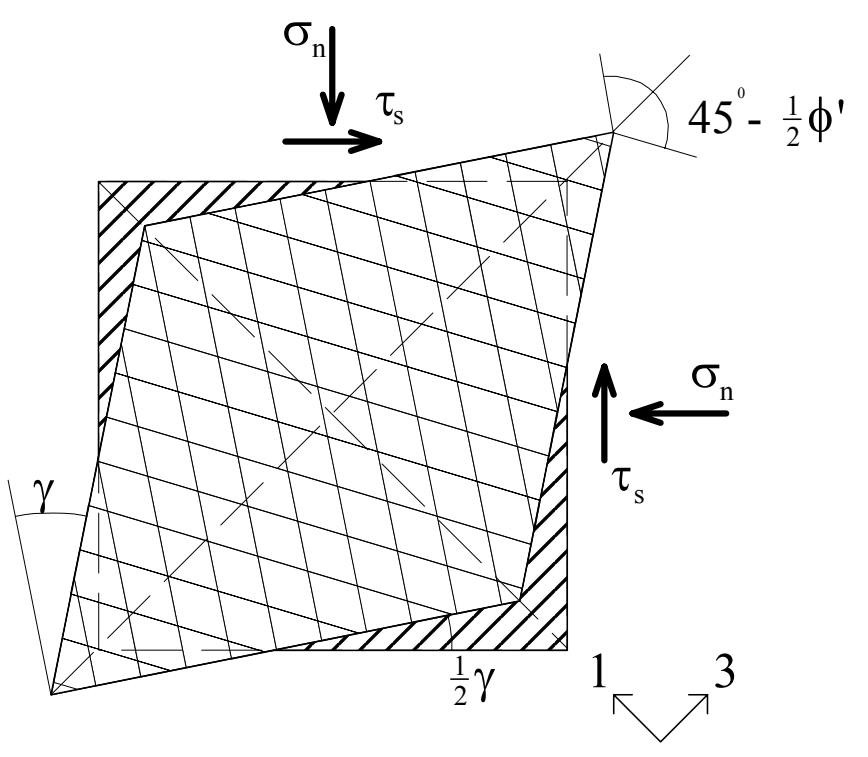

Figure A. 7. Simple shear test according to Mohr-Coulomb

De Josselin de Jong (1971) also published his idea to allow the two deformations to be unequal, so:

$$
a \neq b
$$

in which:

$$
\begin{aligned}
& a \geq 0 \\
& b \geq 0
\end{aligned}
$$

The rotation of the axial direction (figure A.8.), caused by the left sliding, is then:

$$
\begin{aligned}
\tan \left(\alpha_{1}\right) & =\frac{(a-b) \cdot \cos ^{2}(\theta)}{1-(a-b) \cdot \sin (\theta) \cdot \cos (\theta)} \\
& \approx(a-b) \cdot \cos ^{2}(\theta)
\end{aligned}
$$

and the rotation of the lateral direction, caused by the left sliding, will be:

$$
\begin{aligned}
\tan \left(\alpha_{3}\right) & =\frac{(a-b) \cdot \sin ^{2}(\theta)}{1+(a-b) \cdot \sin (\theta) \cdot \cos (\theta)} \\
& \approx(a-b) \cdot \sin ^{2}(\theta)
\end{aligned}
$$

These two rotations are not the same, which cannot be corrected with a free rotation. This means for an unequal double sliding that the plastic deformations are not coaxial.

With a deformation of:

$$
\begin{aligned}
& \varepsilon_{11}=(a+b) \sin (\theta) \cos (\theta) \\
& \varepsilon_{33}=-(a+b) \sin (\theta) \cos (\theta) \\
& \varepsilon_{13}=\frac{(a-b)}{2}\left(\cos ^{2}(\theta)-\sin ^{2}(\theta)\right)
\end{aligned}
$$


and a shear band angle of:

$$
\theta=\frac{1}{4} \pi+\frac{1}{2} \phi
$$

the angle of non-coaxiality $i$ between the major principal directions of the stress and strain is defined by:

$$
\tan (2 i)=\frac{2 \varepsilon_{13}}{\varepsilon_{11}-\varepsilon_{33}}=-\frac{a-b}{a+b} \tan (\phi)
$$

So, there is a wide range of solutions:

$$
-\frac{1}{2} \phi \leq i \leq+\frac{1}{2} \phi
$$

which means for a sliding model there is not a uniqueness at collapse.

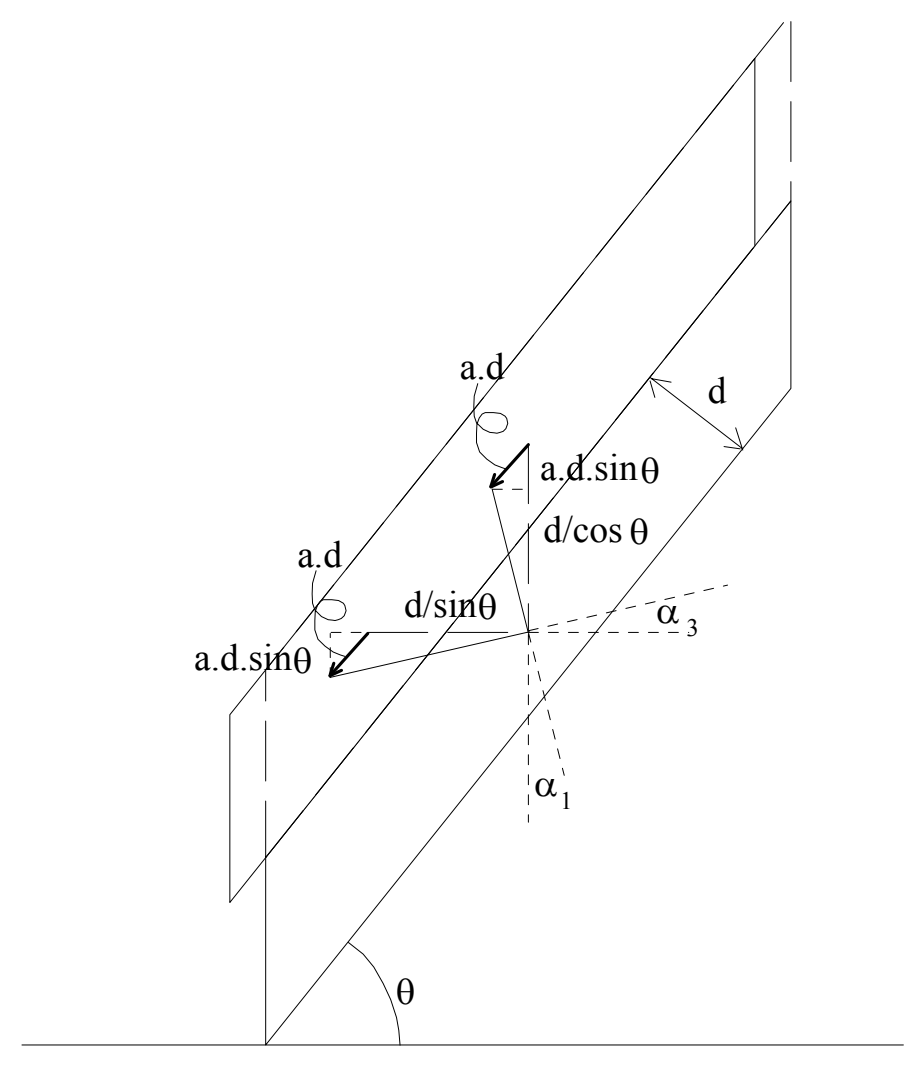

Figure A.8. Axial and lateral rotation 


\section{Micro-macro relation}

\subsection{Stress}

If a region with volume $V$ is considered, with an on microscopic level nonuniform stress state, $\sigma_{i j, \mu}$, which is in equilibrium, then the average stress $\sigma_{i j}$ is defined by:

$$
\sigma_{i j}=\frac{1}{V} \int_{V} \sigma_{i j, \mu} d V
$$

By using the Gauss's divergence theorem (Drescher and De Josselin de Jong, 1972), this can be written as:

$$
\sigma_{i j}=\frac{1}{V} \sum_{k=1}^{n_{g}} \sum_{l=1}^{n_{c l g}}\left(u_{i, k, l} F_{j, k, l}\right)
$$

in which:

$$
\begin{aligned}
n_{g} & =\text { number of grains } \\
n_{c / g} & =\text { number of contacts per grain } \\
u_{i, k, l} & =\mathrm{i} \text { - component of the } 1^{\text {th }} \text { contact vector of the } \mathrm{k}^{\text {th }} \text { grain } \\
F_{j, k, l} & =\mathrm{j} \text { - component of the } \mathrm{l}^{\text {th }} \text { contact force of the } \mathrm{k}^{\text {th }} \text { grain }
\end{aligned}
$$

The summation of the contact forces over all the contacts can be done at once:

$$
\sigma_{i j}=\frac{1}{V} \sum_{k=1}^{n_{c}}\left(d_{i} F_{j}\right)_{k}
$$

For a two-dimensional x-y field, this will give, for circular grains:

$$
\begin{aligned}
& \sigma_{x x}=\frac{1}{V} \sum_{k=1}^{n_{c}}\left(d\left[c^{2} F_{n}+s c F_{s}\right]\right)_{k} \\
& \sigma_{y y}=\frac{1}{V} \sum_{k=1}^{n_{c}}\left(d\left[s^{2} F_{n}-s c F_{s}\right]\right)_{k} \\
& \sigma_{x y}=\frac{1}{V} \sum_{k=1}^{n_{c}}\left(d\left[s c F_{n}-c^{2} F_{s}\right]\right)_{k} \\
& \sigma_{y x}=\frac{1}{V} \sum_{k=1}^{n_{c}}\left(d\left[s c F_{n}+s^{2} F_{s}\right]\right)_{k}
\end{aligned}
$$

in which:

$V=$ volume of a structure

$F_{n}=$ normal force

$F_{s}=$ shear force

and: 


$$
\begin{aligned}
s & =\sin (\alpha) \\
c & =\cos (\alpha) \\
d & =\text { distance between centres of two grains } \\
& =\text { lenght of a contact }
\end{aligned}
$$

After every iteration in Grain, the stresses are calculated in this way. It was found that these stresses are almost perfectly equal to the boundary stresses.

\subsection{Strain}

Since a relation has been found between the macro stresses and the micro forces $\left(\sigma_{i j} \Leftrightarrow F_{i j}\right)$ and a relation between the micro forces and the micro displacements $\left(F_{i j} \Leftrightarrow n_{i j}\right.$ ), only the relation between the micro displacements and the macro strains $\left(n_{i j} \Leftrightarrow \varepsilon_{i j}\right)$ has to be found to solve the relation between the macro stresses and the macro strains $\left(\sigma_{i j} \Leftrightarrow \varepsilon_{i j}\right)$. Therefore the micro-macro relation of the strains can be a key to the complete stress-strain relation.

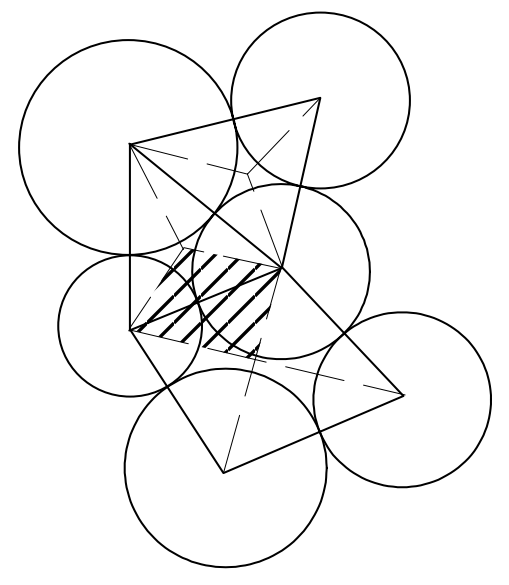

Two-dimensional grain structure

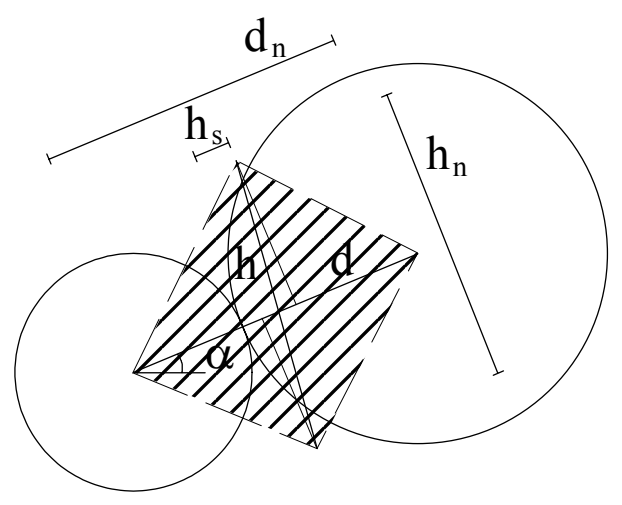

Diamond definitions

Figure A.9.

If a two-dimensional grain structure is considered, then the whole surface $O$ can be divided in diamonds with a surface:

$$
O_{k}=\frac{1}{2}\left(d h_{n}\right)_{k}
$$

So, the total surface of the grain structure will be:

$$
O=\sum_{k=1}^{n_{c}} O_{k}=\sum_{k=1}^{n_{c}} \frac{1}{2}\left(d h_{n}\right)_{k}
$$


With this, the macro strains can be written as:

$$
\varepsilon_{i j}=\frac{1}{O} \sum_{k=1}^{n_{c}} \frac{1}{2}\left(\delta d_{i} h_{j}+\delta d_{j} h_{i}+\delta h_{i} d_{j}+\delta h_{j} d_{i}\right)_{k}
$$

If the macro strains would only depend on $\delta d$, so $h$ is assumed to be constant $(\delta h=0)$, then the strains can be solved:

$$
\begin{gathered}
\varepsilon_{x x}=\frac{1}{O} \sum_{k=1}^{n_{c}} \frac{1}{2}\left(\delta d\left[h_{n} c^{2}\right]+\delta s_{h}\left[s c h_{n}+s^{2} h_{s}\right]\right)_{k} \\
\varepsilon_{y y}=\frac{1}{O} \sum_{k=1}^{n_{c}} \frac{1}{2}\left(\delta d\left[h_{n} s^{2}\right]+\delta s_{h}\left[-s c h_{n}+c^{2} h_{s}\right]\right)_{k}
\end{gathered}
$$

in which:

$O=$ surface of grain structure

$\delta d=n=$ normal displacement

$\delta s_{h}=$ shear displacement

This relation has been found by Kruyt (1994) as well:

$$
\varepsilon_{i j}=\frac{1}{O} \sum_{c \in O} \frac{1}{2}\left(\delta d_{i}^{c} h_{j}^{c}+\delta d_{j}^{c} h_{i}^{c}\right)
$$

The micro-macro relation for the strains seems to be found. But for a twodimensional isotropic compression test $\left(\delta s_{h}=0\right)$, it becomes clear that $h$ is not constant enough.

The total strain is defined as:

$$
\varepsilon_{t o t}=\varepsilon_{x x}+\varepsilon_{y y}
$$

The theory above will give for the isotropic compression test:

$$
\varepsilon_{\text {tot }}=\frac{1}{O} \sum_{k=1}^{n_{c}} \frac{1}{2}\left(\delta d h_{n}\right)_{k}
$$

although the correct answer is:

$$
\begin{aligned}
\varepsilon_{t o t} & =\frac{1}{O} \sum_{k=1}^{n_{c}} \frac{1}{2}\left(\delta d h_{n}+\delta h_{n} d\right)_{k} \\
& =\frac{1}{O} \sum_{k=1}^{n_{c}} \frac{1}{2}\left(\varepsilon d h_{n}+\varepsilon h_{n} d\right)_{k} \\
& =\frac{2}{O} \sum_{k=1}^{n_{c}} \frac{1}{2}\left(\delta d h_{n}\right)_{k}
\end{aligned}
$$

So, the error is $100 \%$. It has to be concluded that this solution was not correct because the influence of $\delta h$ was neglected. The problem is that $h$ does not only depend on the contact itself but also on the positions and therefore the deformations and the rotations of the surrounding grains. This means that the micro-macro relation for the strains is far more complex than the micro-macro relation for the stresses. 


\section{Biaxial test: analytical}

\subsection{Normal and shear forces}

During a biaxial test, the average normal force $\bar{F}_{n, \alpha}$ in a specific direction $\alpha$ in the first quadrant will, because of symmetry, be equal to the average forces of the other quadrants:

$$
\bar{F}_{n, \alpha}=\bar{F}_{n,(\pi-\alpha)}=\bar{F}_{n,(\pi+\alpha)}=\bar{F}_{n,(-\alpha)}
$$

The function

$$
\bar{F}_{n, \alpha}=\bar{F}_{n}\left(A c^{2}+B s^{2}\right)
$$

in which $A$ and $B$ are constants, holds this symmetry.

This is also the case for the shear force $\bar{F}_{s, \alpha}$, although the direction of the forces and so the sign changes per quadrant:

$$
\bar{F}_{s, \alpha}=-\bar{F}_{s,(\pi-\alpha)}=\bar{F}_{s,(\pi+\alpha)}=-\bar{F}_{s,(-\alpha)}
$$

The function bellow holds this description:

$$
\bar{F}_{s, \alpha}=\bar{F}_{s}(Q s c)
$$
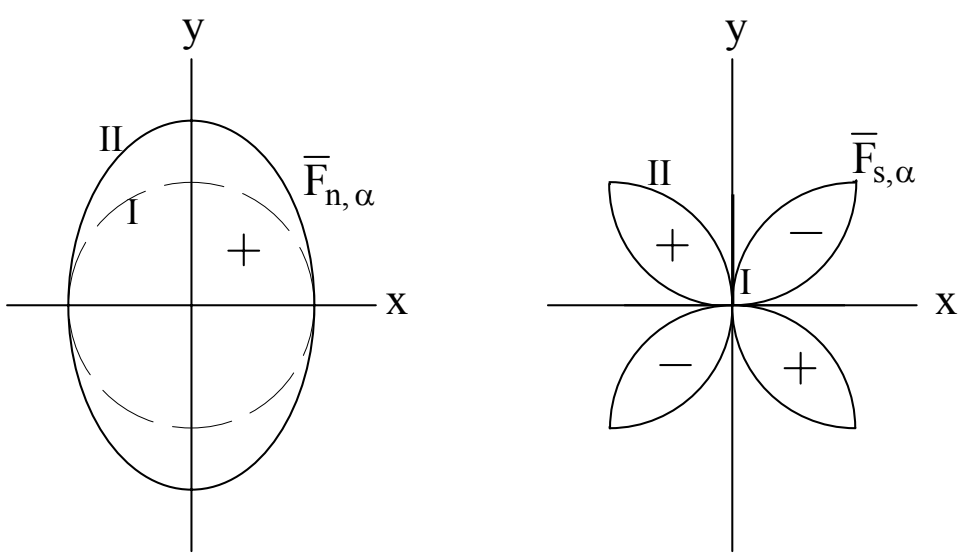

Figure A.10. Normal and shear force versus contact angle

During phase I, isotropic compression $\left(\sigma_{x x}=\sigma_{y y}\right)$, the shear forces are taken as zero $(Q=0)$ :

$$
\begin{aligned}
& \bar{F}_{n, \alpha}^{I}=\bar{F}_{n}^{I}\left(1 c^{2}+1 s^{2}\right) \\
& \bar{F}_{s, \alpha}^{I}=0
\end{aligned}
$$


During phase II, the loading phase, the forces can be described as:

$$
\begin{aligned}
& \bar{F}_{n, \alpha}^{I I}=\bar{F}_{n}^{I I}\left(A c^{2}+B s^{2}\right) \\
& \bar{F}_{s, \alpha}^{I I}=\bar{F}_{s}{ }^{I I}(Q s c)
\end{aligned}
$$

If $\bar{F}_{n}^{I I}$ is the average normal force then:

$$
A+B=2
$$

So the normal force can be expressed as:

$$
\bar{F}_{n, \alpha}^{I I}=\bar{F}_{n}^{I} x\left(A c^{2}+[2-A] s^{2}\right) \quad \text { with } x=\frac{\bar{F}_{n}^{I I}}{\bar{F}_{n}{ }^{I}}
$$

The alteration of this force is:

$$
\Delta \bar{F}_{n, \alpha}=\bar{F}_{n, \alpha}^{I I}-\bar{F}_{n, \alpha}^{I}=\bar{F}_{n, \alpha}^{I}\left([A x-1] c^{2}+[2 x-A x-1] s^{2}\right)
$$

Horizontal force equilibrium for a contact yields:

$$
\frac{\Delta \bar{F}_{s, \alpha}}{\Delta \bar{F}_{n, \alpha}}=-\frac{c}{S}
$$

which solves the shear force:

$$
\begin{aligned}
\bar{F}_{s, \alpha}^{I I} & =\delta \bar{F}_{s, \alpha}^{I I} \\
& =-\frac{c}{s} \delta \bar{F}_{n, \alpha}^{I I} \\
\bar{F}_{s, \alpha}^{I I} & =-\bar{F}_{n}^{I}\left([A x-1] \frac{c^{3}}{s}+[2 x-A x-1] c s\right)
\end{aligned}
$$

In the isotropic phase I, a certain average stress $\overline{\sigma_{0}}$ is expected:

$$
\begin{aligned}
\bar{\sigma}_{0} & =\frac{\bar{\sigma}_{x x}+\bar{\sigma}_{y y}}{2} \\
& =\frac{1}{2 V} \sum_{k=1}^{n_{c}}\left(d F_{n}\right)_{k} \\
& =\frac{1}{2 V} n_{c} \bar{d} \bar{F}_{n}^{I}
\end{aligned}
$$

The horizontal stress $\bar{\sigma}_{x x}$ and the vertical stress $\bar{\sigma}_{y y}$ are equal to the average stress $\bar{\sigma}_{0}$ :

$$
\bar{\sigma}_{x x}=\sigma_{3}=\bar{\sigma}_{y y}=\bar{\sigma}_{0}=\frac{1}{2 V} n_{c} \bar{d} \bar{F}_{n}^{I}
$$

So: $\quad \bar{F}_{n}^{I}=\frac{2 \sigma_{3} V}{n_{c} \bar{d}}$

The analytical relations of $\bar{F}_{n, \alpha}^{I I}$ and $\bar{F}_{s, \alpha}^{I I}$ have been found. These can be checked by probabilistic analysis. 
Table A.3. shows the expectation value $\bar{E}$ for several goniometric functions.

\begin{tabular}{||c|c|c|c|c||}
\hline $\bar{E}$ & 1 & 2 & 3 & 4 \\
\hline $1 / 2$ & $\overline{s^{2}}$ & $\overline{c^{2}}$ & & \\
\hline $3 / 8$ & $\overline{s^{4}}$ & $\overline{c^{4}}$ & & \\
\hline $1 / 8$ & $\overline{s^{2} c^{2}}$ & & & \\
\hline $1 / 16$ & $\overline{s^{2} c^{4}}$ & $\overline{s^{4} c^{2}}$ & & \\
\hline 0 & $\bar{s}$ & $\overline{s c^{3}}$ & $\overline{s^{3} c}$ & $\overline{s^{3} c^{3}}$ \\
\hline
\end{tabular}

Table A.3. Expectation values

If these are filled out in the relations of $\bar{F}_{n, \alpha}^{I I}$ and $\bar{F}_{s, \alpha}^{I I}$ mentioned in (A.42) and (A.43), the stresses are found:

$$
\begin{aligned}
\bar{\sigma}_{x x} & =\frac{1}{V} \sum_{k=1}^{n_{c}} d_{k}\left(c^{2} F_{n}+s c F_{s}\right)_{k} \\
& \left.=\frac{1}{V} \bar{d} n_{c} \bar{F}_{n}^{I} \overline{\left(\left\{x A c^{4}+x[2-A] c^{2} s^{2}\right\}+\left\{\left(-[A x-1] c^{4}-[2 x-A x-1] c^{2} s^{2}\right)\right\}\right.}\right) \\
& =2 \sigma_{3}\left(\left\{x A \frac{3}{8}+x[2-A] \frac{1}{8}\right\}+\left\{\left(-[A x-1] \frac{3}{8}-[2 x-A x-1] \frac{1}{8}\right)\right\}\right) \\
& =\sigma_{3}
\end{aligned}
$$

And in the same way:

$$
\begin{aligned}
& \bar{\sigma}_{y y}=\ldots=\sigma_{1} \\
& \bar{\sigma}_{x y}=\ldots . .=0 \\
& \bar{\sigma}_{y x}=\ldots . .=0
\end{aligned}
$$

As long as there is no correlation between $d, n_{c}$ and $\alpha$, the analytical solution for the biaxial test is correct. 
During the loading phase II of the biaxial test the lateral pressure $\sigma_{3}$ remains constant:

$$
\begin{aligned}
\bar{\sigma}_{0} & =\frac{\bar{\sigma}_{x x}+\bar{\sigma}_{y y}}{2} \\
& =\frac{1+\frac{\sigma_{1}}{\sigma_{3}}}{2} \sigma_{3} \\
& =\frac{1}{2 V} n_{c} \bar{d} \bar{F}_{n}^{I I} \\
\text { So: } x & =\frac{\overline{F_{n}^{I I}}}{\bar{F}_{n}^{I}}=\frac{1+\frac{\sigma_{1}}{\sigma_{3}}}{2}
\end{aligned}
$$

Due to symmetry, the part $[A x-1] \frac{c^{3}}{S}$ in $\bar{F}_{s, \alpha}^{I I}$ must be zero, so:

$$
A=\frac{1}{x}
$$

The average forces can now be simplified to:

$$
\begin{aligned}
& \bar{F}_{n, \alpha}^{I I}=\bar{F}_{n}^{I}\left(c^{2}+\frac{\sigma_{1}}{\sigma_{3}} s^{2}\right) \\
& \bar{F}_{s, \alpha}^{I I}=\bar{F}_{n}^{I}\left(1-\frac{\sigma_{1}}{\sigma_{3}}\right) c s
\end{aligned}
$$

in which:

$$
\bar{F}_{n}^{I}=\frac{2 \sigma_{3} V}{n_{c} \bar{d}}
$$




\subsection{Elastic behaviour of cohesive materials}

The average normal and shear forces were found to be:

$$
\begin{aligned}
& \bar{F}_{n, \alpha}^{I I}=\bar{F}_{n}^{I}\left(c^{2}+\frac{\sigma_{1}}{\sigma_{3}} s^{2}\right) \\
& \bar{F}_{s, \alpha}^{I I}=\bar{F}_{n}^{I}\left(1-\frac{\sigma_{1}}{\sigma_{3}}\right) c s
\end{aligned}
$$

The alterations of these forces since the isotropic compression are:

$$
\begin{aligned}
& \Delta \bar{F}_{n, \alpha}^{I I}=\bar{F}_{n}^{I}\left(\frac{\sigma_{1}}{\sigma_{3}}-1\right) s^{2} \\
& \Delta \bar{F}_{s, \alpha}^{I I}=-\bar{F}_{n}^{I}\left(\frac{\sigma_{1}}{\sigma_{3}}-1\right) s c
\end{aligned}
$$

So, the deformations will be:

$$
\begin{gathered}
\Delta n_{\alpha}=\frac{\Delta \bar{F}_{n, \alpha}^{I I}}{k_{n}}=\frac{\bar{F}_{n}^{I}}{k_{n}}\left(\frac{\sigma_{1}}{\sigma_{3}}-1\right) s^{2} \\
\Delta s_{h}=\frac{\Delta \bar{F}_{s, \alpha}^{I I}}{k_{s}}=-\frac{\bar{F}_{n}^{I}}{k_{n} \kappa_{v}}\left(\frac{\sigma_{1}}{\sigma_{3}}-1\right) s c
\end{gathered}
$$

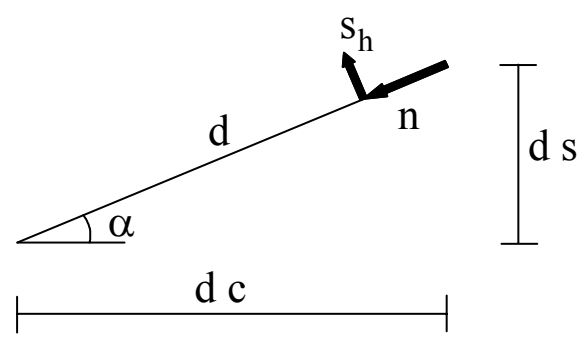

Figure A.11. Contact definitions

If the grains do not rotate, then the contact definitions will give us:

$$
\begin{array}{ll}
e_{y y}=d s & \Delta e_{y y}=s \Delta n-c \Delta s_{h} \\
e_{x x}=d c & \Delta e_{x x}=c \Delta n+s \Delta s_{h}
\end{array}
$$


With this, the strains can be solved as:

$$
\begin{aligned}
\Delta \varepsilon_{y y} & =\frac{1}{n_{c}} \sum_{i=1}^{n_{c}}\left(\frac{\Delta e_{y y}}{e_{y y}}\right) \\
& =\frac{1}{n_{c}} \sum_{i=1}^{n_{c}}\left(\frac{\Delta n-\frac{c}{s} \Delta s_{h}}{\bar{d}}\right) \\
& =\frac{\bar{F}_{n}^{I}}{\bar{d} k_{n}}\left(\frac{\sigma_{1}}{\sigma_{3}}-1\right) \frac{1}{n_{c}} \sum_{i=1}^{n_{c}}\left(\overline{s^{2}}+\frac{\overline{c^{2}}}{\kappa_{v}}\right) \\
& =\frac{2 V}{\bar{d} k_{n} n_{c} \bar{d} \frac{n_{c}}{n_{c}}}\left(\sigma_{1}-\sigma_{3}\right)\left(\frac{1}{2}+\frac{1}{2 \kappa_{v}}\right)
\end{aligned}
$$

which will give:

$$
\Delta \varepsilon_{y y}=\frac{V\left(1+\frac{1}{\kappa_{v}}\right)}{\bar{d}^{2} k_{n} n_{c}} \Delta \sigma_{1}
$$

And in the same way:

$$
\begin{aligned}
\Delta \varepsilon_{x x}= & \frac{1}{n_{c}} \sum_{i=1}^{n_{c}}\left(\frac{\Delta e_{x x}}{e_{x x}}\right)=\ldots \ldots . \\
= & \frac{V\left(1-\frac{1}{\kappa_{v}}\right)}{\bar{d}^{2} k_{n} n_{c}} \Delta \sigma_{1}
\end{aligned}
$$

In this way, it is demonstrated that cohesive granular materials can be described by a Young's modulus and a Poisson's ratio:

$$
\begin{aligned}
& E=\frac{\Delta \sigma_{y y}}{\Delta \varepsilon_{y y}}=k_{n} \frac{\bar{d}^{2} n_{c}}{V} \frac{\kappa_{v}}{\kappa_{v}+1} \\
& \nu=-\frac{\Delta \varepsilon_{x x}}{\Delta \varepsilon_{y y}}=-\frac{\kappa_{v}-1}{\kappa_{v}+1}
\end{aligned}
$$


Which can also be written as:

$$
\begin{aligned}
& E=k_{n} \frac{\bar{d}^{2} n_{c}}{V} \frac{3-3 v_{\mu}}{5-4 v_{\mu}} \\
& v=-\frac{1-2 v_{\mu}}{5-4 v_{\mu}}
\end{aligned}
$$

The elasticity is almost equal to the result of Bathurst and Rothenburg (1988):

$$
E=k_{n} \frac{\bar{d}^{2} n_{c}}{V} \zeta \quad \text { where } \quad 0<\zeta<1
$$

The number of contacts depends on the volume and the grain sizes, so it is better to rewrite this equation.

If $\delta V=\bar{d}^{3}$ and $n_{v}=\frac{V}{\delta V}$ and $n_{c / v}=\frac{n_{c}}{n_{v}}=\frac{\bar{d}^{3} n_{c}}{V}$

then:

$$
\begin{aligned}
E & =n_{c / v} \frac{k_{n}}{d} \frac{\kappa_{v}}{\kappa_{v}+1} \quad \text { with } n_{c / v}=\frac{\bar{d}^{3} n_{c}}{V} \\
v & =-\frac{\kappa_{v}-1}{\kappa_{v}+1}
\end{aligned}
$$

The contact ratio $n_{c / v}$ depends only on the number of contacts per micro volume. For the isotropic compression, the normal and shear forces are:

$$
\begin{aligned}
& \bar{F}_{n, \alpha}^{I I}=\bar{F}_{n}^{I} \frac{\Delta \sigma}{\sigma} \\
& \bar{F}_{s, \alpha}^{I I}=0
\end{aligned}
$$

In the same way, an identical Young's modulus is found:

$$
\frac{E}{1-v}=n_{c / v} \frac{k_{n}}{2 \bar{d}}
$$




\subsection{Elastic behaviour of non-cohesive materials}

The stiffness between two grains is not constant for non-cohesive materials:

$$
\begin{aligned}
& F_{n}=k_{n} n \\
\text { where : } & k_{n}=M \sqrt{n} \\
\text { so : } & k_{n}=M^{\frac{2}{3}} F_{n}^{\frac{1}{3}}
\end{aligned}
$$

The average stiffness depends on the average pressure $\sigma_{0}$ :

$$
\overline{k_{n}}=\bar{M}^{\frac{2}{3}} \bar{F}_{n}^{\frac{1}{3}}=\left(\frac{2 \sqrt{2 \bar{r}} G_{\mu}}{3\left(1-v_{\mu}\right)}\right)^{\frac{2}{3}}\left(\frac{2 \sigma_{0} V}{n_{c} \bar{d}}\right)^{\frac{1}{3}}
$$

This can be filled out in the solution for cohesive structures:

$$
\begin{aligned}
E_{50} & =\left(\frac{2 \sqrt{2 \bar{r}} G_{\mu}}{3\left(1-v_{\mu}\right)}\right)^{\frac{2}{3}}\left(\frac{2 \sigma_{0} V}{n_{c} \bar{d}}\right)^{\frac{1}{3}} \frac{\bar{d}^{2} n_{c}}{V} \frac{\kappa_{v}}{\kappa_{v}+1} \\
& =\left(\frac{\sqrt{\sigma_{r e f}} G_{\mu}}{3\left(1-v_{\mu}\right)} n_{c / v}\right)^{\frac{2}{3}} \frac{2 \kappa_{v}}{\kappa_{v}+1}\left(\frac{\sigma_{0}}{\sigma_{r e f}}\right)^{\frac{1}{3}}
\end{aligned}
$$

which gives for non-cohesive materials:

$$
E_{50}=E_{r e f}\left(\frac{\sigma_{0}}{\sigma_{r e f}}\right)^{\beta}
$$

in which:

$$
\begin{aligned}
\sigma_{r e f} & =1 \text { bar } \\
\beta & =\frac{1}{3} \\
\kappa_{v} & =3 \frac{1-v_{\mu}}{2-v_{\mu}} \\
n_{c / v} & =\frac{n_{c}}{n_{v}}=\frac{\bar{d}^{3} n_{c}}{V} \\
E_{r e f} & =\left(\frac{\sqrt{\sigma_{r e f}} G_{\mu}}{3\left(1-v_{\mu}\right)} n_{c / v}\right)^{\frac{2}{3}} \frac{2 \kappa_{v}}{\kappa_{v}+1}
\end{aligned}
$$

So, the stiffness behaviour does not depend on the average grain size. 


\subsection{Failure of cohesive materials}

The relation between the strength of a granular material and its micro parameters has always been one of the most difficult problems in the field of theoretical discrete element mechanics. This is because not only average events are important, but also the probability that an event will occur. This also applies to the failure behaviour of cohesive granular materials. When the first cracks appear during a loading test, total failure will not directly occur; the contacts of the surrounding grains will take over the load of the broken contacts. Only when a particular amount of cracks per volume has weakened the area in such that it cannot handle any more load, does total failure occur. One single crack is sufficient to cause a chain reaction in the formation of new cracks, which results in very sudden, total failure of the structure. The normal force distribution in the lateral direction at that moment is schematised in figure A.12.

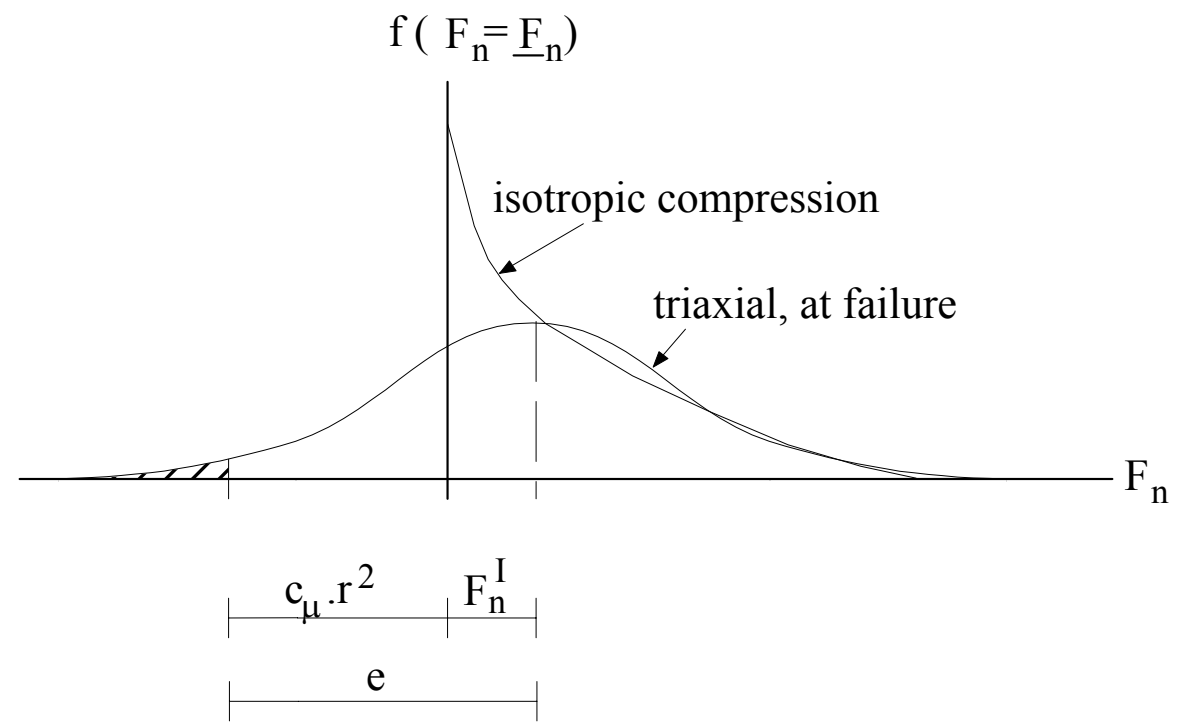

Figure A.12. Probability of micro failure per volume

The average normal force and the contact strength are described by:

$$
\begin{aligned}
\bar{F}_{n}^{I} & =\beta \sigma_{3} \quad \text { with } \quad \beta=\frac{2 V}{n_{c} \bar{d}}=\frac{2 \bar{d}^{2}}{n_{c / v}} \\
c_{\mu} \bar{r}^{2} & =\beta c_{\mu} \frac{n_{c / v}}{8}
\end{aligned}
$$

The amount of contacts per volume which have to be broken for a total failure is illustrated by the shaded surface in the figure. Once this surface has passed the micro failure criterion, the granular structure is broken. 
If the percentage of the contacts is small then the beginning of this surface can be registered by a factor $\beta$ times the increase of the axial stress:

$$
e=\beta \Delta \sigma_{1}=\beta\left(\sigma_{1}-\sigma_{3}\right)
$$

During loading and at failure the average normal force in the direction of the minor principal stress is constant $\left(\bar{F}_{n, \alpha=0}^{I I}=\bar{F}_{n}^{I}\right)$, so failure takes place at:

$$
e=c_{\mu} \bar{r}^{2}+\bar{F}_{n}^{I}
$$

These two relations can be combined to:

$$
\sigma_{1}=2 \sigma_{3}+c_{\mu} \frac{n_{c / v}}{8}
$$

This form is equal to the Mohr-Coulomb criterion:

$$
\sigma_{1}=\left(\frac{1+\sin \phi^{\prime}}{1-\sin \phi^{\prime}}\right) \sigma_{3}+\frac{2 c^{\prime} \cos \phi^{\prime}}{1-\sin \phi^{\prime}}
$$

This means that cohesive granular materials (except regular structures such as crystals) will fail according the Mohr-Coulomb criterion with:

$$
\begin{array}{rlrl}
\sin \phi^{\prime} & =\frac{1}{3} & \text { so: } \quad \phi^{\prime} & =19.5^{\circ} \\
c^{\prime} & =\frac{c_{\mu} n_{c / v}}{16 \sqrt{2}} \quad \text { with: } & n_{c / v}=\frac{\bar{d}^{3} n_{c}}{V}
\end{array}
$$

The angle of internal friction is completely constant and does not depend on the contact force distribution or the grain size distribution. The cohesion depends only on the cohesion between two contacts $c_{\mu}$ and the compaction of the granular structure $n_{c / v}$. 


\section{Cylinder test: analytical}

The stresses in a thick-walled hollow cylinder sample during the test depend on the axial and radial pressures, but also on the shape of the sample. For a continuum model these stresses can be solved analytically.

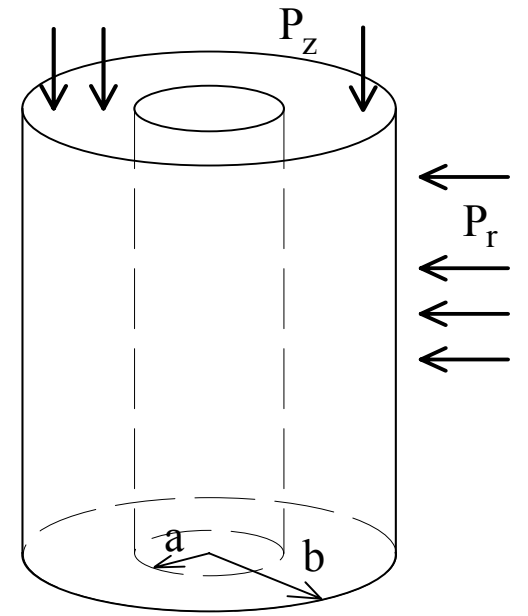

Figure A.13. Cylinder test

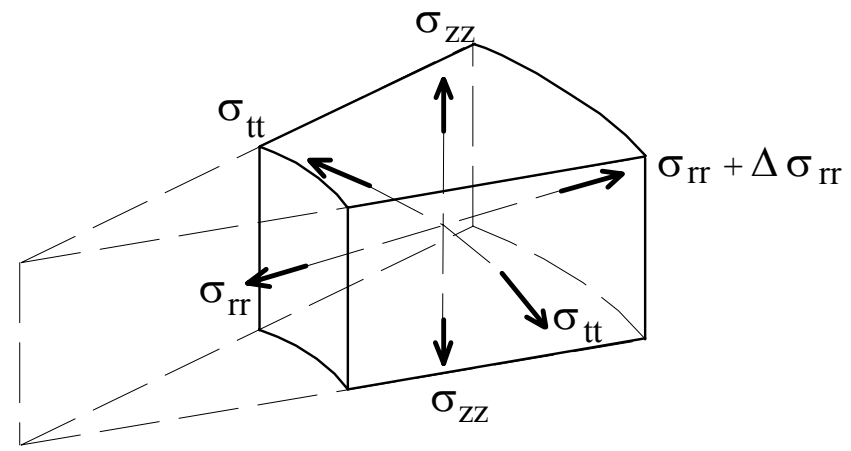

Figure A.14. Equilibrium of element

The sum of the radial forces on the equilibrium element is zero:

$$
\sum F_{r}=0
$$

which gives:

$$
\frac{\delta \sigma_{r r}}{\delta r}+\frac{\sigma_{r r}-\sigma_{t t}}{r}=0
$$

Axial symmetrical loading can be denoted:

$$
\frac{\delta}{\delta t}=0 \text { and } u_{t}=0
$$

so, the strains can be written as:

$$
\begin{aligned}
& \varepsilon_{r r}=\frac{\delta u_{r}}{\delta r} \\
& \varepsilon_{t t}=\frac{u_{r}}{r} \\
& \varepsilon_{z z}=\frac{\delta u_{z}}{\delta z}
\end{aligned}
$$


The shear deformations in the directions of the principal stresses are all found to be zero:

$$
\begin{aligned}
& \gamma_{r t}=\frac{1}{r} \frac{\delta u_{r}}{\delta t}+\frac{\delta u_{t}}{\delta r}-\frac{u_{t}}{r}=0 \\
& \gamma_{t z}=\frac{1}{r} \frac{\delta u_{z}}{\delta t}+\frac{\delta u_{t}}{\delta z}=0 \\
& \gamma_{r t}=\frac{\delta u_{z}}{\delta r}+\frac{\delta u_{r}}{\delta z}=0
\end{aligned}
$$

With the two constants of Lamé:

$$
\lambda=\frac{v E}{(1+v)(1-2 v)} \quad \text { and } \quad \mu=\frac{E}{2(1+v)}
$$

and the total volumic strain:

$$
e=\varepsilon_{r r}+\varepsilon_{t t}+\varepsilon_{z z}
$$

one can express the main stresses:

$$
\begin{aligned}
\sigma_{r r} & =2 \mu \varepsilon_{r r}+\lambda e \\
\sigma_{t t} & =2 \mu \varepsilon_{t t}+\lambda e \\
\sigma_{z z} & =2 \mu \varepsilon_{z z}+\lambda e
\end{aligned}
$$

The mains shear stresses are all zero:

$$
\tau_{r z}=2 \mu \varepsilon_{r z}=\mu \gamma_{r z}=0 \quad \text { etc. }
$$

By filling out equations (A.99) and (A.102) in (A.103), and these last three equations in (A.97), the basic differential equation is found:

$$
(2 \mu+\lambda)\left(\frac{\delta^{2} u_{r}}{\delta r^{2}}+\frac{1}{r} \frac{\delta u_{r}}{\delta r}-\frac{1}{r^{2}} u_{r}\right)+\lambda \frac{\delta^{2} u_{z}}{\delta r \delta z}=0
$$

The last part is zero, so (A.105) can be simplified:

$$
\frac{\delta^{2} u_{r}}{\delta r^{2}}+\frac{1}{r} \frac{\delta u_{r}}{\delta r}-\frac{1}{r^{2}} u_{r}=0
$$

The general solution of this differential equation is:

$$
u_{r}=A r+\frac{B}{r}
$$

The other directions are:

$$
\begin{aligned}
& u_{t}=0 \\
& u_{z}=D z+C
\end{aligned}
$$

where $A, B, C$ and $D$ are integration constants, to be determined from the boundary conditions. The general expression for the volume strain, corresponding to the solution is:

$$
e=2 A+D \text { with } D=\frac{\delta u_{z}}{\delta z}
$$


The main stresses can be expressed as:

$$
\begin{aligned}
\sigma_{r r} & =2 \mu\left(A-\frac{B}{r^{2}}\right)+\lambda(2 A+D) \\
\sigma_{t t} & =2 \mu\left(A+\frac{B}{r^{2}}\right)+\lambda(2 A+D) \\
\sigma_{z z} & =2 \mu(D)+\lambda(2 A+D)
\end{aligned}
$$

The boundary conditions are:

$$
\begin{array}{ll}
\text { For } r=a: & \sigma_{r r}=0 \\
\text { For } r=b: & \sigma_{r r}=P_{r} \\
& \sigma_{z z}=P_{z}
\end{array}
$$

In this case the constants $A, \mathrm{~B}$ and $D$ are given by:

$$
\begin{aligned}
& A=\left\{\frac{\lambda+2 \mu}{2 \mu(3 \lambda+2 \mu)}\right\} \frac{b^{2}}{b^{2}-a^{2}} P_{r}-\left\{\frac{\lambda}{2 \mu(3 \lambda+2 \mu)}\right\} P_{z} \\
& B=\left\{\frac{1}{2 \mu}\right\} \frac{b^{2} a^{2}}{b^{2}-a^{2}} P_{r} \\
& D=\left\{\frac{\lambda}{3 \mu \lambda+2 \mu^{2}}\right\} \frac{b^{2}}{b^{2}-a^{2}} P_{r}+\left\{\frac{\lambda+\mu}{3 \mu \lambda+2 \mu^{2}}\right\} P_{z}
\end{aligned}
$$

If the pressure stresses are taken positive then they will become:

$$
\begin{aligned}
& \sigma_{z z}=P_{z} \\
& \sigma_{t t}=\left(\frac{b^{2}}{b^{2}-a^{2}}\right)\left(1+\frac{a^{2}}{r^{2}}\right) P_{r} \\
& \sigma_{r r}=\left(\frac{b^{2}}{b^{2}-a^{2}}\right)\left(1-\frac{a^{2}}{r^{2}}\right) P_{r}
\end{aligned}
$$

The stresses at the inner surface $(r=a)$ are:

$$
\begin{aligned}
& \sigma_{r r}=0 \\
& \sigma_{t t}=\frac{2 b^{2}}{b^{2}-a^{2}} P_{r} \\
& \sigma_{z z}=P_{z}
\end{aligned}
$$




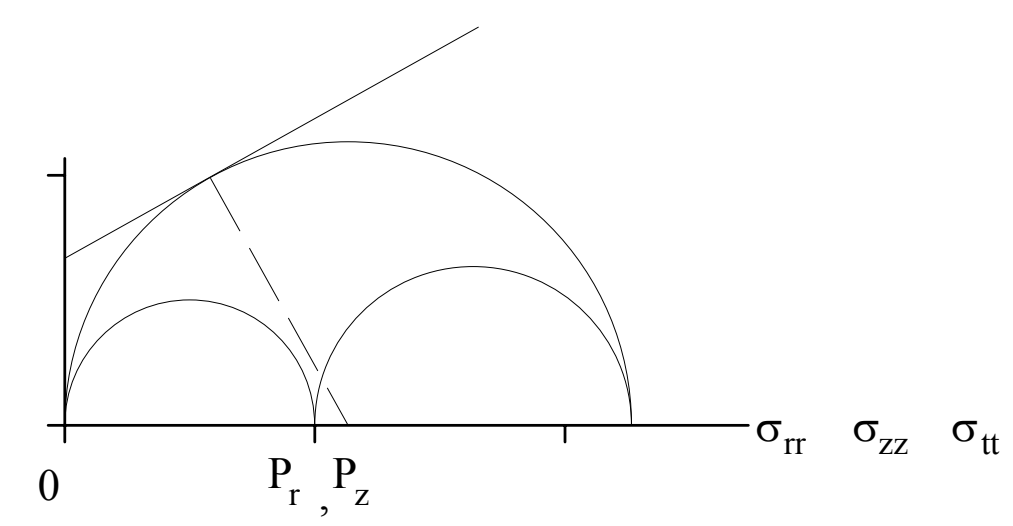

Figure A.15. Stresses at the inner surface of the cylinder

$$
\left(a=1 / 3 b, P_{r}=P_{z}\right)
$$

The stresses at the outer surface $(r=b)$ are:

$$
\begin{aligned}
\sigma_{r r} & =P_{r} \\
\sigma_{t t} & =\frac{b^{2}+a^{2}}{b^{2}-a^{2}} P_{r} \\
\sigma_{z z} & =P_{z}
\end{aligned}
$$

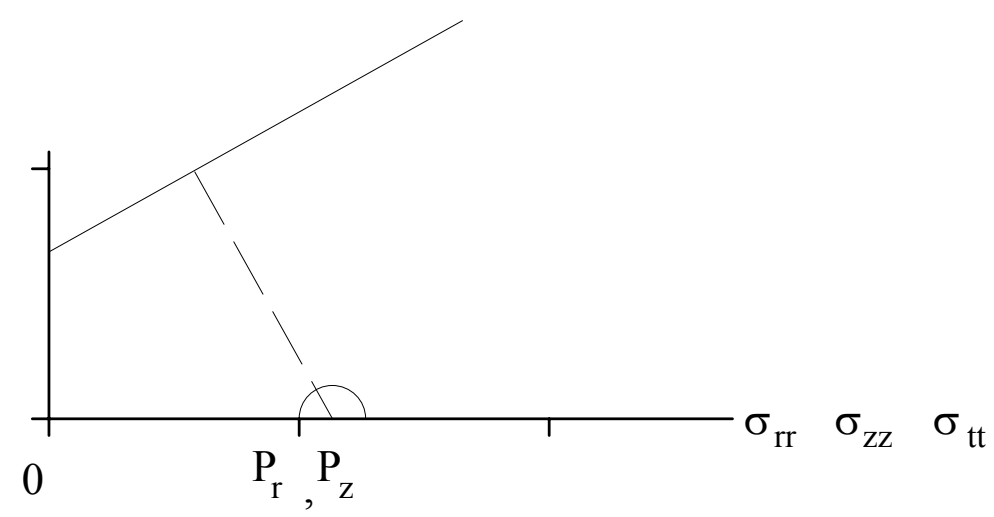

Figure A.16. Stresses at the outer surface of the cylinder

$$
\left(a=1 / 3 b, P_{r}=P_{z}\right)
$$

One can see that failure will always occur at the inner surface of the cylinder $(r=a)$ and that the vertical load $P_{z}$ is not important for failure as long as:

$$
0<P_{z}<\frac{2 b^{2}}{b^{2}-a^{2}} P_{r}
$$




\section{Crystal: analytical}

One of the most basic structures, in which tension forces can be created only by compressive forces, is drawn below.

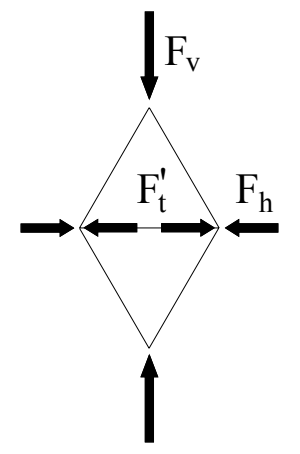

Figure A.17. Basic structure

If shear forces do not exist, then the horizontal contact force $F_{t}$ can become negative, if the vertical force is too large:

$$
\left|F_{t}\right|=\frac{1}{6} \sqrt{3} F_{v}-F_{h} \quad \text { if } \quad F_{s}=0
$$

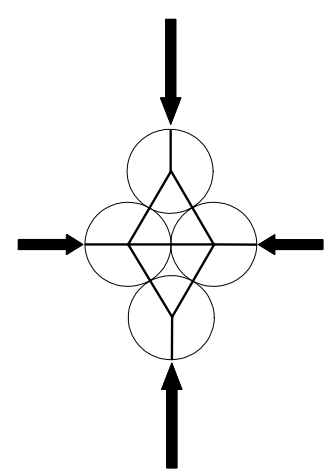

Micro structure

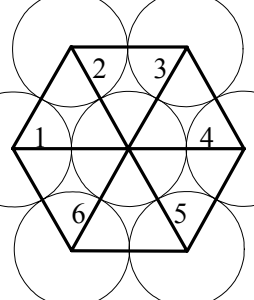

Crystal structure

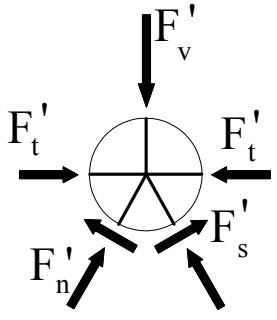

Horizontal boundary

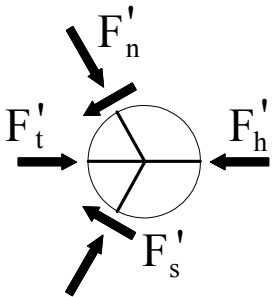

Vertical

boundary

Figure A.18.

If we build up a whole crystal out of this structure without neglecting the shear force, then the horizontal stress for each grain is found to be:

$$
\sigma_{x x}=\frac{r}{V} \sum_{k=1}^{n_{c / g}}\left(c^{2} F_{n}+s c F_{s}\right)_{k}
$$

in which the volume for each grain:

$$
V=6 \cdot \frac{1}{3} \Delta=\frac{6}{3} \cdot \frac{1}{2} \cdot 2 r \cdot \sqrt{3} r \cdot 2 r=4 \sqrt{3} r^{3}
$$


Summation over the six contacts, as listed in the table, will give:

$$
\sigma_{x x}=C \cdot\left(2 F_{t}^{\prime}+F_{n}^{\prime}-\sqrt{3} F_{s}^{\prime}\right)
$$

in which the constant $C$ depends on the grain radius:

$$
C=\frac{1}{4 \sqrt{3} r^{2}}
$$

In the same way the vertical stress and the shear stress are found:

$$
\begin{aligned}
\sigma_{y y} & =C \cdot\left(3 F_{n}^{\prime}+\sqrt{3} F_{s}^{\prime}\right) \\
\sigma_{x y} & =0
\end{aligned}
$$

\begin{tabular}{||c|c|c|c|c||}
\hline \hline$k$ & $s$ & $c$ & $F_{n}$ & $F_{s}$ \\
\hline 1 & 0 & -1 & $F_{t}{ }^{\prime}$ & 0 \\
\hline 2 & $1 / 2 \sqrt{ } 3$ & $-1 / 2$ & $F_{n}{ }^{\prime}$ & $F_{s}{ }^{\prime}$ \\
\hline 3 & $1 / 2 \sqrt{ } 3$ & $1 / 2$ & $F_{n}{ }^{\prime}$ & $-F_{s}{ }^{\prime}$ \\
\hline 4 & 0 & 1 & $F_{t}{ }^{\prime}$ & 0 \\
\hline 5 & $-1 / 2 \sqrt{ } 3$ & $1 / 2$ & $F_{n}{ }^{\prime}$ & $F_{s}{ }^{\prime}$ \\
\hline 6 & $-1 / 2 \sqrt{ } 3$ & $-1 / 2$ & $F_{n}{ }^{\prime}$ & $-F_{s}{ }^{\prime}$ \\
\hline
\end{tabular}

\section{Table A.4. Contact forces on one grain}

For the horizontal boundary, we know:

$$
\begin{aligned}
F_{v} & =\sigma_{y y} \cdot 4 r^{2} \\
\sum F_{y y} & =0 \\
\sigma_{y y} & =C \cdot\left(3 F_{n}^{\prime}+\sqrt{3} F_{s}^{\prime}\right)
\end{aligned}
$$

which is equal to the vertical stress we found before. For the vertical boundary, this is different:

$$
\begin{aligned}
F_{h} & =\sigma_{y y} \cdot 4 \sqrt{3} r^{2} \\
\sum F_{x x} & =0 \\
\sigma_{x x} & =C \cdot\left(F_{t}^{\prime}+F_{n}^{\prime}-\sqrt{3} F_{s}^{\prime}\right)
\end{aligned}
$$

These result are not equal to the horizontal stress we found before. This means that edge actions are formed, especially on the vertical boundaries. 
During phase I, isotropic compression $\left(\sigma_{x x}=\sigma_{y y}\right)$, the shear forces are zero, so the contact forces can be solved:

$$
\begin{aligned}
& \sigma_{x x}=C \cdot\left(2 F_{t}^{\prime}+F_{n}^{\prime}-\sqrt{3} F_{s}^{\prime}\right) \\
& \sigma_{y y}=C \cdot\left(3 F_{n}^{\prime}+\sqrt{3} F_{s}^{\prime}\right) \\
& F_{s}^{\prime}=0
\end{aligned}
$$

or:

$$
F_{n}^{\prime}=F_{t}^{\prime}=\frac{\sigma_{x x}}{3 C} \text { and } F_{s}^{\prime}=0
$$

During phase II, for example the biaxial test, the shear forces do not remain zero. But because of symmetry, another third relation between the deformations of the contacts can be found:

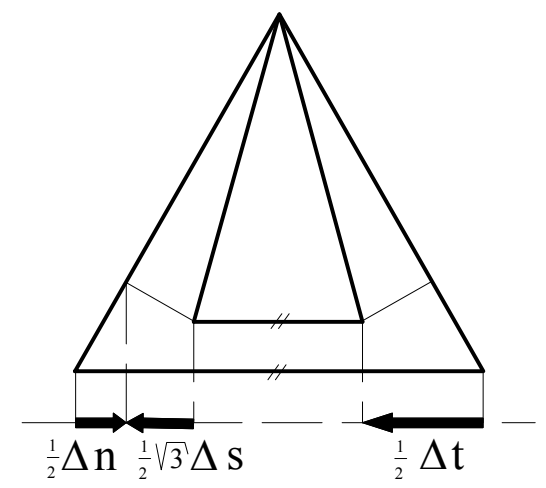

Figure A.19. Contact deformations

which is:

$$
\frac{1}{2} \Delta t=\frac{1}{2} \Delta n-\frac{1}{2} \sqrt{3} \Delta s
$$

The following three equations describe the contact forces of the grains, which are not near the boundaries, during loading:

$$
\begin{aligned}
& \Delta \sigma_{x x}=C \cdot\left(2 \Delta F_{t}^{\prime}+\Delta F_{n}^{\prime}-\sqrt{3} \Delta F_{s}^{\prime}\right) \\
& \Delta \sigma_{y y}=C \cdot\left(3 \Delta F_{n}^{\prime}+\sqrt{3} \Delta F_{s}^{\prime}\right) \\
& \Delta F_{t}^{\prime}=\Delta F_{n}^{\prime}-\frac{\sqrt{3}}{\kappa_{v}} \Delta F_{s}^{\prime}
\end{aligned}
$$

or: 


$$
\begin{aligned}
& \Delta F_{n}^{\prime}=\frac{1}{6 C} \frac{\left(\kappa_{v}+2\right) \Delta \sigma_{y y}+\kappa_{v} \Delta \sigma_{x x}}{\left(\kappa_{v}+1\right)} \\
& \Delta F_{s}^{\prime}=\frac{1}{6 C} \frac{\kappa_{v}\left(\Delta \sigma_{y y}-\Delta \sigma_{x x}\right)}{\left(\kappa_{v}+1\right)} \sqrt{3} \\
& \Delta F_{t}^{\prime}=\frac{1}{6 C} \frac{\left(\kappa_{v}-1\right) \Delta \sigma_{y y}+\left(\kappa_{v}+3\right) \Delta \sigma_{x x}}{\left(\kappa_{v}+1\right)}
\end{aligned}
$$

For a biaxial test the lateral pressure $\sigma_{x x}$ is constant $\left(\Delta \sigma_{x x}=0\right)$, so:

$$
\begin{aligned}
& F_{n}^{\prime}=\frac{1}{6 C} \frac{\left(\kappa_{v}+2\right) \sigma_{1}-\kappa_{v} \sigma_{3}}{\left(\kappa_{v}+1\right)} \\
& F_{s}^{\prime}=\frac{1}{6 C} \frac{\kappa_{v}\left(\sigma_{1}-\sigma_{3}\right)}{\left(\kappa_{v}+1\right)} \sqrt{3} \\
& F_{t}^{\prime}=\frac{1}{6 C} \frac{\left(\kappa_{v}-1\right) \sigma_{1}+\left(\kappa_{v}+3\right) \sigma_{3}}{\left(\kappa_{v}+1\right)}
\end{aligned}
$$

In practice, the stiffness ratio $\kappa_{v}$ is slightly larger than one, so tension forces will never occur and the crystal has a negative Poisson's ratio. The crystal will not fail because of tension failure, but because of shear failure which will take place at a much higher pressure. This is why crystals structures can be extremely strong. 


\section{CURRICULUM VITAE (Dutch)}

\section{$\underline{\text { Personalia }}$}

Naam:

Geboortedatum:

Burgerlijke staat:

Nationaliteit:

\section{Opleidingen}

sept. 1987 - juni 1992

aug. 1981 - juli 1987
Stefan van Baars

22 oktober 1968 te Zevenaar

Ongehuwd

Nederlandse
Civiele Techniek aan de Technische Universiteit te Delft, sectie geotechniek. Afstudeerwerk leidde tot een $3^{\mathrm{e}}$ plaats in de Waterbouwprijs 1993. Aanvullend Examen in de Waterbouw. V.W.O.- $\beta$, Nederrijn College te Arnhem .

\section{Ervaring}

febr. 1993 - sept. 1996 Promotie-onderzoek aan de Technische Universiteit te Delft, sectie geotechniek.

Docent-examinator Mechanica en Constructieleer.

aug. 1992 - nov. 1992 Onderzoek naar bodemreiniging, bij de Ecole Nationale des Ponts et Chaussées te Parijs.

aug. 1990 - dec. 1990 Studie naar de haalbaarheid van het toekomstige eiland IJburg, bij Ballast Nedam Engineering.

$\underline{\text { Taalbeheersing }}$

Nederlands

Engels

Duits

Frans
Moedertaal

Goed zowel mondeling als schriftelijk Goed zowel mondeling als schriftelijk Goed mondeling, redelijk schriftelijk 


\section{CURRICULUM VITAE}

$\underline{\text { Personal details }}$

Name:

Stefan van Baars

Birthday:

Marital status:

Nationality:

October 22nd, 1968 in Zevenaar

Unmarried

Dutch

\section{$\underline{\text { Education }}$}

Sept. 1987 - June 1992 Civil Engineering at the University of Technology Delft, Department of Geotechnics. Graduation work led to a $3^{\text {rd }}$ prize at the Hydraulic Engineering Contest 1993.

Additional Certificate for Hydraulic Engineering.

Aug. 1981 - July 1987 Lyceum, Nederrijn College in Arnhem .

\section{$\underline{\text { Experience }}$}

Feb. 1993 - Sept. 1996 Dissertation research at the University of Technology Delft, Department of Geotechnics.

Teacher-examinator Mechanics and Construction.

Aug. 1992 - Nov. 1992 Research into soil cleaning, at the Ecole Nationale des Ponts et Chaussées in Paris.

Aug. 1990 - Dec. 1990 Study into the feasibility of the future island IJburg, at Ballast Nedam Engineering.

\section{$\underline{\text { Languages }}$}

Dutch

English

German

French
Mother language

Good, both orally and in writing

Good, both orally and in writing

Good orally, quite good in writing 


\section{$\underline{\text { Publications }}$}

Failure of cohesive granular materials,

Ninth International Conference on Fracture, Sydney, April 1997

Discrete element modelling of granular materials,

Dissertation, University of Technology Delft, ISBN 90-9009494-6, 1996

Discrete element modelling of granular materials,

Heron, volume 41, no. 2, ISSN 0046-7316, 1996

Discrete element modelling of granular materials,

Communications on hydraulic and geotechnical engineering,

no. 95-5, ISSN 0169-6548, 1995

Modelproeven in een geotechnische centrifuge,

De Ingenieur, no. 7-8, 1992, (Allersma, H.G.B. and Baars, van S.) 


\section{SAMENVATTING}

\section{Discrete Elementen Analyse van Granulaire Materialen}

Tijdens de productie van olie en gas beginnen, enkele jaren na het maken van een boorgat, zanddeeltjes en kleine zandsteenbrokjes los te breken van het boorgatoppervlak. Deze deeltjes kunnen in een korte tijd de transportleidingen en installaties grote schade toebrengen. Door simulatie van het boorgatgedrag met de dikwandige-cilinderproef, zijn er vier fenomenen gevonden die niet met de conventionele continuümmechanica kunnen worden verklaard:

1. Ondanks de drukspanningen, ontstaat het bezwijken op microniveau ten gevolge van trekscheuren.

2. Deze scheuren staan niet diagonaal op, maar lopen parallel aan, het boorgatoppervlak.

3. Deze scheuren veroorzaken twee lijnrecht tegenoverliggende uitbraken.

4. Het functionele bezwijken van het boorgat begint bij een hogere radiale drukspanning dan voorspeld.

Om het gedrag van granulaire materialen te beschrijven, ontwikkelde Cundall in 1969 een computermodel die gebaseerd is op de basiselementen van zo'n materiaal, namelijk de korrels zelf en hun interacties. Lindhout heeft in 1992 geprobeerd om met dit model de cilindertest te beschrijven. Als gevolg van compactieproblemen, stabiliteitsproblemen en de lange computerrekentijd kon zijn doel niet worden gehaald. Daarom is er een nieuw model ontwikkeld door de schrijver, die niet de bewegingsvergelijkingen maar de evenwichtsvergelijkingen gebruikt om de nieuwe korrelposities te berekenen. Dit model kan zowel voor niet-cohesieve korrels (zand) als voor cohesieve korrels (zandsteen) worden gebruikt. De resultaten kunnen in het algemeen goed worden beschreven met een verbeterd Mohr-Coulomb model, hoewel er een aantal uitzonderingen zijn.

Ten eerste zullen, tijdens het belasten van een granulaire structuur, veel contacten tussen de korrels bezwijken. Niet door schuifdeformatie, zoals Coulomb suggereert, maar door bezwijken op trek. Ten tweede ontstaan deze microscheuren altijd in de richting van de grootste hoofdspanning, hetgeen een andere richting kan zijn dan het waargenomen bezwijkoppervlak. Zo vormen de axiale microscheuren tijdens een biaxiaalproef een diagonaal bezwijkoppervlak, maar de axiale microscheuren in een cilinderproef kunnen een bezwijkoppervlak parallel aan het boorgat vormen.

Tijdens het ontstaan van een natuurlijk zandsteen veroorzaakt het verschil in horizontale en verticale grondspanningen een anisotropie in de sterkteeigenschappen van het materiaal. Dit kan de twee tegenoverliggende uitbraken verklaren. De conclusie dat een boorgat bij een hogere radiale spanning bezwijkt, komt door een verschil in definitie tussen lokaal bezwijken en functioneel bezwijken en de grote reststerkte van een dikwandige-cilinder. 
